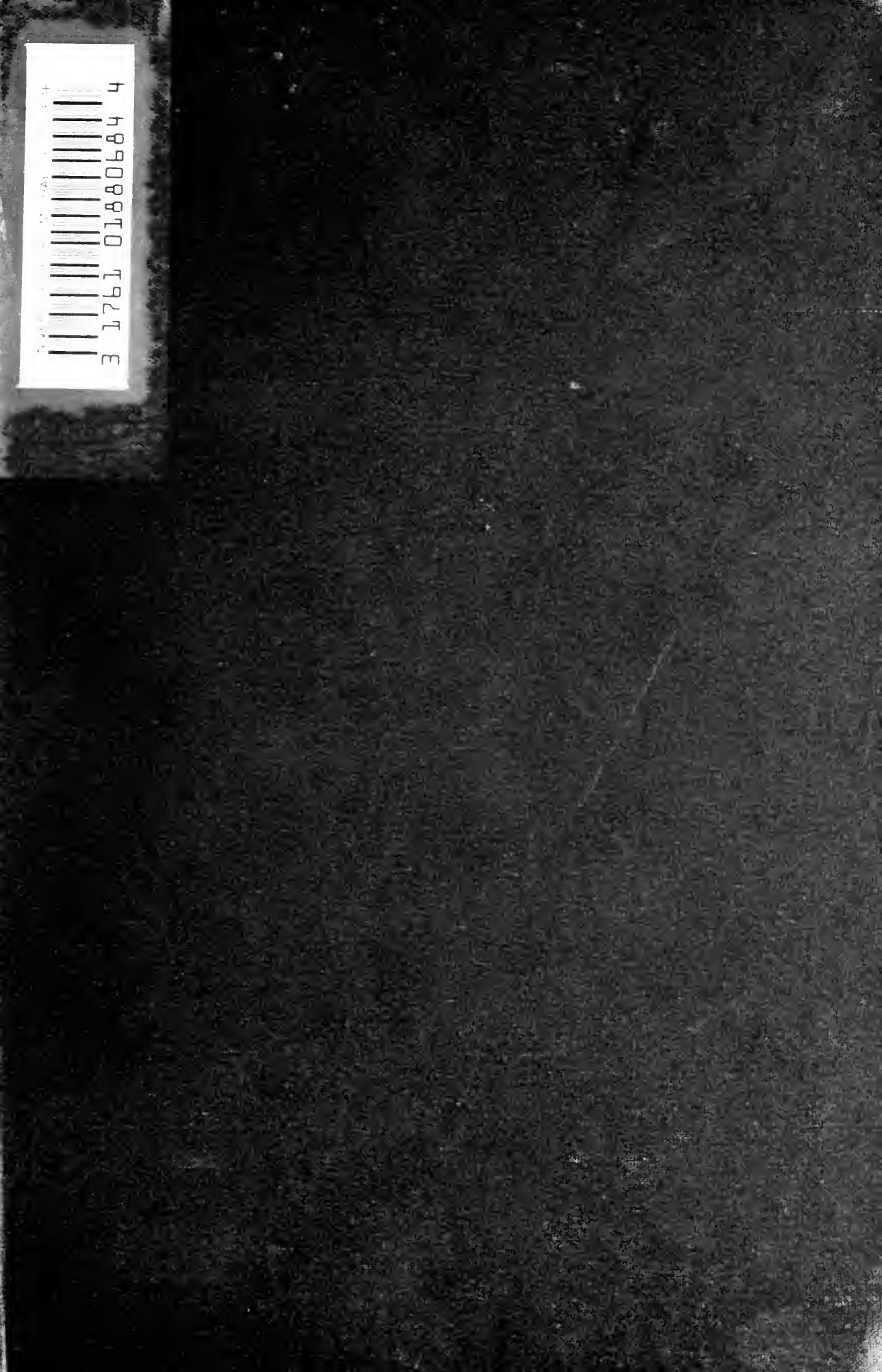


301 


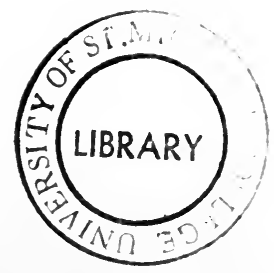






\section{HENRI BERGSON}

AN ACCOUNT OF HIS IIFE ANI) PHHOSOHHY 


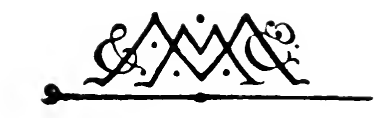
MACMILLAN AND CO., Limited
LONDON - BOMBAY - CAICUTTA MELBOURNE
THE MACMILLAN COMPANY
NEW YOKK - BOSTON - CHICAGO
DALLAS - SAN FRANCISCO

THE MACMILLAN CO. OF CANADA, Ltd.

TORONTO 


\section{HENRI BERGSON}

AN ACCOUNT OF HIS LIFE AND PHILOSOPHY

$\mathrm{BY}$

ALGOT RUHE

AND

NANCY MARGARET PAUI.

MACMILLAN ANI) CO, LIMITED

ST. MARTIN'S STREET, LONION

I 9 I 4 
COPYRIGHT 


\section{PREFACE}

MY chief object in writing this book is that it may serve as a guide to the work of Monsieur Bergson. The biographical chapter is subsidiary to that end, and the remaining chapters are arranged to give the reader a comprehensive view of his teaching. The main principles and most important applications of the philosophy are set out at length and in language closely following Monsieur Bergson's own, though rarely by quotation except when passages are taken from sources inaccessible without difficult research. Detailed criticism of opposing doctrines is for the most part either omitted or very much abridged, and arguments in support are shortened. When the same subject has been discussed in different books certain parts of those books are collated in the general exposition I have given of that subject. And I believe there is not one statement included that lacks the direct authority of some writing or public utterance of Monsieur Bergson himself. Obviously it is out of the question on this plan to give specific references either in the text or by notes. I content myself with thus explaining my method and with referring my 
readers to the admirable bibliography at the end of the English version of Les Données immédiates de la conscience (Time and Free Will, Pogson, George Allen \& Co.). Where, however, as in the biographical chapter, I have given verbatim extracts from papers, addresses or letters, not generally accessible, full reference to particulars will be found.

However closely my book follows the thought of the philosopher, it cannot possibly do justice to the far ampler exposition of that thought which he has given in his own words. It will, I hope, serve to bring out in the minds of some who have already studied the great works of this great thinker a clearer outline of what they have read, and will confirm in them their hold on his intention and meaning. It will also serve others perhaps as a more or less popular introduction to his thought and as a work of occasional reference. But it can never, I am glad to say, be supposed to render superfluous the study of Time and Free Will, Matter and Mcmory (Paul and Palmer, George Allen \& Co.), and Creative Evolution (Mitchell, Macmillan \& Co.). My great desire is that it may send every one who reads it to those books, whether for the first time, or for another perusal in a fresh understanding of them. To this end it is addressed. I venture also to believe that by assembling together in one book all the main features of the doctrine, while omitting much of the discussion, argument and illustration with which it is necessarily presented and enriched by its author, I have prepared the way for certain students to enter 
into the mind of their teacher, to learn to share his aims and purposes, and so take those first steps which are essential to real apprehension.

This book runs on parallel lines with one that I have written in Swedish as a companion to the six volumes of my translation of the works of Monsieur Bergson. In its English dress it is the result of collaboration with one of the English translators of Matière et Mémoire. My Swedish manuscript was discussed in detail with Miss Paul, and to her is due the form in which it is now presented to the reader.

ALGOT RUHE. 



\section{CONTENTS}

CHAYTEK

I. LIFE ANU PERSONALITY - - - . I

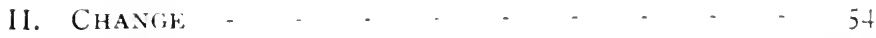

III. FREEISOM ANH THL WILI - - . 88

IV. BONY ANU SOUL

V. LIFE - - $\quad \ldots \quad+\quad-\quad-175$

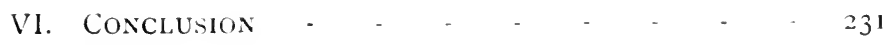

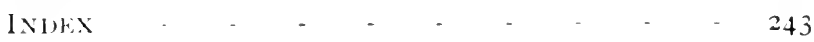

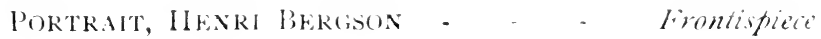





\section{CHAPTER I.}

\section{LIFE AND PERSONALITY.}

BERGSON, though in the prime of life, in the plenitude of activity and at the height of his fame, is generally considered to be still as full of promise as performance. His outward life too is no more than a career, doubtless brilliant but nevertheless rather typical of the French professor than characterized by striking events. His life is to be found in his works. In his laborious existence there has been no room for romantic incident, at any rate of the kind that is likely to fall under public notice. In fact, if we are to speak of a history in connexion with Bergson, that history will be concerned not with the man but with his renown. The rise and spread of his renown, its fluctuations and the disputes it has occasioned, will some day, when a more comprehensive view becomes possible, be matter of great interest in the history of thought. At present, for an author who is attempting to give a sketch of the personality of Henri Bergson, nothing is more remarkable than the paucity of writings concerning the man himself, the thinker whose influence and importance are being daily more and more impressed 
upon the peoples of two continents. I shall be content here to support my own view of him by the opinions of some of his colleagues and of his disciples, and to give some idea of the place he now fills in public attention on both sides of the Atlantic. The sources of my contribution towards a characterization of him are to be found first in certain writings of his own, now not easily accessible, and secondly in my personal impressions of him. I shall indicate these in the course of my narrative.

Henri Bergson was born on the I8th of October, I859, in the Rue Lamartine, Paris. He appears to have spent some part of his childhood in London; at all events his knowledge of English is almost that of a native. His school days in Paris were passed at the Lycée Fontane, the name of which has since been changed to Lycée Condorcet.

$\mathrm{He}$ is said to have been distinguished in all three branches of school work-in classics, in mathematics, and in the natural sciences-and to have taken prizes on every possible occasion. His first published work was the solution of a mathematical problem, which not only won him a prize at his school in 1877 but was printed in extenso in the Annales mathématiques of the following year.

After he had passed his baccalauréat he hesitated between the faculties of letters and of science. $\mathrm{He}$ had great gifts for mathematics and for the natural sciences, but he nevertheless entered the Ecole Normale 
Superieure on the classical side in 1878 . Here he won special distinction as a Hellenist. It is said that during his year of attendance his was the only name which had the honour of appearing in a book kept by Professor Tournier, himself a master of verbal criticism, to put on record the names and date of birth of those students who had proposed decisive emendations and corrections of certain Greek texts, supposed to be corrupt.

After three years at the Ecole Normale, Bergson left with the academic rank of Licencié-ès-Lettres. He was at once appointed master in a school at Angers and remained there two years. At a prize-giving in the school on August 3rd, I882, the customary address was allotted to him. The subject that he chose points to the existence in his mind of some degree of doubt and hesitation as to his career. It gives hints also as to the character of his own solution of the great problem of reconciling the desire to conquer vast realms of knowledge with the concentration on one pursuit, necessarily asked of any man who would make his way in the world. His subject was specialization. ${ }^{1}$

Among other remarkable features of this early work we may note the maturity and sureness of the language, the subtlety of thought and the fine characterization of men and things. We may discover also the first indication of that theory of the difference between man and beast which is one of the dominant ideas in Creative Evolution.

1 Bergson, La Spécialité, Discours, Angers, I882, I6 pp. 
"We must needs resign ourselves," he says, " to know only a few things if we would not be ignorant in all.

"But we can hardly resign ourselves too late. Every one of us should begin, as mankind began, with the noble yet simple-minded ambition to know everything... We can never understand any particular truth unless we have caught a glimpse of the relations it may have with other truths. Can you say that you know a building because you have been shown the stones of which it will be made? Yet in a building there are only stones. It is because the whole art of building is one of arrangement, and the important matter for our knowledge is not each stone but the place it fills. You have all handled a microscope, and may have seen in their box those little slips of glass each of which encloses some anatomical preparation. Take one of them, put it under the lens and look. You will see a tube divided into compartments; slip the glass along and watch cell succeed to cell, each clearly distinguishable. But what is the object, and what have you seen? You will be obliged, if you want to know, to abandon the microscope and consider as a whole with your naked eye that ugly spider's foot. And it is because we have looked at reality itself as it were with a microscope, that we have divided it into parts. If we do not begin by giving a glance at the whole, if we pass at once to the consideration of the parts, we may perhaps see very well, but we do not know what we are looking at. 
"I would have a man give himself up to a special science only when he has no longer need to study all the rest. $\mathrm{He}$ might take longer to acquire knowledge, but the advance of knowledge itself would be hastened.

"If the mathematical sense reveals itself in the power to think correctly and to express a meaning clearly, what man of letters can afford to dispense entirely with mathematics? If philosophy is the science of general ideas, the man who sets no store by it will make but a feeble critic. Literature itself is a geometry without figures and a metaphysic freed from the jargon of the schools... Whereas we acquire manual skill only on condition of choosing a special occupation, we cannot, on the contrary, except by the development of all the others, bring any one of our mental powers to perfection... No doubt there is always one that is dominant and remarkable; but it stands out only because the others bear it up. I might compare it to the fine musician you sometimes distinguish in a poor orchestra ; he dominates it, so that it is he alone whom you hear. Yet perhaps he would not succeed in a solo. . . .

" Here precisely is what distinguishes intellect from instinct and man from the beast. The inferiority of the animal lies entirely in this-that it is a specialist. It does one thing to admiration; it can do nothing else... The bee has solved a difficult problem in trigonometry-could it solve another?... Our intellect has become what it is through the varied habits it has successively contracted, whereas the intellect of 
the animal has little by little narrowed itself, and has atrophied within the narrow limits of a speciality... The best way to succeed is not to aim too early at success. At all events it would be childish if, in order to prepare ourselves the better for life, we were to take from life at the outset all that makes its nobility and worth, et propter vitam vivendi perdere causas."

While he was at Angers Bergson compiled and published in Paris, in I884, a text book for the use of schools-Extraits dc Lucrèce, avec commcntaire et notes, a study, as he says, of the poetry, the philosophy, the physics, the text and language of Lucretius. The eighth edition of this book was issued as recently as I912. Its success is assuredly not to be attributed to the later fame of the young schoolmaster, but to the real merit of the work itself which, in spite of changes in education that have occurred in France, has enabled it to hold its own for thirty years.

Naturally enough, the position which Bergson sought to win was one that should bring with it the possibility of promotion to a professorial chair in a University. In 1883 he succeeded in obtaining such a position at Clermont-Ferrand, once the capital of the province of Auvergne. During the years he spent there he was not only occupied as a schoolmaster at the Lycée Blaise-Pascal, but also as Chargé de Conférences to the Faculté des Lettrcs. In spite of this laborious and ill-remunerated doubling of parts he wrote, during the five years of his residence at Clermont-Ferrand, his two theses for the doctor's 
degree, one in Latin: Quid Aristoteles de loco senserit, and the other in French: Essai sur les données immédiates de la conscience. ${ }^{1}$ Both were published by Félix Alcan in 1889.

In the same year Bergson removed to Paris and there took his degree of Docteur-ès-Lettres with distinction in philosophy, after a brilliant defence in public of his two theses.

During the five years of "spiritual retreat" which he spent in Auvergne all the main lines of his philosophic structure were laid down and he prepared himself by special studies for its building. It is said that he busied himsclf with all the great variety of subjects of which we find traces in his work-with art and literature, with medicine, hypnotism, biology, the drama and even sport. Clermont-Ferrand, in fact, offers admirable surroundings for the pursuit of studies by a meditative mind. Here Pascal brooded over his thoughts about empty space; here Rameau the musician wrote his epoch-making work on harmony. It seems that, as Monsieur Desaymard has said, ${ }^{2}$ thought concentrates itself here more easily than elsewhere; at all events these great men must have found within those wide horizons, following the rhythmic line of distant hills, some freedom from distraction

${ }^{1}$ English Translation, Time and Free Will, Pogson. Published by George Allen \& Co.

${ }^{2} \mathrm{~J}$. Desaymard. M. Bergson à Clermont-Ferrand. Bulletin historique et scientifique de l'Auvergne. Acad. des Sciences, Belleslettres et Arts à Clermont-Ferrand, ii. série, 1910, pp. 214-216, and 243-267. 
and encouragement to seek the larger issue. So too, his associations with his colleagues and the spirit of the little university town must have contributed to influence a mind like his, needing both to enter deeply into the substance of his own thought and to communicate it to others. Moreover those years, I883I888, appear to have been among the most brilliant, and therefore fruitful, in the annals of that University. The town was not then, as it is now, given up to the pursuit of sport and industry ; some interest was still being shown in the things of the mind. The professors had their influence in the administration of the town; indeed the mayoralty was for long an appanage of the University. The Rector at that time was Bourget, father of the distinguished author. It would seem that Bergson was welcome in the old-world society of the place, where the art of conversation was still both known and practised. The local journals were favourable to him, and the Moniteur du Puy-de-Dôme of February 2 Ist, I884, reporting a lecture given by him on the I8th of February at the request of the University, wrote of him as follows: "Yesterday evening there was an entertainment in the University buildings. Here in Auvergne the cult of letters is not forgotten. A lecture was announced, a philosopher was to speak on 'Laughter; what do we laugh at? Why do we laugh ?' Many people did not know; some had never thought about it, although they had lived happily and well... The audience, much interested, had assembled in such numbers that many 
could not obtain admission and were obliged to return home grumbling at the luck of their fellows. But all those who had found room on the benches left the place delighted, nay charmed, with what they had heard. They had learned a number of things concerning the subject itself, and had found besides-what many of the audience had secretly hoped to findin this lecture on laughter more than one opportunity to laugh." Here is introduced a very good description of the manner in which the young philosopher presented his subject, a manner full of the characteristics which are to be found later in the more famous lecturer, not only when he speaks from the professorial chair but also in his books. "He begins modestly with an anecdote and, while the audience is still laughing, the lecturer has made his point and drawn his conclusion from the little story. $\mathrm{He}$ is in process of formulating his general thesis without having announced in set terms what he was driving at. He hides from his hearers the thread along which he strings his illustrations and by means of which he draws his audience to the end that he desires..."

The newspaper gives no epitome of the ideas of the lecture. For sixteen years Bergson allowed them to grow and to mature before he published them in the Revue de Paris, I9oo, and then in Le Rire, ${ }^{1}$ a little book which, especially on account of its later passages, occupies a far more important place in the work of ${ }^{1}$ Translation, Laughter, Brereton and Rothwell. Macmillan, 19r I. 
the thinker than might perhaps appear at a casual glance. ${ }^{1}$

In the following year, at the distribution of prizes (we are told by the Moniteur of August 5th, I885), " the customary address was given by M. Bergson, professor of philosophy. It was a remarkable study of 'La Politesse' [Good Manners] written in a beautiful style and containing observations and sketches of character full of originality and point. We give a verbatim report of the address, which was received with much applause."

As this address has never been reprinted from the columns of the paper, it is well to quote from it here at considerable length.

Bergson begins his speech with a jesting allusion to the ceremonious manners of some savage races. He goes on to a fine ironic description of ceremonious persons elsewhere, and speaks of the various grades of those manners which may really be called good. He then continues as follows:

"Each of us has a particular disposition which he owes to nature, to habits engrafted by education... to his profession...t to his social position. The division of labour which strengthens the union of men in all important matters, making them interdependent one with another, is nevertheless apt to compromise those social relations which should give charm and pleasure to civilized life. It would seem, then, that the power we have of acquiring lasting

${ }^{1} \mathrm{~J}$. Desaymard, Op. cit. pp. 102-107. 
habits appropriate to the circumstances of the place we desire to fill summons in its train yet another which is destined to correct it and give it flexibilitya power, in short, to give up for the moment, when need arises, the habits we have acquired and even the natural disposition we have developed-a power to put ourselves in another's place, to interest ourselves in his affairs, to think with his thought, to live in his life; in a word, to forget ourselves. These are good manners, which in my opinion are nothing but a kind of moral plasticity. The accomplished man of the world knows how to talk to any man on the subject that interests him; he enters into the other's views, yet he does not therefore adopt them; he understands everything, though he does not necessarily excuse everything. So we come to like him when we have hardly begun to know him; we are speaking to a stranger and are surprised and delighted to find in him a friend. What pleases us about him is the ease with which he descends or rises to our level, and, above all, the skill with which he conveys the impression that he has a secret preference for us and is not the same to everybody else. Indeed, the characteristic of this man of consummate breeding is to like all his friends equally well and each of them more than all the rest. Consequently our pleasure in talking to him is not without a trace of flattered vanity. We may say that the charm of his manners is the charm belonging to everything that can be called grace." Here M. Bergson introduced the famous analysis of grace 
which afterwards appeared in Les Données immédiates de la conscience (Time and Free Will), and continued : "Good manners are the grace of the mind. Like the manifestation of bodily grace they evoke the idea of limitless adaptability; they suggest too that this adaptability is at our service and that we can count upon it. Both, in short, belong to the order of things that have a delicately balanced equilibrium and an unstable position. A mere touch would reverse that equilibrium and send them at once into an opposite state. Between the finest manners and an obsequious hypocrisy there is the same distance as between the desire to serve men and the art of using them in our own service... The balance is not easy to keep. We need tact, subtlety, and above all a respect for ourselves and for others.

"Beyond this form of good manners, which is no better than a talent, I can conceive another which is almost a virtue... There are timid and delicate souls who, because they mistrust themselves, are eager for approbation and desire to have their vague sense of their own desert upheld by praise from others. Is this vanity or is it modesty? I do not know. But whereas the self-confident man annoys us by his determination to impose on everyone his own good opinion of himself, we are attracted by those who anxiously await from us that favourable verdict on their worth which we are willing to give. A welltimed compliment, a well-deserved eulogy, may produce in these delicate souls the effect of a sudden gleam 
of sunlight on a dreary landscape. Like the sun it will bestow new life, and may even transform into fruit blossoms that without it would have withered untimely. It takes up its dwelling in the soul and gives it warmth and support, inspiring that self-confidence which is the condition of joy, bringing hope into the present and offering an earnest of success to come. On the other hand a careless allusion or a word of blame, uttered by those in authority, may throw us into that state of black discouragement in which we feel discontented with ourselves, weary of others, and full of distaste for life itself. Just as a tiny crystal dropt into a saturated solution summons to itself the immense multitude of scattered molecules and makes the bubbling liquid change suddenly into a mass of solids, so, at the merest hint of reproach, there hasten from every quarter, from the hidden depths of the heart, fears that were seemingly conquered, wounds of disillusion that were healed over, all the vague and floating griefs which did but await the moment when they might crystallize together into a compacted mass, and press with all their weight upon a soul thenceforward inert and discouraged. Such morbid sensibility is supposed to be rare because it is careful to hide what it suffers; but who among us, even the strongest and best equipped for the battle of life, has not known at times the pain of wounded self-respect, and felt as though the springs of the action he was about to undertake were broken within him ... while at other times he was uplifted in joy and a 
sense of harmony overflowed him, because the right word spoken in a happy hour reached that profound interior chord which can vibrate only when all the powers of life thrill in unison. It is some such word that we should know how and when to speak; therein lie the heart's good manners-the good manners that are a virtue. For they argue the love of our neighbour and the lively desire to win his love; they shew charity at work in the difficult domain of a man's self-love, where it is as hard to recognize the disease as to have a desire to heal it. And this suggests to us a general definition of good manners, as embodying a regard for the feelings of others which will enable us to make them pleased with both themselves and us. Underlying them is a great and real kindness, but it may very likely remain ineffectual unless there be joined to it penetration of mind, suppleness, the power of making fine distinctions and a profound knowledge of the human heart.

"Education, while it increases that mental flexibility which is a quality dominant in the man of the world, enables the best among us to acquire knowledge of the hearts of men, whereby kindliness is rendered skilful and becomes the good manners of the heart. This our forefathers recognized when they termed the studies of the later years of school life the humanities. Doubtless they held in remembrance the sweetness and light coming of long companionship with the best minds of all time and so well summed up in the Latin word humanitas. They had in mind also the 
profound knowledge of the human heart which may be attained through a sympathetic study of the classics and which, adding penetration to charity, gives it power to move freely along the thousand byways of sensitiveness and self-love. Perhaps too they had in mind that high self-control with which men who have read much and thought much . . . give utterance even to their most cherished theories, their deepest convictions. This again is yet another form of good manners ...

"There is a way of expressing our opinions without giving offence; there is an art which teaches us to listen, gives us a desire to understand, enables us to enter on occasion into the mind of others-in short, to exhibit in discussions, even those on politics, religion and morals, the courtesy too often reserved for trivial and indifferent matters. Where this courtesy is maintained it seems to me that divisions are less acute and disputes less bitter... But such respect for the opinions of others is not to be acquired without sustained effort; and I know no more powerful ally in the overcoming of that intolerance which is a natural instinct than philosophic culture. Aristotle said that in a republic where all the citizens were lovers of knowledge and given to reflexion they would all love one another. He did not mean by this, I take it, that knowledge puts an end to dispute, but rather that dispute loses its bitterness and strife its intensity when lifted into the realm of pure thought-into the world of tranquillity, measure and harmony. For the 
idea is friendly to the idea, even to the contrary idea ..."

Although this address treats of a subject rather remote from those which Bergson usually discusses, it has its value as an early indication of thoughts that find a prominent place in his later work. Moreover we are entitled to regard the speech as an avowal by this young man of an ideal he would follow-an ideal he has certainly realized. No man has better or more completely fulfilled the counsels he gave here than their author; no man has more consistently applied his own doctrine to his life.

Even down to the period of his sojourn at ClermontFerrand, Bergson was still inclined to devote himself to the physical and biological sciences. It appears, in fact, that it was a criticism of the metaphysical basis of those sciences that led him first to psychology and then to wider philosophical study.

We shall gain an idea of the range of his reading and interests at this time by the following extract taken from the programme of his lectures for the year I886 :

\section{Formal Statement.}

I. Matter (Criticism of the theories of mechanism).

2. Mind (Criticism of materialism).

3. Explanation and criticism of Kant's proofs of the existence of God.

4. Goodness and Becoming. 


\section{Historical Statement.}

I. Aristotle and his influence on the sciences.

2. The Philosophy of Malebranche.

3. Spinoza; a detailed criticism of The Ethics.

It has been said that Bergson at the outset of his career laid down in detail a plan of his work and never deviated from that plan. This obviously is in one sense incorrect. The variety of subjects to which his interest and attention were given is sufficient to show that his choice among them was not made beforehand. But if this statement means that from the beginning his thought had a certain unity both of process and of consequence, it is justified. He says himself that the bearing and importance of a philosophical doctrine are to be measured by the variety of the ideas into which it opens out, and by the simplicity of the principle that sums it up. No doctrine sustains this test better than his own.

It was at Clermont-Ferrand that Bergson discovered the value of the words 'impossible' and 'negation' as starting points of new and vitalizing thought. It was here that one day, when taking his regular walk after he had lectured on the antinomies in regard to movement of the Eleatic school, an inspiration came to him, bringing the master idea of his whole doctrinethe idea of duration.

In Paris whither he moved in 1889 he was first at the Collège Rollin and later at the Lycée Henri-Quatre. 
Already distinguished by his early philosophical work, he met with consideration among French thinkers; and his teaching established his reputation. One indication will suffice to show the character of this teaching. Lionel Dauriac, a young French philosopher, says: "I have had in my hands notes taken at these memorable lectures. I doubt whether there has been given in France for a very long time any teaching of equal value; yet no one regarded it as subversive." 1

His first years at the Lycée Henri-Quatre were devoted to preparatory studies for Matière et Mémoire. ${ }^{2}$ This book appeared in I896, but some passages embodied in it had been printed earlicr in the same year in the Revuc philosophique and the Revue de métaphysique et de morale.

In regard to the origin of this book, which merits the title of corner-stone of his work, Bergson has himself given information of great value. At a meeting of the Société française de Philosophie, in Igor, he said: "I set myself the following problem :What is it that modern physiology and pathology can teach with regard to the time-honoured question of the relation between matter and mind, when the learner is without prejudice and is determined to forget every speculation that he has already entertained on the subject, and is also determined to set aside,

${ }^{1}$ Quelques réflexions sur la philosophie de Monsieur Henri Bergson. L'Année philosophique, Pilon, Paris, I9I I.

2 Eng. Trans. Matter and Memory, N. M. Paul and W. S. Palmer, Sonnenschein, now G. Allen \& Co., London, I9I I, pp. xivi and 339 . 
in the pronouncements of scientific men, all that is not purely and simply a statement of facts? When I began to study the subject I soon discovered that the problem could not be solved, even provisionally, unless it were narrowed down to that of memory. And in memory itself I was led to mark out a field which I had more and more to restrict. After having fixed on the memory of words I saw that the problem thus formulated was still too great, and that it is the memory of the sound of words which puts the question in its most precise and most interesting form. The literature of aphasia is enormous; I took five years to consider it. And then I arrived at this conclusion : that between the psychological fact and its substratum in the brain there must be a relation answering to no one of the ready-made concepts offered by philosophy for our use."

An interesting and important address on Le BonSens et L'Education, affording us another clue to Bergson's manner of thought and at the same time throwing light on his personal view of life, was given by him at a distribution of prizes at the Concours général des lycées et collèges in I895.

This address has recently been reprinted with slight changes in L'Opinion; and we translate from this version the most significant passages.

After pointing out that " the method of good sense is in speculative concerns to appeal to the will and in practical concerns to have recourse to reason," he 
goes on to say that, although we have to speak of it as " the result of a mixture, of a close accord, between the demands of thought and those of action," he inclines to a totally different view in regard to its fundamental character- " to see in good sense the original disposition, and in the habits of thought and the laws of the will two effluences, two divergent developments, of this primitive faculty of orientation." "I cannot," he says, "represent to myself either the play of associated wills without an ultimate end that is reasonable, or the natural functioning of thought without a goal that is practical. These two forms of activity must, then, be derived from one and the same power, answering to the fundamental needs of life in a society; and this kind of social sense is just what we call good sense." Having thus stated his position he continues as follows:

"If good sense is, as we have said, the very essence of the spirit, ought we not to find it, as Descartes has said, ' whole in each one of us,' innate and universal, independently of education? It would be so, I believe, if there were nothing in the individual soul and human society but what is alive; if we were not condemned to carry along with us a dead weight of errors and prejudices ; if also we were not prone, through momentary or enduring distraction, to live and to think on the surface, outside our real and living self ; if, finally, we never allowed our intellect to come to decisions that are, so to speak, abstract, but kept it steadily in touch with the tense energy of the will. But 
seldom does nature produce spontaneously a free soul, mistress of herself-a soul throbbing in unison with life. As a rule, education must step in, not so much to impart an impulse as to clear away hindrances; rather to raise a veil than to bring light...

"Among the most formidable hindrances to freedom of the spirit are the ideas which language bestows upon us ready-made and which we drink in, so to speak, from the world that surrounds us. They never assimilate with the substance of ourselves; yet although they have no part in the life of the spirit they remain with us, mummified in their stiffness and their immobility. How is it, then, that we so often prefer them to those which live and vibrate? Why does our thought, instead of striving for the mastery of its own kingdom, remain rather in exile from it? Partly, no doubt, because we are distracted, and, while we amuse ourselves by the way, forget where we are going... It may be that a natural and necessary law requires our mind to begin by accepting ready-made ideas, and live as it were in a state of tutelage until the day (for ever adjourned by some) of that act of will whereby it becomes master of itself. The child sees no more in external nature than the rude and conventional forms which he scrawls upon paper the moment he has a pencil in his hand. These forms come between his eye and the object; they present him with a useful simplification of it. And for many people this convention lasts until the moment when art comes to open their eyes to nature. 
Now, I would liken the ideas that we find wrapped up in words to these childish drawings. Each word represents indeed a part of reality, but a part roughly cut out, as though with a view only to man's convenience and his need and without regard to the articulations of the real. We are driven to accept provisionally this ready-made philosophy and science; but both are only steps by means of which we may climb higher. Beyond the ideas that have grown set and cold in language we must seek the movement and the warmth of life."

After pointing out that in classical education there was to be seen " just this effort to break through the ice of words" and "rescue thought from automatism," Bergson went on to discuss the office of philosophy :

"Philosophy carries forward in the same direction the work thus begun; it submits to criticism the ultimate principles of thought and action; it attaches no value to truth passively received; it would have each one of us reconquer truth by reflexion, earn it by effort; and, embracing it in the depths of our own self and animating it with our own life, lend it strength enough to fertilize thought and direct the will... But we must do more than set aside symbols and accustom ourselves to see; we must learn to abandon a too abstract manner of judging and cultivate a habit of attention to the particular. Certain branches of knowledge have the advantage of keeping us more closely to life. Thus a serious study of the past will help us to understand the present, provided always that we remain on our guard against specious analogies, 
and that we seek in history, as a contemporary historian has finely said, causes rather than laws. The physical and mathematical sciences have a less concrete aim ; but they are admirably calculated to make us understand the characteristic virtue and the special end of methods we employ all too lightly in everyday life. As they generalize only where there are stable laws, and make deductions only where men create their own definitions, they reveal clearly the ideal conditions of strict deduction and of a generalizing that is legitimate ...

"The education of good sense will not consist then merely in setting free the intellect from ready-made ideas, but also in turning it away from ideas that are over-simplified, in arresting it on the slippery incline of deduction and generalization, and lastly, in curing it of excessive confidence in itself."

In I900, the year of the Universal Exhibition, Bergson took part in the first Congrès international de Philosophic, which was held in Paris. His share in the proceedings was an address entitled Notes sur les origines psychologiques de notre croyance à la loi de causalité. This short paper (it consists of only fifteen pages of large type) may be regarded as one of the most important of his minor works. On the other hand, the lecture given in the following year before the Institut psychologique international, on Le Rêve, ${ }^{1}$ must in his own opinion be considered to be not of the

1 This article has been reprinted in the Revue Scientifique, $4^{\text {th }}$ series, No. 15, 705-713, June, 1901. 
first importance, since the study of this subject has recently undergone great development.

In the same year Bergson began to contribute to the Transactions of the Société française de Philosophie; and some of his contributions have appeared in its Bulletin. His introductory addresses to the Society and his share in the discussions, whether oral or by letter, are a valuable, even an indispensable, commentary on his published work. These discussions with a small circle of men of like studies and pursuits shew Bergson profiting by the freedom of an intimate give and take of attack and defence, and displaying a manner very sympathetic, very detached, frank and often slightly ironical. His first contribution was the famous paper on Le Parallélisme psychophysique et la Métaphysique positive, filling nearly forty pages, in the course of which he gives the information that we have already quoted about the origin of Matière et Mémoire. In 1903 he contributed a paper on La place et le caractère de la philosophie dans l'enseignement sccondaire, and in 1905 on Esprit et Matière. In I90I he wrote a paper on L'Inconscient dans la vie mentale. He also contributed to the discussion on Le vocabulaire technique et critique de la philosophic. At the beginning of 1902 he published an article in the Revue philosophique on L'Effort intellectucl, which happily supplements some parts of Matière et Mémoire. ${ }^{1}$

${ }^{1}$ Some extracts from this article will be given in substance under the heading "Intellection" in Chapter III. 
In July of the same year he gave an address on Intellect and Will at a distribution of prizes at the Lycée Voltaire, from which we quote the more important passages.

He begins by criticising received opinions as to the nature of intellect, and then continues as follows: "Real intelligence enables us to penetrate to the inside of what we are studying, to reach the very bottom of it, to breathe its spirit, to feel the rhythm of its soul. Whether it be the intelligence of a scientific man or of an artist, of a lawyer or a physician, an artisan or a tradesman, in any and every case it is a current of sympathy set up between the man and the thing, as though between two friends who need no words between them and have no secrets from each other. See how the good critic divines the hidden meaning of his author, how the accomplished historian reads between the lines of the documents he is examining, how the practised chemist foresees the reactions of bodies he is handling for the first time, how the knowledge of the good physician anticipates manifest signs of the disease, how the skilful lawyer understands our case better than we do ourselves. All these men in their different spheres shew the same power of the mind-the power of attuning themselves to things, following them in their subtlest movements and vibrating in sympathy with them. What is this power? Are we to identify it with the totality of our acquired and stored up knowledge? Not altogether, since it is continually and successfully applied 
to matters that are entirely new. Is it purely and simply the power of reasoning? It is not this either ; for reasoning alone leads us to no more than general conclusions-stiff, ready-made clothing which seldom fits the unforeseen and changing forms of particular instances. This power of the mind moulds itself upon the form special to each problem, and works only, as it were, to measure. No, it is neither knowledge alone, nor reasoning alone; it is nothing that can be learnt by heart or stated in a formula. It is a complete adaptation of the mind to its object, an exact focussing of attention, a certain interior tension, giving us at the moment of demand the strength we need to seize swiftly, to grasp with vigour, to retain enduringly. In short, it is in the proper sense of the word intelligence.

"Consequently intelligence has always in the grown man a bias towards some one direction which it prefers to all others. It has a chosen domain wherein it feels at home. It has an environment of familiar objects with which it has established sympathetic communication. These objects may be more or less varied, the domain greater or smaller; none the less both are limited. There is not, there cannot be, a man of universal intelligence. But the wonder of wonders is that the more completely our intelligence is at home within its limited domain (provided that this be not too small) the less it feels itself a stranger elsewhere. Nature has thus ordered human affairs. There are subterranean ways between the most widely 
separated fields. Between the most diverse orders of things pass, like invisible threads, the mysterious laws of analogy. We are astonished when we see how the man who is a master in his own science art or profession moves with comparative ease in very different worlds... If you stretch a cord by hanging from it a heavy weight, and then sound near it on some musical instrument the note which it is itself able to produce, it will vibrate in unison. But just because it is capable of this it will also respond to all the harmonics of the note. So it is with our intelligence. The particular tension we have been able to give to our mind will teach it to vibrate in unison with some one note; but if it gives this note true, if the tension is what it ought to be, the mind can give equally well, although more faintly, a thousand harmonics of this fundamental sound.

// "Now observation shows us that this perfect adjustment of the mind to the things with which it is occupied may in large measure be acquired. And it is acquired by an effort of the will. In spite of appearance it is nothing more than concentrated attention, and therefore is a form of voluntary effort. The greater this effort, the more profound, the more complete, is the resulting intelligence... It is a severe effort and demands an ever-increasing expenditure of power, as though we had to deal with a coiled spring whose resistance grew with the pressure we put upon it. It is an effort that may become painful-indeed so acutely painful that most men put it off indefinitely. This is 
why so many are brought to a standstill halfway to their goal, are content with mediocre ability, and expect that practice will make them perfect in their chosen task. But practice, that is, habit, will not make them perfect. It can extract from the effort once made all that effort has to bestow; it gives back quite honestly as change the full value of the gold coin of endeavour, but it does not put a halfpenny more in the till. Every real advance of intelligence, every increase in its penetration and range, represents an effort by which the will has driven the mind to a higher degree of concentration.

"Concentration-here lies the whole secret of intellectual superiority. This it is which distinguishes man from the beast - the beast who is the scatter-brain of nature, always at the mercy of impressions from without, always living externally to itself, whereas man can gather himself into himself and concentrate himself. This it is also that distinguishes a man who is sensible and alert from the erratic man and the dreamer. Such men abandon their minds to every chance idea, he, never relaxing his hold upon himself, continually brings all his attention to bear on the realities of life. This concentration it is, once more, that distinguishes the great man from the ordinary man-the latter content with a mediocre ability in which he rests and lets go of himself, the former tense in the persistent endeavour to surpass himself. This it is perhaps that is the essence of genius, if it be true that genius is the vision of a moment won by years of labour, brooding, 
and patient expectancy. Indeed the reason that our attention is usually fixed on a man's intellectual qualities is because they are the most obvious and most brilliant; we do not sufficiently recognize that the deep-lying source of all energy, even of intellectual energy, is the will. Grace, delicacy and subtlety of the mind, the imagery of the poet, the discoveries of men of science, the creations of the artist-all this is what we see; what we do not see is the strong travail of the will, wringing from its very substance these amazing manifestations. Just so the untiring movement of the great engine in the cellars of the theatre is translated on the stage before the dazzled eyes of spectators into changeful cataracts of light.

"Strive then to sustain this fire of energy within you; call upon your powers, concentrate your attention, bring to bear the utmost strength of your will, so that your intelligence may attain the fullness of its range. Go down into the depths of your being and bring thence to the surface all that there is--nay more than there is-within you. Remember that the will can perform this miracle; you have only to demand that it shall..."

The first number of the Revue de métaphysique et de morale of the year 1903 opens with a remarkable essay by Bergson entitled Introduction a la métaphysique. ${ }^{1}$

1 This work is about to appear with other minor works in I9r 4 . The English Translation by Mr. T. E. Hulme, An Introduction to Metaphysics, was published by Macmillan \& Co. Ltd. in r9r 3 . 
In the same year he made his first contribution to the Academie des Sciences morales et politiques, of which he had become a member. During the ensuing years he was a regular contributor, especially of accounts of recent scientific works which he undertook to present on behalf of their authors or which had been submitted by candidates for prizes in the Academy. His interest even carried him into the delicate matter of deciding on the claims of certain applicants for charitable funds distributed by the society.

Among the most important of his publications in the proceedings of the Academy is a critical study on La Vie et les Euvres de Félix Ravaisson-Mollien. On account of the remarkable analogies between this artist-thinker and Bergson the study is worthy of note. In form, and in its quality of literary criticism, it is a masterpiece. We quote some passages from it in another connexion. (See pages $32 \mathrm{ff}$.)

At the International Congress of Philosophy at Geneva, in I904, Bergson presented a paper entitled Le Paralogisme psycho-physiologique, in which he attacks once more the parallelist doctrine in psychology, shews its origin, and lays bare its foundation as resting not on experience but on a metaphysical hypothesis. He ends by characterizing it as a logical absurdity. The report of the discussion on the paper, given by the Revue de métaphysique et de morale, speaks of the deep feeling aroused by this article, "un mouvement de surprise et d'inquiétude." 1 It is hardly too much to

$$
1 \text { Revue, etc., 1904, pp. 1027-1037. }
$$


say that from this date a new era in psychology begins.

In the same year the Bulletin de l'Institut général psychologique contained a short article by Bergson on Les courbes respiratoires pendant l'hypnose. While still at Clermont-Ferrand he had begun to study the phenomena of hypnotism, and the effect of these studies was already visible in his published work. The first contribution that he sent to the Revue philosophique in 1886 was on $L a$ simulation inconsciente dans l'état d'hypnotisme. The attention of the Society for Psychical Research in England (of which Society he was at a later date to become president) was drawn to this article, and subsequent correspondence resulted in the inclusion in Mr. Myers's Human Personality, Vol. I. p. 447, of a case contributed by M. Bergson.

It was in 1907 that L'Evolution créatrice appeared. A portion of Chapter IV. (on the idea of 'Nothing ') had been inserted in the Revue Philosophique in November of the previous year. With this book, which both in actual size and in philosophic inclusiveness is his greatest work, a new phase in the history of its author begins. Until then he was but little known or studied outside France; within two or three years after the publication of L'Evolution créatrice his books were translated and his thought disseminated very widely both in Europe and America. This increase in popularity has necessarily brought about a change in Bergson's attitude towards the public, especially 
during the last few years. Formerly he addressed only his colleagues or his pupils ; of late he has accepted invitations from different bodies, at home and abroad, asking him to speak to mixed audiences. And, instead of publishing his minor works exclusively in academic and professional reviews, he gives some of them to reviews of a more general character.

Before we leave entirely behind us the earlier phases of the philosopher we must cast a glance over his matured opinion with regard to the aim and tendency of philosophy, as he displayed it in the address in memory of Félix Ravaisson-Mollien.

In connexion with his criticism of the Essai sur la métaphysique d'Aristote by Ravaisson-Mollien, ${ }^{1}$ Bergson says :

" The intellect, beguiled by the simplification introduced into the study of things through marshalling them under general ideas, is no doubt led to picture itself as penetrating in this way the very substance of which the things themselves are made. As it makes further advance in the series of its generalizations it sees itself climbing higher and higher on the ladder of realities. But that which it takes for a greater spirituality is only the increasing rarefaction of the air it breathes. It does not discover that the more general an idea the more abstract and empty it is ; and, that in travelling from abstraction to abstraction, from

1 Notice sur la Vie et sur les $E$ Euvres de R. M. lue dans les Séances du 20 et 27 Février, I904. Séances et travaux de l'Academie des Sciences morales et politiques, vol. clxi. pp. 673-708. 
generalization to generalization, our progress is towards pure 'Nothing.' It were better to confine ourselves to the data of the senses, which yield us no doubt only a part of reality but at least allow us to remain on the solid ground of the real. But we may take quite another position; and this would prolong the vision of the eye by a vision of the mind. Without leaving the domain of intuition-that is, of things that are real, individual, concrete-we may seek beneath the intuition of the senses an intuition of the intellect. We may pierce by a strong effort of mental vision the material envelope of things, and thus read within them the form, invisible to the eye, which materiality unfolds and manifests. Then will appear the unity that links being to being, the unity of a thought which we see passing from inert matter to the plant, from the plant to the animal, from the animal to man, gathering itself into its own substance until, from concentration to concentration, we come to the divine thought that thinks all things in thinking itself. Such was the doctrine of Aristotle. Such is the intellectual discipline of which he sets us the rule and the example. In this sense Aristotle is the founder of metaphysic and the initiator of a certain manner of thoughtphilosophy in essence."

His last words are as follows: "In the history of philosophy we watch, above all, the ever-renewed effort of a reflexion which endeavours to diminish difficulties, to resolve contradictions, to measure, with always increasing approximation, a reality that 
is in fact incommensurable with our thought. At rare intervals we see the uprising of a soul that appears to triumph over these complexities by sheer force of simplicity-the soul of an artist or poet, dwelling in touch with its origin, reconciling in a harmony that the heart can feel terms that are perhaps irreconcilable for the intellect. When such a soul borrows the voice of philosophy the language it speaks is not always understood in the same fashion by all men. To some it seems vague; and in that which it expresses it is vague. To others it is clear, because they feel and know within themselves all that it suggests. To many ears it brings no more than the echo of a vanished past; but others hear in it, as in a dream, the joyful song of the days that are to come... What can be bolder, what more new, than thus to tell the physicist that the inert is to be explained only by the living, the biologist that life can never be understood except from the side of thought, the philosopher that generalizations are not truly philosophical, the schoolmaster that he should teach the whole before its parts, scholars that they should begin with perfection, man-more than ever given up to selfishness and hatred-that the motive natural to him is generosity?"

These words spoken by Bergson of another philosopher may unhesitatingly be applied to himself. In every sentence we find a likeness to his work and character. That which Ravaisson-Mollien has only foreshadowed, he realizes with both precision and depth, and with a creative originality that gives to both his 
arguments and his theses the character of a new revelation. ${ }^{1}$

During 1898 a change occurred in Bergson's external circumstances. He left the Lycée and became a professor at the Ecole Normale, where however he remained only two years, leaving it in Igoo to become a professor at the Collège de France. Here he occupied first the chair of Greek Philosophy, and afterwards, as successor to Gabriel Tarde, the chair of Modern Philosophy. Quite recently this famous college, recognizing the quality of its professors, has introduced a wise reform: they may themselves determine the number of hours which they deem necessary to give to lectures; no time-table is imposed upon them.

About this time M. Bergson moved to the house which he still occupies. It stands just at the boundary of Paris, where the city joins the commune of Boulogne, close to the old fortifications which separate the suburb of Auteuil from that part of the Bois de Boulogne where the racecourse of Auteuil at times attracts the crowds of the great city. Its actual situation is peaceful and secluded, within an enclosure containing several houses each having its own garden and each occupied by one family. On the wroughtiron gates admitting to the enclosure we read the name Villa Montmorency, a name which applies to the whole settlement. This is occupied for the most

\footnotetext{
E. Le Roy: Une philosophie nouvelle, Henri Bergson, Paris, 1912.
} 
part by men of letters. No street-cries are allowed there and no beggars; carriages and motors are warned that they must drive slowly.

Most of the houses are surrounded only by a low fence and can be seen by passers-by; but the threestoried house of the philosopher is completely screened by a high paling, and all the windows are closely curtained. There is a verandah in front of the house shading both the front door and the windows of his own study; under this are a few chairs. In fine weather he can slip out from his study into the open air and still have perfect privacy.

During the long vacation he goes to the Jura mountains, to his Villa Bois-Gentil near St. Cergue, westward from Geneva. Here he has a glorious view of Mont Blanc on the one hand and the blue crescent of Lake Leman on the other. The house stands very high among pine trees, and its view is uninterrupted except on one side, where a modern tourists' hotel intercepts it.

This seclusion, both in Paris and at his country house, became more than ever necessary to the philosopher after the publication of L'Evolution créatrice.

Among the great number of accounts of this book, some given with much detail and well written, there have been a few criticisms to which Bergson has replied. In one of these replies, dealing chiefly with the development of the geometrizing intellect, we find the following words which, if we consider 
them attentively, may emancipate us from much idle disputation on a point of attack that has been often chosen by his opponents. ${ }^{1}$

"I have never maintained that it was necessary 'to put something different in the place of intellect,' or to set instinct above it. I have simply tried to shew that when we leave the domain of mathematics and physics to enter that of life and consciousness, we must make our appeal to a certain sense of life which cuts across pure understanding and has its origin in the same vital impulse as instinct-although instinct, properly so called, is quite a different thing. This sense of life is nothing more than consciousness penetrating further and further into its own depths and seeking, by a sort of torsion upon itself, to replace itself in the direction of nature. It is a manner of experience as old as humanity, but a manner from which philosophy is far from having obtained all that it is possible to obtain. To describe this special experience, to determine the exact limits of its competence, to shew how it is superposed upon the sensible experience which itself is directed in the same way as the intellect-is this to take an anti-intellectual attitude? The other experience too, sensible experience, that which is to-day the one that matters for the positive sciences, was practised in crude fashion for centuries of humanity before any man sought to purify it ; and the creators of our modern science, when in the name of this experience of the senses they began to protest

${ }^{1}$ Revue de métaphysique et de morale, 1908, p. 30. 
against the superbly intellectual theses which were the science of that day, when they maintained that no reasoning can prevail over experience, no principle over a fact, were no doubt considered anti-intellectual. If we are to construe the accusation in this sense we may admit in our turn that we also are anti-intellectual. We shall be in good company.

"But the man who is really anti-intellectual is rather he who, seeking to induce philosophy to be no more than a systematization of the sciences (that is to say, at bottom, seeking to fill up by an arbitrary hypothesis lacunae in our actual knowledge), would guide it gently towards the point where it has no choice other than that between an indefensible dogmatism and a resigned agnosticism-two roads to bankruptcy. He is truly anti-intellectual who, because he refuses to distinguish between the cases where intellect attains reality and those others in which it can do no more than manipulate its symbols, comes to hold all knowledge as symbolic and all science as relative to our intellect. If there is any conclusion to be drawn from L'Evolution créatrice it is, on the contrary, that the human intellect and positive science, wherever they are concerned with their proper object, are verily in contact with the real and penetrate more and more profoundly unto the absolute."

If we compare this passage with the analyses of intellect, intuition and instinct that Bergson gives elsewhere-of which summaries will be found in the later part of this book-we see that this answer to his 
opponents throws into clearer relief the several functions he attributes to these faculties.

Certain other objections raised by some few of his colleagues were answered by him during a discussion at the Sociéte française de Philosophie, on the results of an important enquiry with regard to the evolution of the teaching of philosophy, set on foot by M. Alfred Binet and published in the Année psychologique of 1908 (pp. 152-23I).

"We find here," he says, " reference to a belittling of science, to some sort of subordinating of science to metaphysics. Where, when, in what terms, have I ever said anything of the sort ? Who can show me, in all that I have written, a single line, a single word which can be interpreted in this fashion?

"Let us cast aside generalities; let us speak, if you please, of the sciences and not of science. There are mathematical sciences, physical sciences, biological sciences, and so forth. What have I said of mathematics? I have said that however large the share that creative imagination has in them they never lose sight of space and matter; that matter and space, moreover, are realities; that matter is ballasted with geometry; and that mathematics, consequently, are in no way a game, but a real laying-hold upon the absolute. I attribute also the same absolute value to the physical sciences. These, indeed, enunciate laws the form of which would have been different if other variables and other units of measure had been chosen, above all, if the problems had been taken in 
a different chronological order. But all this is due to the fact that we are obliged to break up nature into fragments and examine one by one the problems that it sets before us. Ideally physics does reach the absolute, and, in fact, as it advances it draws ever nearer to this ideal limit. If there is among modern conceptions of science any doctrine in which positive science is set higher than this, I should like to hear of it. Most of them regard all knowledge as relative to the human intellect; I believe, on the contrary, that it is reality in itself, absolute reality, which the mathematical and physical sciences go some way towards revealing. Science only becomes relativeor rather symbolic-when from the physico-chemical side it attacks the problems of life and consciousness. But here too it remains entirely legitimate. All it needs is to be complemented by a study of another kind, by metaphysic. In short, all my researches have no other object than to bring about an understanding between metaphysic and science, and to consolidate each by means of the other without sacrificing anything in either-after having in the first instance clearly distinguished them one from another."

At a later date, on the occasion of the presidential address he delivered in England in I9I3 to the Society for Psychical Research, Bergson recurs to the subject of the order in which mankind has approached the various problems with which it is faced.

"Mathematics," he says, "have come down to us from ancient Greece, physics has already existed for 
three or four hundred years, chemistry dates from the eighteenth century, biology is hardly younger; but psychology is an affair of yesterday, and "psychical research' is not far from being its contemporary. Is this late birth a subject for regret? I have sometimes wondered what would have happened if modern science, instead of starting from mathematics and addressing itself to mechanics, astronomy, physics and chemistry, instead of concentrating all its strength on the study of matter, had begun by considering mind-if Kepler, Galileo, Newton, for example, had been psychologists. We should certainly have had a psychology of which we can form no idea at the present day, any more than we could have imagined, before Galileo, what our physics would be. This psychology, when compared with ours as it actually is, would probably have been very much what our physics is when compared with that of Aristotle."

The relation of M. Bergson's doctrine to the problems of religion has been much discussed and very widely misunderstood. An enquiry initiated by the Mercure de France afforded opportunity for a brief though important statement on his part in regard to this matter. ${ }^{1}$

"I yield," he says, " to your friendly importunity; but, nevertheless, I feel quite unable to foretell what

1 The answers to this enquiry were collected into a book, and published by F. Charpin: La Question religieuse. Enquête internationale, Paris, 1908. 
the external manifestation of the religious sense may be in the time to come. I can only say that it does not seem to me likely to be disintegrated. Only that which is made up of parts can be disintegrated. Now I am willing to admit that the religious sense has been gradually enriched and complicated by very diverse elements; none the less it is in essence a simple thing, sui generis, and resembles no other emotion of the soul. It may perhaps be urged that a simple element, although it cannot be decomposed, may yet disappear, and that the religious sense will inevitably vanish when it has no object to which it can attach itself. But this would be to forget that the object of the religious sense is, in part at least, prior to that sense itself; that this object is felt even more than it is thought; and that the idea is, in this case, the effect of the feeling quite as much as its cause. The progressive deepening of the idea may therefore make the religious sense clearer and ever clearer; it cannot modify that which is essential in it, still less effect its disappearance."

Again, in regard to this subject, we find a reply to certain objections in a letter from him to Father Joseph de Tonquédec, S.J. ${ }^{1}$

“ I speak of God (pp. 268-272 of L'Evolution créatrice) as of the source whence issue successively, by an effect of his freedom, the 'currents' or 'impulses' each of which will make a world; he, therefore, remains distinct from them, and it is not of him that we can

1 Cited in the Annales de Philosophie chrétienne, Mar. I912. 
say that 'most often it turns aside' or it is 'at the mercy of the materiality that it has been bound to adopt.' Finally, the reasoning whereby I establish the impossibility of 'nothing' is in no way directed against the existence of a transcendent cause of the world; I have, on the contrary, explained (pp. 299-30r, and 323) that this reasoning has in view the Spinozist conception of being. It issues in what is merely a demonstration that 'something' has always existed. As to the nature of this 'something,' it is true that nothing in the way of a positive conclusion is conveyed. But neither is it stated in any fashion that what has always existed is the world itself; and the rest of the book explicitly affirms the contrary."

Quite recently Bergson speaks in terms that are even more emphatic in reply to a new Etude by Father de Tonquédec entitled Bergson est-il moniste? He expresses himself as follows :

"I have, as a philosopher, for the moment nothing to add ; because the philosophic method, as I understand it, is exactly moulded on experience (both interior and exterior) and does not permit of our enunciating a conclusion which, in however small a degree, outstrips the empirical considerations on which it rests. If my work has succeeded in winning some confidence from minds hitherto indifferent to philosophy it is for this reason-I have never given admission to any merely personal opinion, or to convictions which, by this particular method, could not be rendered objective. Now the considerations set 
forth in my Essai sur les données immédiates result in bringing to light the fact of freedom; those of Matière et Mémoire point directly, I hope, to the reality of spirit ; those of L'Evolution créatrice exhibit Creation as a fact. From all this emerges clearly the idea of a God, Creator and free, the generator of both matter and life, whose work of creation is continued on the side of life by the evolution of species and the building up of human personalities. From all this emerges, consequently, a refutation of monism and of pantheism in general. But before these conclusions can be set out with greater precision, or considered at greater length, certain problems of quite another kind would have to be attacked-the problems of ethics. I am not sure that I shall ever publish anything on this subject; I shall do so only if I attain to results that appear to me as demonstrable, or as clearly to be shewn, as those of my other books. All that I could say in the meantime would be beside the mark for philosophy, or even outside its domain as I understand it ; philosophy in my view being constituted according to a clearly defined method and able, thanks to this method, to lay claim to an objectivity as great as that of the positive sciences, though of a different kind." 1

In I9Io Bergson wrote only his usual reports to the Academy on recent work, and the new introduction for the English translation of Matière et Mémoire,

1 Etudes, Revue fondée en 1856 par des Pères de la Compagnie de Jésus, vol. 130, 1912, pp. 514, 515. 
which appeared first in English and was afterwards added to the seventh edition of the work in French. In this introduction he was able to point out that some opinions which were considered paradoxical at the date of the first publication of the work in 1896 (as, for instance, that which rejects the localization of the memory-images of words and explains aphasia quite otherwise than by such localization) are now very widely held. The conception of aphasia, he observes, which was then classical, universally admitted and believed to be unshakeable, has been considerably shaken during the last few years.

In April I9II he took part in the fourth Congress of Philosophy at Bologna, having been prevented by illness from taking part in that held at Heidelberg some years before. His contribution to the Transactions was a paper on L'Intuition philosophique, afterwards published in the Revue de métaphysique et de morale, November I9II. Although this lecture was addressed to philosophers by profession it is perhaps one of those among Bergson's writings understood best by the general public. During the same year, a year marked by rich and varied work on his own part, he wrote an introduction to the French translation of William James's Pragmatism, in which, under the heading Vérité et réalité, he indicates his position in regard to certain aspects of pragmatism as this is represented by William James.

As soon as he returned from Bologna Bergson went to England where, on the 26th and 27th of May, he 
gave lectures at Oxford on La Perception du changement (lectures which were printed in French by the Clarendon Press), and on the 29th the Huxley Lecture at the University of Birmingham, taking as his subject Life and Consciousness. This appeared in the Hibbert Journal of October in the same year. In the same number there was also an article by Mr. Balfour on Creative Evolution and Philosophic Doubt, which made Bergson's name known to large numbers of people who had never before heard of his importance to philosophy.

During this year a literary daily paper, ParisJournal, published an interview with Bergson, in which he found opportunity to express certain intimate and personal views on art and on the relation between art and philosophy. Some passages from this will appear under their appropriate headings in the later part of this book.

During the following year, I9I2, the only public utterance he gave in Paris, otherwise than from his Chair at the Collège de France, was in response to an invitation by a Parisian society called Foi et Vie to speak on 'L'Ame et le corps.' His address, which was followed by others given by men of the first rank (among them Henri Poincaré), was published with these in a volume entitled Le Matérialisme actuel. ${ }^{1}$ In October of that year, at the invitation of the London University, he delivered at University College a course of four lectures on The Nature of the Soul.

${ }^{1}$ Flammarion, Paris, I913. 
Admirable summaries of these lectures appeared in The Times; their excellence is the more remarkable that the lectures were spoken in French.

$\mathrm{He}$ was again in England in May I9r3, when, as President of the Society for Psychical Research, he delivered the address from which we have already quoted a passage on the order of the sciences. In the earlier part of it he makes clear what his position is in regard to the objects of the Society, and alludes to his own published utterances on the relation of spirit and matter. He deprecates all polemic against the opponents of the Society and expresses his definite opinion in regard to polemic in general. "I believe," he says, "that the time given to refutation in philosophy is usually time lost. Of the many attacks directed by the many thinkers against each other, what now remains? Nothing, or assuredly very little. That which counts and endures is the modicum of positive truth that each contributes. The true statement is of itself able to displace the erroneous idea and becomes, without our having had the trouble of refuting any one, the best of refutations. But we are here concerned with something very different from refutation and counter-criticism. I am anxious to shew that behind the prejudices of some and the ridicule of others there is concealed, invisible but active, a certain metaphysic unconscious of itselfunconscious and therefore inconsistent, unconscious and therefore incapable of perpetually refashioning itself on observation and experience, as should every 
philosophy worthy of the name. I am anxious to shew, moreover, that this metaphysic is natural, that it is the result of a habit of the human mind acquired long ago, one therefore that we have an interest in seeking out beneath the criticism or the ridicule which overlie it, in order to put ourselves on our guard against it. Thus we shall escape being ourselves influenced by that mental habit and be free from the artificial obstacles that it might place in our path."

Speaking of the relation between mental life and the brain, he insists once more on the doctrine of the relation between the body and the mind which he had elaborated in Matter and Memory. "Cerebral phenomena," he says, "are indeed for mental life what the movements of the conductor's bâton are for the symphony ; they indicate the motor articulations, they do no more. We should find nothing of the operations of the mind, properly so called, within the brain. The brain, apart from its sensorial functions, has no other office than to exhibit in pantomime the mental life."

Early in I9I3, at the invitation of Columbia University, and as a delegate from the University of Paris, Bergson crossed the Atlantic to lecture in New York and in some other university towns in the United States. His lectures were attended by crowds and added to his reputation in America.

On his arrival, Mr. W. Dawson-Johnston, Librarian of Columbia University, presented to $M$. Bergson a pamphlet entitled, "A Contribution to a Biblio- 
graphy of Henri Bergson," with an introduction by Professor John Dewey which concludes as follows: "It is the object of the following bibliographical pages to help to bring an even wider audience in touch with the vital influences that radiate from Professor Bergson's thought. They should facilitate a more intelligent understanding of his lectures and enable those interested to follow up by more leisurely reading the desire for further knowledge that will spring from them."

This bibliography shews how large a place is occupied by his thought in the minds of men of all civilized countries. From year to year the flood of books, articles and pamphlets increases in volume. Certain librarians in America, Germany and Sweden reckoned in I9I2 that $4 \mathrm{I} 7$ books and articles on Bergson had appeared; in the year I9II alone there were seventynine, and in 1912 one hundred and twenty-six. Yet no count was made of newspaper articles, although among them there are many that have considerable value. Short book reviews were also excluded. At this moment there exist translations of his works in English, German, Italian, Russian, Swedish, Magyar, Danish and Polish. In England and in Sweden all his chief works have appeared in translation.

With regard to his reputation in France it is impossible to give an accurate account. In its fluidity and varying form it is the best proof of the flexibility and the truth to life of his philosophy. Yet there are sources of information which point to the extent 
and penetration of his influence and the vigour of the opposition it provokes. For instance, an instructive enquiry " on the qualities of the Bergsonian philosophy which give to it its specific character and have contributed to create its very rapidly attained and undoubted reputation " was set on foot as recently as IgII by the most important organ of theoretic socialism in France, Le Mouvement socialiste. In inviting answers the Editor admits that it was mainly the ' anti-intellectualism' of Bergson that had attracted his attention:- "Is not the realism of Marx and Prudhon at bottom hostile to every intellectualist doctrine?"

(The attitude of this review in relation to ordinary socialistic dogmas is certainly akin to that of Bergson in relation to an intellectualist philosophy. We find in both the same desire to come to close quarters with reality and the same mistrust of formalism. One of its principal contributors, and the most enlightened and most original, Georges Sorel, had previously, in the year of the publication of L'Evolution créatrice, written a study of it which must be reckoned among the most important that have appeared.)

Among the many answers that were received, most of them of real significance, the only one which seriously attempts to give an explanation of the sudden rise of Bergson's popularity and of the resistance, sometimes bitter and prejudiced, that he meets, especially in his own country, is that of René Gillouin. To this author had been entrusted the important task of publishing 
extracts from Bergson's work, with an introduction. $\mathrm{He}$ is, besides, the writer of a fine study of the thought of the philosopher, with whom he is on terms of friendship. In answer to the questions he wrote as follows : "The enormous and very rapid success of Bergson's philosophy is the result of many causes, but to my mind the most important is this. Towards 1880 philosophy was about fifty years behind the stage of advance reached by the physical sciences. In M. Bergson it has suddenly recovered all the ground it had lost. Bergsonism was vaguely anticipated in the minds of men; in the measure in which it took shape we recognized it. And this is why a philosophy so amazingly new has not met with the usual fate of novelties... It offers an open way when all other roads are closed." Then, in explanation of certain forms that the resistance to it has taken, Gillouin says with a touch of derision: "We resign ourselves with a certain discomfort to the necessity of believing that a man who has sat on the same bench at school with us, or has had no more than the same education as ourselves, can possess genius while we have nothing of the sort."

The discussion was not confined to France, and Professor Draghicesco of Bucharest, in his reply to the enquiry, gave the most comprehensive opinion concerning the possibilities that are bound up with the reception of Bergson's philosophy, not only in regard to science and philosophy generally, but also in regard to religion, morals, education and social 
progress. We quote a few sentences indicating the line he takes :

"This immense and decisive influence on the philosophy of the future is already foreshadowed by an actual success marking a definitely new direction in the evolution of modern thought-a new discredit that has fallen on the old, official, cut-and-dried methods of the schools. In the sphere of religion and morals it will have-unintentionally, almost in spite of itself -practical and theoretic consequences that are incalculable. Moral philosophy, led astray by an inflexible rationalism, will find its proper road and true methods. It will be the same with religious speculation ..."

Bergson's own opinion is characteristically more modest, and his anticipations do not range so far. In a letter, dated from London on March 7 th, I9I4, to the Editor of Le Figaro, in which he comments on an article about himself that had appeared in that journal on February 28th, he writes as follows :

"Allow me, then, to say that the spread of what men agree to call 'Bergsonism' is due simply to this : the initiated see, and the uninitiated divine, that they have here to do with a metaphysic moulded on experience (whether exterior or interior); with an unpretentious philosophy determined to base itself on solid ground; with a doctrine that is in no sense systematic, that is not provided with an answer to every question, and that distinguishes different problems to examine them one by one-a philosophy, 
in short, capable like science of indefinite progress and advance towards perfection. Each of my books has cost me several years of scientific research; and each of them issues in no vague generalities but in conclusions which are able to throw light on some one aspect of very special problems. This, I repeat, is what men perceive, dimly or distinctly, when they become adherents of this philosophy."

With this authoritative declaration on the philosopher's part we bring to a close our imperfect sketch of his personality and go on to trace out, to the best of our ability, the main lines and principles of his doctrine.

(Note. While these pages were passing through the press Monsieur Bergson was elected a Member of the Academy; and his three most important works, Essai sur les données immédiates de la conscience, Matière et Mémoire, and L'Évolution créatrice, were placed upon the Roman Index.) 


\section{CHAPTER II.}

\section{CHANGE.}

\section{The self and duration.}

In beginning the study of this new philosophy we do well to recognize the need to question and perhaps reject opinions that have long been regarded as established. But indeed any man who disinterestedly reflects upon himself, and contemplates and seeks to understand the world about him, may at times hear an inner voice like that of the 'demon' of Socrates forbidding him to accept that which is generally accepted and even that which he believes he sees, a voice whispering in his ear the arresting word ' $\mathrm{im}$ possible';-impossible, even when facts and reason seem to urge him to believe it possible, or true and certain;-impossible, because a different experience, as yet perhaps vague and obscure, nevertheless forces him to doubt the established or most plausible opinion.

From one point of view all our knowledge seems rooted in experience. Such knowledge gives sufficient truth for the practical needs of everyday life; and yet, if we look more closely and reflect more deeply, we discover that this practical truth is full of absurdities 
and doubts, of errors and contradictions. The objects that we see change continually in form, colour and size, according to the angle from which we view them and the surroundings among which they are placed. When we look with greater care we find ourselves obliged to abandon the idea that we really know them as they are; all that we know is the manner in which they present themselves to us. Our knowledge of things then, we must admit, is external and superficial; it is only ourselves that we know from within. Of our own existence alone are we sure; that alone do we know beyond dispute. We can exclude or deny everything else; but our relation with our self rests upon an intellectual sympathy, an understanding immediate and natural to us. And it is from this inner experience of ourselves that light is shed upon our knowledge of the external world.

If at the outset I look upon myself as though with an inner eye the first thing that I see is this: I change unceasingly. Insensibly I pass from one state to another; and all my impressions, feelings, desires and representations are but changes in my own existence, which, as it were, takes their colour. This process of change is more persistent and profound than we are at first inclined to suppose. I may admit freely that I change, but I am inclined to regard each stage as an entity and to believe that it remains unmodified while it lasts. Change appears to me to consist in the passage from one state or stage to another; yet a slight effort of attention would show me that there is 
no feeling, no representation, no volition, that is not altering every moment.

Let us take as an example the most stable of internal states, the visual perception of an unmoving external object. The object may remain the same; I may look at it from the same side and angle, and under the same light. Nevertheless, the vision that I have of it is different in every successive moment, even though it be only in that I have looked at it a moment longer. My memory is there, bringing something from the past into the present; my mind, like a snowball, grows larger by all that it gathers as it goes; my present vision shares in all $I$ have and am. That which we call a 'state' is indeed itself a change; there is no essential difference between the passing from one state to another and the remaining in what we call the same state. Transition is fluent, continuous, constant. For practical purposes, and for reasons derived from practice, we close our eyes to the uninterrupted change that is the very essence of the life of the spirit. In order that we may lay hold upon and describe the living process within ourselves, we are obliged to direct attention upon selected and therefore fragmentary parts of an undivided whole, and these we afterwards call 'states.' Where there is, in reality, a gentle slope we think we see the steps of a staircase. Where there is, in truth, the fluidity of fugitive shades, blending one into another, we think we see defined and well marked colours, solid, as it were, and placed side by side like the beads of a necklace. Attention is 
concentrated on certain shining points in the fluid mass which contains all that we think and feel and will-all that at a given moment we really are. If we give this meaning to the concept 'state' we cannot claim for it the character of a static element. States of ourselves are continued in an endless current.

Again, just as the understanding with its artifices picks out from the flow of consciousness isolated states, so with its artifices it tries to join them together. It invents a self, stiff, formless, colourless, a solid string on which it threads the states like beads; nay, this colourless substratum is dyed every moment with the colour of the bead it bears, and so becomes invisible and as though it did not exist. And indeed it does not exist, except as an aid to thought, an image for the convenience of our logic and our language.

Here is our first discovery in regard to the self and its continual and constant change. The life of the spirit is not like that of material objects in space; time is the very stuff of which it is made. In other words, it is not static but dynamic; it is not a thing but a process; it has a history.

With the inward eye I glance once more at my personality as it is in repose. I notice to begin with a crust, as it were, formed upon its surface--the mass of impressions made on my personality by external objects crowding upon me from the material world. They present themselves to me with clear, defined outlines, each separated from the other. I see how they group and arrange themselves as objects that I 
perceive. Then I observe memories more or less closely connected with these impressions and serving to interpret them. Finally, I become aware that among these impressions and memories mingle efforts on my part, nascent actions and desires. All these, welded together, form the surface as it were of a sphere, which ever tends to grow larger and to incorporate itself more and more with the outer world.

If, on the other hand, I withdraw into myself, if, leaving the periphery of my existence, I approach its centre, if I seek in its depths that which is least variable and most persistent-myself; then I find that my personality takes on a very different look. Below the crust of massed impressions I find an ever-flowing current, a stream unlike any stream in the world of things. Upon this current are borne states of soul, each of which foreshadows that which is about to come and sums up all that have gone before. But in truth it is only after these states have passed by, and I turn to look at the track they have left, that they show themselves as separate one from another. While each one was present and actual it revealed itself to me as so completely one with my own life that it would have been impossible to indicate its beginning or its end ; nor could I have analysed it into component states, as I may when I reflect upon it afterwards, subdividing into artificial parts a real and living whole. My life is an unceasing advance; my past eats its way into the future and grows as it goes on. Whole 
and undiminished it pursues me. All that I have felt, thought and willed, from earliest childhood onwards, endures, seeking to overtake the present and force the door of consciousness. But the mechanism of the brain is so constituted as to keep this door nearly closed, and relegate the greater part of our memories to the shadow-land of the unconscious. That which seems likely to throw light on the present situation and help us with the action we are preparing-that, in short, which is useful-it admits to consciousness. It may happen that some memories not wholly utilitarian slip in by the partly open door and, as messengers from the unconscious, bear witness to all that unawares we carry with us. And even when this does not happen we still have a vague sense of our past as present with us. Indeed, what shall we say of character, what can we mean by it, if it is not the condensation and expression of all the experience we have had from our childhood until now ? More-did not our character begin before our birth, in the predispositions we inherited? No doubt only a small portion of our past enters into conscious thought, but it is with our whole past, including all our original bent, that we desire, feel and act. Our whole past. urges us on-as tendency manifesting itself in action and desire-however small a part of it is represented in consciousness.

Just because the past survives it is impossible for us ever to pass twice through the same state of mind, ever to repeat ourselves. Circumstances may appear 
to be the same, but even if we grant that they are the same they act no longer on the same person, since they take him at a new moment of his history and himself. At every moment our personality is being built up through an accumulating experience, and its change is unceasing. On the surface a man's states may seem to be repeated, but the change that is always going on in his depths makes real repetition impossible. Our duration - the process whereby we move from the past through the present into the future, the process ever amassing our present to add it to our past-this cannot be reversed or turned back upon itself. We can never live again the smallest fragment of our life or repeat the most trivial of its incidents; to do this we should first have to blot out all that intervenes between then and now. We might efface the memory of what happened from our thought, but never from our character.

Thus our personality germinates and grows. At every moment something new is added, something, we may even say, that could not have been foreseen. I may explain my actual state as a result of what was in me and what acted on me ; but if I regard it as what it really is-the moment of a developing history-I see that it could never have been perceived before it happened; since not only all that ever has been perceived in that history is concentrated in it, but also that which the actual present is adding to it. It is, in short, an original moment of a no less original history. 
The aspect of the sitter, the nature of the artist, the colours on the palette may be taken as explaining a portrait; but with all this knowledge at hand not even the artist himself could have foretold exactly what the portrait would be. Even he could not have produced it before it was produced. Every moment of our life is in a way created; every moment as it issues from us modifies our life, is a new form we ourselves give to ourselves. And the more we reason upon what we do the more complete is this self-creation. When we give a precise meaning to the word exist we discover that for a conscious being to exist is to change, to change is to grow, to grow is to enter upon a creation that never ceases. Must we say this also of existence in general ?

\section{Matter.}

The material object has characters precisely the reverse of those we have just described. Either it remains what it is or, under the influence of external force, it changes by the displacement of parts in it which themselves remain unchanged. In analysing the material object we stop only when we have attained the limit of our division; that is to say the atom or the electron or whatever be the latest word of science.

In a group of material corpuscles a previous state may at any time be repeated, either spontaneously or under the influence of an external cause. The object does not grow old. Nothing in it is created anew. 
What the group will be is determined by what it is, and a superhuman intellect might calculate, it has been said, the position that all parts of the world would occupy in space at any future moment, were all parts of the world no more than material. Our manner of dealing with things in daily life, as in science, is based on the supposition that the time we know in ourselves as change has no hold upon them, effects no interior change in them ; and that therefore they will invariably behave as we expect. The rapidity of mathematical time might indeed increase indefinitely, and the past present and future of material objects be displayed all at once in space, without calling for any alteration either in the formulae of science or the language of common sense.

All this is applicable to an object taken separately, to an isolated group, or to a scientific system. Yet even in the material world there is a true succession. In reasoning about these objects or systems we may picture to ourselves their past present and future displayed at once. Nevertheless this has not happened ; the history of an object unfolds by degrees, as though in a duration analogous to our own. When I wish to ford a flooded river I have to wait till the water falls; and the time I spend in waiting is not the mathematical time which would apply to any scientific system of the material world, whether hastened or retarded or taken as it stands. It coincides with my impatience, with a certain stretch of my own life which I can neither shorten nor increase at will. It is not 
thought, but lived; it is no longer relative, but absolute. I am driven to acknowledge that, although I have isolated the river, the spate, and its subsidence, and by my senses and my understanding have set them apart, yet there is a Whole to which they belong, a Whole from which I cannot really divide them; and that this endures after the manner of a consciousness.

The work of science, by which groups of phenomena are set apart and systems made, is not entirely a matter of artifice. Unless it had some objective validity we could never understand why it should be applicable here and inapplicable there. Groups and systems are isolated for the convenience of study, but the scientific man does not or should not forget that every such group or system remains, in real fact, subject to external influences from which it cannot be isolated. By these influences the smallest object is linked with all the rest, allied not only with the whole solar system but with that immeasurably greater Whole we call the universe. By the threads of mutual influence that pass from particle to particle every atom of matter is linked with the immanent duration of the universe.

The universe then, we say, has duration. The systems marked out by science in the physical world, as separate things, have their duration only because they are inseparably bound up with the rest of the universe. And from the moment that we recognize this connexion and replace them mentally in the 
Whole, we see that there is nothing to hinder our attributing to them a manner of existence analogous to our own.

Moreover, the materiality of a body is not bounded by the surface that we see and touch. Wherever the influence of a material thing can be felt, there the thing is present. If we consider only its attractive force we see it affecting the sun and planets, perhaps the whole universe. The greater the advance of physics the more does it tend to efface the limiting lines of bodies, even those of the smallest corpuscles into which scientific imagination has divided them. Every material point acts upon all other material points. And when we have duly apprehended the fact that a thing is wherever its action reaches, we are enabled to see with Faraday all atoms interpenetrating each other and each of them filling the world.

The limiting lines that our perception marks out in the Whole, as boundaries of this object or of that, are in fact lines along which action may be directed. The distinguishing features of the individuality of an object, as it is for our perception, are the diagrammatic foreshadowing of the influence we ourselves may be able to bring to bear on some point of space. They form, as it were, an outline plan of the possibilities of our eventual action. By this limiting power of our perception we carve a way of our own through the maze of reality. If perception were extinguished the individuality of each thing would be lost; it would merge into that universal interaction which is reality itself. 


\section{The living body.}

We are driven to ask ourselves what the relation is between the body that perceives and the material world upon which it casts the image of its own virtual actions, and in the flux of which its sensory organs create all other bodies. The living body assuredly occupies space and is intimately bound up with everything else in space; it is subject to the same physical and chemical laws as other parts of matter. But, whereas our own perception divides matter into separate things and an artifice of science creates isolated systems among things, the living body has been isolated by nature itself. Its many parts complement each other; their functions depend upon each other. It is individual in a higher degree than any other body, even more so than the crystal, since a crystal possesses neither heterogeneous parts nor diverse functions. No doubt it is not easy to distinguish individuality with certainty in the animal kingdom, and in the case of plants it becomes almost insurmountably difficult. No doubt individuality is susceptible of infinite degrees and is nowhere, not even in man, complete. Nevertheless there is an incontestable tendency in life to form systems that are naturally isolated and closed ; there is a bias towards individuality. It is mainly, too, by the possession of this bias that a living being is distinguished from the mere material thing. If we would find in the inorganic world some likeness to the living organism we must not look for it in any material object by itself but in the universe 
as a whole. Here, in this likeness, we discern the essential character of the living organism. Like the universe in its totality, like every conscious being taken separately, it is something that endures ; its past is prolonged into its present and persists, both active and actual. Thus it is that the organism passes through phase after phase, alters with age, has in short a history. If I consider my own body I find that, like my consciousness, it matures step by step as it passes from childhood to old age. Indeed maturity and old age are strictly conditions of my body only ; it is by metaphor that I call corresponding changes in my conscious personality by similar names. And if from the consideration of my own complex body I pass to the consideration of an unicellular organism, one of the infusoria, if in fact I descend the ladder of living beings from the top to the bottom, I discover in this single cell exactly the same process of growing old, although in many cases individuality is so little defined that we cannot say precisely what it is that does grow old. The infusorium is worn out at the end of a certain number of divisions, and is only saved from decay by a conjugation that might be indefinitely postponed. Even in a tree, which in a sense does not grow old (since its terminal branches are always young, always equally capable of producing new trees from cuttings), something grows old, were it only the leaves and the woody heart. Moreover such an organism is indeed rather a society than an individual. In anything that is alive we can 
find somewhere an open book in which time writes down a story.

We have here attempted to sketch the relations between the conscious self, the material object, the living body, and the eternal movement that passes through the worlds. Despite all their differences we see that the self, the object, and the living body display characteristics common to them all-we see duration setting its mark on all that is.

After these preliminaries, in which we have traced something of the essential character of duration, we pass to a consideration of movement, in the course of which that character will be further manifested. In this connexion we shall endeavour to explain in some degree the philosophical method of Bergson, as shewn in his manner of regarding movement.

\section{Philosophic methods.}

The philosophies of Plato, of Aristotle and of Plotinus are the development of a principle that may be formulated thus: "There is more in the immutable than in the moving, and it is by way of diminution that we pass from the stable to the unstable.' Our intelligence, in fact, is so constituted that it attends by preference to rigidity-to fixed points taken out from the flowing current of reality. When human thought follows its natural bent towards the furtherance of practical action these fixed points alone seem to be of importance, and the philosophic principle which exalted 
the immutable above the moving was shaped in accordance with this natural bent. The difficulties inherent in metaphysic-its antinomies, its antagonistic schools and systems - are mainly due to a transference of manners of thought coming of our habitual pursuit of practical ends to the disinterested and speculative search after a knowledge of the real. The confusion arises from the fact that in thought we place ourselves in the unmoving in order to lie in wait for the moving thing as it passes by, instead of placing ourselves in the moving thing itself and, by thought, travelling with it. It arises in part also from our belief that we can reconstruct reality-which is tendency, that is, mobility-by means of percepts and concepts whose very function is to immobilize and hold it fast. It is easy enough to understand how thought can extract fixed concepts from moving reality, but it is only too easy to forget that we can never, from these concepts, reconstruct the moving real. Yet it does not follow that we cannot lay hold upon it in some other way.

Intelligence can adopt another method; it can place itself within reality and adjust itself to its ceaseless change. In short it can lay hold upon it by that intellectual sympathy we know as intuition. This is not easy; it is in fact extremely difficult. The mind has to do violence to itself ; it must reverse the direction in which it habitually thinks; it must for ever be recasting the forms of its thought. But if we succeed in doing this, we shall find ourselves possessed of the very rhythm of the inner life of things. Only so will 
a progressive philosophy be built up, a philosophy that will leave behind the disputes of the schools.

We have been long in coming to this clearness of sight concerning our own processes. Galileo brought modern science to birth when, as he studied the movement of a ball down an inclined plane, he abandoned the attempt to find its principle in the concepts of ' high' and 'low' (by means of which Aristotle believed movement could be explained), in favour of an indefinite number of points, chosen at will in the line traced by the ball. But even this did not suffice. A philosophy related to this modern science as the Aristotelian philosophy is related to the science of the Greeks is still occupicd with parts cut out from the continuity of the whole, however many and minute those parts may be. It is doomed to be more or less of a neo-scholasticism. But modern science has grown and is now calling for a different metaphysic. The advance of psychology and of embryology and the advent of the moral sciences suggest the idea of a reality that endures in itself, that is duration. And philosophy responds.

In the new way of looking at the subject-matter of philosophy we not only see many apparently insoluble problems disappear, but we find our daily life transformed and renewed. When the veil of prejudice, woven of the artifices of the schools and the natural defects of common sense, is lifted from before the world as it really is, we begin to think reality and see its truth. 
Let us suppose that instead of trying to ignore intuition we attempt to enter more deeply into it, pouring into it as it were the power of our will; we may thus gain a larger view of it and a wider application. We may arrive at a philosophy which contains all that our senses and our consciousness allow us to lay hold upon, a philosophy which, because it covers the entire field, precludes the possibility of an opposed philosophy. It will give us indeed more than our senses and our consciousness, left to themselves, can give.

But we may well ask how this is possible. How dare we expect that our eyes, whether of the body or of the soul, can be made to see more than they do see? The objection is plausible, indeed serious, but it is met and refuted in experience. From the beginning of humanity there have been men whose peculiar office has been to see, and to make other men see, that which without their aid would never have been discovered. They are the artists.

\section{Art, reality and intuition.}

What is the object of art but to reveal to us, in nature and in the soul, without us and within, many things which we do not reach directly through our senses and our consciousness? The poet who expresses a state of the soul most certainly does not create it out of nothing. We could not understand what he says unless there were in us some impression, at least nascent, corresponding to that which he describes. 
He makes known to us shades of thought and feeling which although invisible to us had doubtless long been ours-it is as though the negative were just plunged into the developing bath. The poet is the developer of our hidden self.

We see the mission of the artist with even greater clearness in that art which comes nearest to material reality - the painter's. The great painter is he in whom a certain vision is native, which has been, or will be, a vision for all men. He has observed in nature much that has escaped our sight. It may be said that he has not seen but has created, that he has given us the product of his imagination, and that we accept his inventions merely because they are to our taste and form an agreeable distraction from our cares. But, if this be so, why do we say of the works of the great masters that they are true? Wherein lies the difference between great art and ingenious fancy?

Let us consider what we feel in the presence of a fine Turner or Corot. If we honestly admire them it is because we have already divined what they would shew us. But we have divined it only as we have divined all that painters have shewn or will shew us, and we have never fully attended to the impression we received. Our vision, though brilliant, was fleeting; it has been lost in the crowd of other shining, fleeting visions which every day of our life succeed and efface each other, producing by their mutual interference the dull blur with which we cover what we see. This vision is isolated for us by the painter; he 
fixes it on his canvas, and so perfectly that henceforward we are obliged to observe in the reality of things that which he has made plain before our eyes.

Art, then, proves the possibility of enlarging our power to perceive the world as it really is; but how are we to do this?

We must remember that the artist is usually called an idealist. He concerns himself less than most men with the positive and material aspect of life. He is, in fact, detached from this aspect. How is it that the man who is detached from what we call real things comes to see more in them than other men? We should be quite unable to answer this question if we had not learnt that our usual vision of the external world and of ourselves does not correspond to reality, if we did not know that the needs of life and action have forced us to lessen and impoverish reality. The more we are entangled in living the less truly are we able to see. The needs of action constrain us to narrow our field of vision. A criticism of experience shews us that there is in the normal life of a man a constant tendency to contract his horizon, to turn away from all that he has no material interest in pursuing. Before we reflect we have to live, and practical life puts blinkers on our eyes so that we see neither right nor left, but only along the straight road that we are following. We have gathered out of the boundless field of possible knowledge all that concerns our action upon things, and of this we make our actual knowledge-the rest we are apt to leave on one side. The brain seems 
to have been made with a view to this choice. Our whole past is automatically preserved, it survives in its entirety; but our practical interest accepts from it only that which throws useful light upon the present situation. The brain helps us in this choice; it actualizes the useful memory and relegates to the subconscious those memories that are not of present service. We may well say the same of perception; ancillary to action, it selects from the whole of reality that which has practical interest for us, and shews us not so much objects themselves as the advantage they may be to us. It divides them into classes and labels them. Indeed we hardly see the object itself; we are content to know the class to which it belongs. $W c$ are content; but from time to time by happy chance men are born who are not bound to the treadmill of practical life. Nature seems to have forgotten to attach their perception to their action. When they see a thing they look at it for itself; they do not observe in order to act but for the pure sake of observation and the joy of it. In one side of their nature, or of their consciousness, or in regard to one of their senses, they are born free; and according to circumstances become painters or sculptors, musicians or poets. What the artist gives us is, in short, a more direct vision of reality ; and the more disinterested he is the more he himself is able to see.

Nature thus at long intervals, and as though unawares, reveals reality to certain privileged beings; 
but is it not possible that philosophy may do the same thing, by different means and in a different way, for other men ? Is it not the very aim of philosophy to lead us, by directing our attention into new paths, to a fuller perception of reality? Does it not seek to turn away attention from that aspect of the world which has a practical interest and to direct it towards that which has no such value for us? Certainly more than one philosopher has said that philosophy is a turning away from practical life, and that speculation is the contrary to action. For Plotinus as for Plato the search after truth calls for detachment and freedom from the illusion of this world. All who have held this view of metaphysic appealed for emancipation to powers other than those of the senses and the intellect. But they never suspected that the necessary training of attention may perhaps consist in nothing more recondite than the removal of its blinkers, in setting it free from the narrowing habits of the practical life. They thought it not enough merely to look at what we have before our eyes; they demanded that attention should be turned elsewhere, calling upon intuitive powers that are entirely different from those which serve us for acquiring a knowledge of the external world and of ourselves. But, just because he might well dispute the existence of such special faculties, Kant held metaphysic to be impossible. He showed finally, and to his eternal glory, that if metaphysic be possible it is only by an effort of intuition. But this intuition he believed to be indeed impossible. He 
thought that to be emancipated from the needs of opine I practical life was to turn one's back on reality. Other philosophers have concerned themselves with the building up of a metaphysic; Kant believed all systems of metaphysic to be equally illusory. Those who differed from him supposed that our senses and our understanding, as they work in everyday life, give us a direct hold on movement in the world and in ourselves. As they encountered indissoluble antinomies they were driven to maintain that the source of contradiction lay in change itself, and that to escape it we must leave the realm of change and raise ourselves above time into the world of fixed and unchanging ideas.

Now if we could prove that what the Eleatics and other philosophers have regarded as movement and change is neither change nor movement, and that what Kant took for time itself is a time that neither lapses nor changes nor endures, we should escape the contradictions which Zeno established in his famous sophisms, and free our understanding from the relativity to which Kant condemned it. "Intuition, in Bergson's meaning, is not what takes place in a soul contemplating its passive image in a mirror, as a dream from which it will awake, and imagining that it has seen as real objects what are no more than visions of a dream. Intuition is metaphysical in tendency; but the knowledge it gives us may be as accurate as the experience we gain in the positive sciences, as indisputable as the best established of their facts. It 
can be acquired, however, only as the fruit of close and long companionship with reality.

\section{Movement and change.}

The change which is most nearly uniform is spatial change, or change of position, e.g. a rolling ball. In the track of such a movement I can imagine restingplaces, and I call these the positions of the moving body. Attempts have been made to reconstruct movement itself by means of these positions, these points through which the moving body passes-and this results in hopeless dilemma. With positions, though their number be infinite, we can never build up a movement. Fixed points can never be parts of a movement; they are only views, snap-shots, taken in a progress; they are halting-places that our imagination makes. Never can the moving body be in any one of these points; the most that we can say is that it passes through them. But the passage, which is movement, has nothing in common with a position, which is immobility. To base movement on immobility is absurd.

It is by an illusion deeply rooted in the mind, and because we cannot help regarding the results of analysis as equally true and sure with our intuitive and immediate knowledge, that when we mark off stopping-places in the course of a movement we come to regard them as parts of the movement itself. Then, finding ourselves unable to reconstruct movement by means of these points, we intercalate other points and suppose ourselves to be nearer to mobility. But still 
movement escapes us, and continues to escape us even when we vainly endeavour to lay hold of it by increasing to infinity the number of our points. Finally, we say that movement is made up of positions, but that there is, besides, an obscure and mysterious passage from one position to another. And, all the time, this obscurity is due to our belief that immobility is easier to understand than movement, and that rest is anterior to motion; the mystery comes of our attempt to pass from rest to motion by way of augmentation, which is impossible, whereas it is quite easy for us to travel by a mere process of diminution from movement to a slower movement, and so to rest. We must learn to see movement as simple and evident ; because immobility is but the extreme limit of the slowing down of motion, a limit that is perhaps imaginary and in nature never realized.

We are like a man who should seek the meaning of a poem in the letters of which it is composed. But the letters are not parts of the poem; they are only elements of its symbol. Just so, the successive positions of a moving body are not parts of its motion; they are points of a space which we suppose to underlie the movement. This empty space is perfect as a symbol, but we shall never touch reality by manipulating symbols. Nevertheless this manipulation satisfies some of the most inveterate habits of our thought. In immobility, in empty space, we find points de reperre for practical action, and when we attempt to gain a clear idea of movement it is with 
space that we begin. But what we find there is only a clumsy imitation, a falsifying of true movement, although useful perhaps for practical life-even more useful than the immediate intuition of reality.

To have the sense of change and time in their original mobility we must by an effort set aside all that comes between reality and ourselves; we must alter those habits of thinking and perceiving which have become second nature to us; we must learn to see each movement as indivisible. This reversal of our ordinary manner of thought, which is of the first importance, may be compassed by following this simple argument : I place my hand at the point $A$ and bring it to the point $B$, passing along the line $A B$. I say that this movement from $A$ to $B$ is a single act. Why should I dream of disputing this, since I have the direct and immediate impression of it? When I move my hand from $A$ to $B$, I may certainly say to myself that I can stop it at any intermediate point. This is indisputable ; but then we no longer have the one undivided movement from $A$ to $B$ which is in question. We have two movements, with a rest between them. Neither from within, by the muscular sense, nor from without, by sight, shall I receive the same impression. If I keep the movement from $A$ to $B$ as what it was, then I feel that it is undivided and am obliged to consider it as indivisible.

It is true that if I watch my hand as it passes from $A$ to $B$, along the line $A B$, I may tell myself that this line can be divided into as many parts as I please; 
and that the movement from $A$ to $B$ can also be divided because it coincides with the line. The moving body at each moment of its transit passes by a point; therefore we may indicate in the movement as many stopping-places as we please, and movement must be infinitely divisible. But, if we reflect a little, we are driven to ask how a movement can coincide with the line it marks out in space, how a moving body can coincide with immobility. How can a moving body be in any point in its trajectory? As it moves it slips through; only if it stopped would or could it be there. But if it stopped and went on again, there would be not one movement but two ; the first movement would have ceased, the second would have begun. A trajectory is always traversed in a single movement, which may last a few seconds, or weeks, or months, or years, but is always one and indivisible.

This argument may convince us, we may have nothing to urge against it, and yet the illusion persists. It is natural to us because, in any movement, that which interests us is not motion but the positions which the moving body has left or will occupy, or might occupy if it stopped in them. We require immobility, and the more completely we represent movement to ourselves as coinciding with space the better we think we understand it.

Yet, in fact, there is no such thing as true immobility, if we mean thereby an absence of movement. Movement is the very stuff of reality, and what we call 
immobility is no more than the apparent stillness of a train seen from our carriage window, when it is travelling at the same pace and in the same direction as our own. This relative immobility is what allows us to act upon things and allows things to act upon us, just as the travellers in the two trains, because they are motionless relatively to each other, might shake hands and talk through the windows. And because immobility is a necessary condition of our action upon things we make it into a reality, and even into an absolute, looking upon movement as secondary to rest. Nothing is more natural in daily life. But to apply this habit of mind in the realm of speculation is to misinterpret the real, and with a light heart to create for ourselves insoluble problems.

This, however, is our customary method. We reason about movement as though it were made up of immobilities; it is for us an infinite series of positions. And although we see clearly that between any two positions there must be some sort of transition all we do when we attend to this transition is to alter it into a new series of positions. We never reach in this way a direct view of the transition itself. We only admit that it exists and give it a name; with that we are content.

What we have just said of movement is equally applicable to any kind of change. Every real change is indivisible; but we like to think of it as made up of successive states. This too is very natural. We must note, however, that if the continuous change I 
call myself is to act on the continuous change I call a thing, both these changes must, in relation to each other, be as one moving train is to another travelling side by side with it at the same pace. The colour of an external object is movement-very rapid vibration -and our own personality also is movement. The whole mechanism of our perception of things, as of our action upon them, is so constituted that between the external motion of the one and the internal motion of the other there is a relation analogous with that of the two trains-assuredly more complex but of the same kind. When the two changes, the change of the object and the change in the subject, have this relation, there is produced the virtual image that we call a state. It is very natural, we must repeat, that we should lay emphasis on the state and not upon the change; indeed, the breaking into states of a continuous change allows us the possibility of perceiving objects and acting upon them, and so our interest in states is of great importance and practical utility. But that which is favourable to action is destructive to speculation. When we think of change as made up of states, then we call into being all the difficulties, all the insoluble antinomies, that the problem of movement, so regarded, involves. It is as though we deliberately shut our eyes to reality.

Let us consider this important and difficult subject in another light.

The eye is accustomed to pick out from the whole visual field images, relatively constant, which seem to 
move from one place to another without being themselves transformed. Movement thus appears to be something of an accidental quality added to the thing that moves. It is convenient to our sense of sight to lay hold of objects in this way; as pioneer of the sense of touch it thus prepares our action on the external world. But when we concentrate attention in the scientific way we find the simplicity of the 'thing' broken up, and so we lose this relation of movement to the thing as it moves. Science in its advance divides matter more minutely than does the eye. The thing is pulverized into molecules, the molecule into atoms, the atom into electrons; and at last we find the substratum of matter, in regard to which movement had seemed to us only an accident, reduced to a mere concession to the habits of our practical life. When we follow the man of science into his 'infinitely little' we detect there a convenient scheme in which for him movement, rather than the thing that moves, stands out as real. Here every material thing is finally broken up into vibratory influences making their way through space. Movement, as we contemplate this picture, seems to require no supporting substance and change no changing object.

It is perhaps even easier to see movement and change as autonomous realities when we consider the sense of hearing. Let us listen to a melody and allow ourselves to be lulled by it. Have we not then an impression of a movement not tied to any moving object, of change apart from any substance that 
changes? This change is sufficient to itself; it is the thing itself, and, although successive, is indivisible. If the melody ended sooner it would no longer be the same whole of sound but another, equally indivisible. If we make abstraction here of all the spatial images which custom entails upon us, there remains pure movement, self-sufficing, not bound up with any changing thing.

\section{Movement and the life of spirit.}

Nowhere is the substantial reality of change so manifest as in our own interior life. Here there is indeed no fixed substratum, nor are there distinct states, defiling in procession like actors on the stage. There is only the indivisible melody of our inner life, unbroken from the beginning of our consciousness. Our personality is just this.

Before the spectacle of this universal movement some of us may perhaps feel as though seized with a vertigo. They are so much accustomed to a ground firm beneath their feet that they are bewildered in this unending flux. Men need fixed points to which they can attach their thoughts and their life. They are not often tempted to listen to the eternal hum of life in those depths where its duration flows. When they think about that duration they begin to fear that if all flows nothing remains, and that if reality is movement nothing exists at the moment when they are thinking of it, since it flees before their thought. But they may rest easy. If they decide to look at change 
directly, without intervening veils, it will appear to them as that which is above all things the most substantial and the most enduring.

We have come now to the point in our analysis of the nature of movement whence we are able to see how we can set about securing a direct vision of duration.

If it is true that change is the very basis of all reality, then we are driven to consider the past otherwise than we have been in the habit of doing. We are all only too ready to see it as non-existent, and philosophers have done their best to confirm in us this natural tendency. For them, as for the ordinary man, only the present has real existence. If anything from the past still endures it is by the aid of the present, by a friendly service of the moment-in a word and without metaphor, by the intermediary of a special faculty that we call memory. The office of memory is to retain, by way of an exception, this or that fragment of the past and to keep it stored as though in a box. This is an illusion, an illusion due to a habit of mind, useful no doubt, indeed necessary to life, since it has provided conditions indispensable to action. But the illusion is extremely dangerous for speculation. It is, in fact, the germ of most of the illusions that have misled philosophic thought.

The simplest consideration shows us that the present, which is said to be all that exists, is in fact a fragment of flowing time. My own present at this moment is that period which I have before me in consciousness 
and to which I limit my attention. At my pleasure I may widen or narrow the field of this attention, just as I may widen or narrow the space between two points of a compass. I may stretch my present to include not only the last few words of the sentence I have just read, but also the last page. If attention were infinitely extensible it would be able to include as large a part as I please of what I call my past; the present indeed holds just as much as an act of attention will embrace. If attention lets go some part of what it held in its field of vision, there and then some part of its present drops out of sight into the past. In other words, our present becomes our past from the moment that it ceases to have an actual importance for us. So too is it with everything that we call actual in the history of a nation.

Consequently there is nothing that need prevent us from pushing the boundary line between present and past as far back as we will. If our attention to life were potent enough, and sufficiently freed from practical interests, it would embrace in one undivided present the whole previous history of our conscious personality, as something both ever present and ever changing like a melody. It is to this eternal present movement that we give the name duration.

\section{Duration, art and life.}

The relation between our idea of movement and change on the one hand and our idea of duration on the other should now be clear. The retention of the 
past in the present implies no more than this-that movement is indivisible. If once we are convinced that reality is change, that change is indivisible, and that in every indivisible change the past is one with the present, then many philosophic enigmas melt away. For example, when we are able to see ourselves in a duration where past and present constitute a unity, a duration which for ever creates something absolutely new (if it is only by adding itself to what is past), the discussion on the freedom of the will is closed for us. And not only philosophy but daily life profits by this manner of seeing all as universal Becoming. In such a view we find a satisfaction as full as that given by art to the few; and it is less rare, more abiding, more within reach of the mass of mankind. Art reveals in things a greater number of qualities and finer shades than we ordinarily discover in them; it increases our comprehension, though rather in width than in depth; it enriches the moment but hardly takes us beyond the moment. By philosophy we may learn not to mutilate life,-dividing the present from the past that clings to it and from the immediate future it bears within its womb. Moreover we may learn from it to take a more spiritual view of art. Philosophy is in truth nearer to art than to science. Science gives us an incomplete and fragmentary picture of reality, a picture it can only present by means of symbols that are of necessity artificial; but art and philosophy are met together in the intuition where both have their roots. We 
may say that the various arts are subdivisions of philosophy.

The more we accustom ourselves to think and perceive all things in the light of the idea of duration, the more profoundly we shall immerse ourselves in real duration. And the more we thus immerse ourselves the more vividly we apprehend the principle in which we share, the principle whose eternity cannot be a still eternity but must be an eternity of movement and of life. For how else could we live and move in it as we do-live and move and have our being ? 


\section{CHAPTER III.}

FREEDOM AND THE WILL.

\section{The phases of mental life.}

Language is but ill-adapted to describe the changes of our inner life. When we speak of that life in words we both simplify it and make it seem more fixed and more solid than it really is-that is to say, we falsify its nature. We establish, among the unnumbered shades of its change, clear distinctions such as those we are accustomed to make among material things. True, in practical life we find it useful to liken things of the mind to material objectsindeed for the scientific treatment of them it is necessary; but we may well ask ourselves whether the insurmountable difficulties, which certain philosophic problems raise concerning the mind, do not come of our persistence in ranging side by side in space changes which do not belong to space. We may well consider whether, if we discard the crude thinking wherein the mind is treated as though it were a thing, we should not bring many of our difficulties to an end.

But for this a serious effort is necessary. Seldom 
and unwillingly does a man give up his habit of applying to the vital functions of his mind the simple mathematics of daily life. Hence we usually regard states of consciousness as susceptible of increase or diminution in magnitude. Psychophysicists say that a sensation may be twice, three times, four times as intense as another sensation of the kind; and even common sense is ranged on their side, as, for instance, when we say that we are more or less cold, more or less pleased,- - thus applying to that which has no size the distinction of greater or less. We are forgetting that when we say one body or one number is greater than another we must be thinking of spaces of different sizes, one of which can contain the other ; and that of a surety a more intense sensation cannot contain a less. We call one number greater than another when it comes after it in the natural series of numbers-the smaller number is contained in it, the larger contains the less. But mental states cannot be added one to another ; their magnitude is intensive, and we must not treat it as though it were extensive. Where there is neither container nor contained we ought not to speak, except by way of metaphor, of quantity and size.

Yet in this matter common sense and science are at one. We use the same words, 'greater' and 'less' for things in space and for the states of our mind; and we compare intensities, or at least express the comparison between them, by means of our vague sense of a relation between two magnitudes. 
We are led to suspect that this manner of interpretation may perhaps be due to our estimating the intensity of our mental state by reference to the magnitude of the outward circumstances that have elicited it. It is true that the larger the orchestra the more intense will be our sensation of sound. But in most cases we judge of the intensity of the state without knowing anything about the nature or the magnitude of the exciting cause. Indeed we often guess at the cause from the intensity of the sensation, and correct our first sensory impression of it. And we are never more sure that we know how intense our sensation is than in cases where the cause to which we refer it admits of no measurement. The artist never doubts that the work of a great master gives him more pleasure than an ale-house sign. We constantly compare intensities without reference to the number or the extent of causes.

When we enter more deeply into the processes of our consciousness, we see that it is absurd to treat a mental phenomenon as we treat an object in space. Each new impression, we find, interpenetrates with all the others and gives a new tone to the whole mind. So, for instance, a new love invades the soul as something strange; little by little it dyes it to its own colour, and changes for the lover all that he perceives and knows. He renews his youth in a glorified world.

When we say that anything occupies a great space in the inner life, or even that it fills it, we really mean that this thing has altered the colouring of all mental 
pictures and memories, and that even where it is not itself distinguishable its image penetrates. But this dynamic idea is very hard to grasp by the reflective intellect, which turns more easily to clear outlines, marked off like those we see in space and easily express in words.

\section{The aesthetic and moral feelings.}

If the sense of the beautiful is not easy to define, this may be because we regard the beauty of art as secondary to the beauty of nature. The function of the artist is understood to be that of expressing by means of his art what in essence evades us. But the real question is whether, except as revealed by the artist, nature is beautiful ; whether indeed, in a certain sense and in this respect, nature is not secondary to art. In any case we may with advantage first examine beauty where it has been produced by conscious effort, and then pass by small degrees to nature, where we may perhaps discover another artist working in another way. In this manner we may come to see that with regard to ourselves the process of art seeks to minimize or eliminate the resistance it meets within us, and so to induce a condition of receptivity in which we accept and submit to its suggestion, and learn to feel in consonance with the emotion it expresses. It is like a refined and spiritualized version of hypnosis. Music, in its ordered rhythm, invades us with such power that it suspends the usual course of our sensations and ideas, and renders us susceptible to the 
smallest artistic hint of this feeling or of that. Art here merely suggests emotion, nature has to express it. Again, as to the charm of poetry, its rhythm masters us, our mind is enchanted, led captive by the thought of the poet; his words conjure up images before our eyes. We are admitted into the living history of the poet's mind; there we attain in sympathy that which without his magic we should have missed. The artist tears away a veil which the exigencies of practical life have placed between his consciousness and ours; and the richer in thought, the more inspired by feeling, is the world into which he brings us, the loftier and the more intense is the beauty he enshrines in his colour, his marble, his notes of music or his words.

We see, then, that the sense of beauty is not a special feeling. Every feeling of which we are capable may take on an aesthetic character, if only it has been suggested, not produced in the ordinary way of cause and effect. Plainly then, we discover why this feeling allows of degrees both of intensity and elevation. There are times when the suggested feeling hardly makes any difference to us; at others our attention is caught by it, though only fitfully or partially; and again it may drive out everything else and take possession of our whole mind. Yet we must remember that the greatness of a work of art depends not so much on the strength with which the feeling it suggests lays hold of us, as on the depth, variety and fullness of the feeling itself. We have to distinguish, then, 
not only grades of intensity, but grades of elevation or depth. What the artist suggests to us does, in fact, embody not a little of his own history. And he seeks to make us share his own emotion, full, personal, new ; seeks to enable us to live what we could never understand.

In relation to the moral feelings we find something of the same kind. Pity, for instance, certainly does involve our suffering, mentally, with others. But this is not all; for if we pity the sufferer our natural desire to avoid pain is set aside. In its higher form pity brings with it even a sort of shadow of a desire to share the suffering. It seems as though we would disavow any suspicion of agreement with the power which inflicts it. The growing intensity of pity, from the lowest form which is a mere feeling of horror and dislike, is obviously a change in quality. We pass from dislike, perhaps through fear of suffering ourselves, to a fellow-feeling, and from that fellow-feeling to some sense of responsibility for the other's suffering and a need for action.

We have to ask ourselves now to what extent physical symptoms should count in an estimate of intensities. By this question we are at once carried to the opposite end of the series of psychic phenomena. Muscular effort certainly does seem to present itself to our consciousness as an affair of size or quantity. There is an apparatus for its measurement. Does it measure at the same time the strength of the will put 
forth? If we consider this closely we shall find, probably, that the idea of an intensity which can be measured has its main source in the crude idea of effort as a force imprisoned like the winds in the cave of Æolus. When we see muscular force marking its results on a registering dial we are apt to believe that it existed before it was set free to be thus manifested. We think of it as having been compressed to a smaller size and then enlarged; and so we come to believe that we can understand how a purely psychic state may have magnitude although it does not occupy space. And indeed this would perhaps be the unanimous opinion of scientific men, but for certain remarkable phenomena to which the attention of physiologists was finally drawn, and which shewed that the feeling of muscular energy at work is a sensation passing from the periphery to the centre and not from the centre to the periphery. Without taking sides in the scientific dispute we may unhesitatingly say that whenever a given effort seems to us to increase the number of muscles contracting in association with it becomes greater, and that our apparent consciousness of greater intensity of effort at a given part of the body is really our awareness that a larger area of the body is affected.

What is true in relation to muscular effort on the one hand and to the aesthetic and the moral senses on the other-examples chosen from opposite ends of the psychic scale-is also true of the mental regions that lie between. In certain cases of deep emotion 
there may be little or no evidence of muscular effort ; but every one of the more violent emotions, anger, hatred, joy, sorrow, may be analysed into a system of muscular contractions gathered up into an idea; and the intensity of these emotions may well be no more than the muscular tension associated with them. But as the emotional state becomes less violent and more profound, peripheral sensations are replaced by inner states. Memories, ideas and so forth, many or few, not outward movements, are marshalled in the definite direction taken by mind. When we say that love or anger grows more violent, we are in fact saying that it is directed outwards towards the surface, and that superficial sensations are replacing inner states. In any case, whether these feelings are superficial or profound, violent or reflexive, their intensity always consists in the assemblage of simple states dimly discerned in them by the mind.

\section{Sensations.}

A sensation however seems to us a simple state; what do we mean by its magnitude? The intensity of a sensation corresponds with an external cause; what are we to make of quantity in an effect which is interior and indivisible? The more intense sensation is usually associated with a greater nervous disturbance. But since we do not know these disturbances as movements, but only as sensations that are quite unlike movements, we do not see how their size can be passed on into the sensation. There certainly is 
nothing in common between, let us say, wave-lengths in space and sensations of sound or light which are not in space. That the more intense sensation appears to us as containing the less, that it seems to us a magnitude, is very likely due to its retaining something of the physical impression with which it corresponds. And of this it could retain nothing were it no more than a conscious translation of molecular movement. Because this movement is translated into pleasure or pain it remains as molecular movement unconscious. No trace of the movements themselves is perceptible in the sensation which translates them. But the natural outcome of receiving a stimulus from sensation is the production of certain automatic movements; and these are very likely to be conscious. If they were not conscious the sensation, whose proper function in our life is to call upon us to make a choice between an automatic reaction and other movements possible to us, would be of no use. The intensity of affective sensations may be no other than our consciousness of the involuntary movements initiated and sketched out, so to speak, in these states-movements which would have been carried on in their own fashion, if, instead of being what we are, we were automata.

On this ground we find ourselves forbidden, for example, to think of a pain which grows more intense as of a note growing louder and louder; we must think of it rather as a musical composition in which more and more of the orchestral instruments come to take part. In a word, we estimate the intensity of a 
pain by the greater or smaller part of the organism interested in it.

We might examine sensation after sensation, and always detect the same peculiarities in regard to our manner of estimating their intensity. Whether it be a sensation of sound, light, heat, weight, or what not, everywhere we detect the inveterate habit that we began to acquire in the very dawn of conscious lifethe habit of attaching a certain quality of the effect to our representation of a certain quantity of the cause, and then going on, unawares, to interpret the quality as quantity, the intensity as size. The representation of intensity occurs at the junction, as it were, between two streams of life, one of which brings us the representation of something spatial, extended, while the other, issuing from the depths of our consciousness, brings the representation of an interior multiplicity which, as we shall show, is not spatial and therefore not numerical.

\section{Pleasure and pain.}

As a rule we look upon the feelings of pleasure and pain as expressing what has just happened, or is happening, in the organism. But we may reasonably ask whether they may not also be an indication of what is about to happen or is likely to happen. Prima facie it is to a certain degree improbable that consciousness, in a bodily life so profoundly utilitarian, should inform us only about the past or the present, both of which have escaped from our control. If in some 
privileged organisms pleasure and pain have appeared, it is more likely in order that opportunity may be afforded for resistance to the automatic reaction that would otherwise occur. Sensation, by this special sign, warns us about the kind of reaction it will be well for us to prepare. There is, in the very heart of the sensation, a sketch plan of the automatic movements of the future, and therefore information requisite for choice. Pleasure and pain do not merely reflect the physical disturbances, movements, or phenomena of the present or the past; they point to those which are making ready to be.

At the first glance this hypothesis does not appear to simplify the problem; when we have made the present state of consciousness a sign of the future rather than a translation of the past, we have only shifted the difficulty of finding out what, in regard to magnitude, there is in common between a physical phenomenon and a state of consciousness. But there is a great difference between the two hypotheses. Physical vibrations coming from without are of necessity unconscious; their movement cannot be perceived in the sensation translating them. On the other hand the automatic movements of the organism that are likely to happen in response to the stimulus will probably be conscious; if it were not so, the sensation would be useless, seeing that its office is to provide us with the opportunity of a choice between the automatic reaction prefigured, and other movements which, as conscious beings, we may elect to make. 


\section{FREEDOM AND THE WILL}

(We propose now to pass to a more detailed discussion of psychic life in its relation with number. Then will follow an account of the philosopher's. doctrine in regard to space and time; and so the way will lie open for that interpretation of the self in which its freedom is established.)

\section{Number.}

Number is doubtless a collection of units; but we have to remember that these units either are exactly alike or are supposed to be so when they are counted. When we count the number of workmen in a factory, and say there are five hundred, we ignore their differences to note only that they are all workmen. But when we pay their wages and name them by name, we look at each man in himself. And if we count a row of fifty windows in the factory, we must at least distinguish them by the position they occupy in space, otherwise they would not be a row. I might sum up all these windows in one image and set them out in a row of an ideal space, or I might imagine one window repeated fifty times in succession. In this latter case I seem to place them rather in duration than in space. But this is not what really happens. Every act of counting material objects, even one by one, presupposes that I keep in memory the images of the preceding objects, and that I place them beside the new image that I call up. Really, then, I do not place them in duration; I leave them in space.

This is true even when we come to abstract numbers. 
A number is, as we have said, a collection of units ; but it is also a unit, because it synthesizes the units that are its parts. Its unity thus includes a multiplicity. But when we speak of the unit parts within that multiplicity we think of them as irreducible, simple, and all alike. There are then, it seems, two kinds of units-one ultimate, out of which a number is formed by addition, and the other provisional, really multiple and owing its unity to a simple act of the perceiving mind. Nevertheless, if we examine the matter more closely we shall find that to this simple act of the mind all unity is due, and that this act is a process of making unity from multiplicity,a unity which is always at bottom no other than provisional. Plainly, every unit is a sum of fractional quantities as many and as small as we like to picture to ourselves. But we could not split it into fractions unless we were in fact regarding it as though it were an object in space. In space it is multiple but in the intuition of the mind it is one.

As a matter of fact we learn by arithmetic to split up indefinitely the units of number. Our common sense prefers to make number out of indivisibles. This is natural enough, for our own mind makes those component units provisionally simple, and in the ordinary way we attend more carefully to the acts of our mind than to the material with which it deals. In the process of arithmetic our attention is directed to this material; but unless we already saw number as in space no arithmetic could induce us to place it 
there. We must always have been in the habit of thinking of number as we think of a side-by-side relation in space.

Taking, then, for granted this conception of number we discover that not all things are counted in the same way; we discover that there are two different kinds of multiplicity. Material objects present themselves to us as though we could see and touch them; we localize them in space, and as they seem to us we count them. But it is quite otherwise with regard to purely affective psychic states, or images not due to sight and touch. Here the terms are no longer given in space, and it is impossible to count them except by a kind of symbolic presentation. So we set them out in some ideal medium, where we see them separately; and whenever we do this they are in space and no longer in duration. True, the operation becomes ever more difficult as we come to deal with the deep interior life, where feelings, sensations and images, as a confused medley that only analysis can disentangle, interpenetrate in our duration. But, if we set out to number them their number is identical with the number of moments they fill as we count them. And such moments are points in an ideal space, whereas the changing quality of duration is undivided and indivisible. Hence we conclude that there are two sorts of multiplicity: that of material things, to which the conception of number applies directly ; and that of the facts of consciousness, which can only be 
considered numerically by help of a symbolic representation into which the notion of space inevitably enters.

\section{Space and the impenetrability of matter.}

Whenever we speak of the impenetrability of matter we do in fact distinguish, without being aware of it, between the two kinds of multiplicity. Sometimes we regard impenetrability as a fundamental property of matter, just like weight or resistance. But it is obvious that a property which like this is merely negative can never be made known to us by our senses; indeed, as far as evidence goes there are certain experiments, physical and chemical, that would suggest a doubt upon the point were not our minds already made up concerning it. In fact a critical examination of our belief shows us that it is based not on a physical but on a logical necessity. To say that two bodies can occupy the same place at the same time implies for us a logical contradiction. The very idea of the number two, or indeed of any other number, brings with it the idea of a side-by-side arrangement in space; and we attribute impenetrability to matter because we think that the idea of number is independent of the idea of space, whereas in truth the idea even of an abstract number is that of different positions in space. When we affirm that matter is impenetrable we are recognizing the connexion between the notions of number and space, and are asserting a property of number rather than a property of matter. 
It will be said, however, that we enumerate distinct sensations, feelings, and so on, which are mutually interpenetrating and each of which yet occupies the whole mind. Certainly we do; but we count them only as represented by artificially homogeneous units made to occupy separate positions in space, and therefore no longer penetrating one another at all. When we assert that matter is impenetrable, intending thereby to distinguish it from everything that is not matter, we do no more than express in a different way a distinction between things already in space, which can be counted directly, and states of the mind which we have to represent symbolically in space before we can enumerate them.

When we watch our psychic states and consider them successively in 'time' we usually picture this time as a homogeneous medium, in which the states are set out one after another as in space and so constitute the kind of multiplicity that is discrete. But true duration, as we have seen, is not spatial at all, nor is it homogeneous. When we analysed the notion of number we were led to the opinion that time, considered as a medium in which distinctions can be made and numbers counted, is in fact nothing but space; and when we find that we are driven to borrow from space symbolic images with which to describe what reflexion shews us concerning time and succession, we see once more that duration must be something wholly different. We are concerned with two different kinds of reality; one heterogeneous, that of sensible 
qualities; the other homogeneous, which is space. Space, conceived by the intellect, is that which enables us to make clear distinctions, to count, to abstract-perhaps also to communicate with one another by speech.

But if we are to define space as that which is homogeneous, every homogeneous medium that has no boundaries must surely be space. For since this homogeneity consists in being without qualities it is not easy to see how one homogeneity can be distinguished from another. Yet we constantly look upon time as a medium without boundaries, homogeneous like space but differing from it. Homogeneity thus appears to take two forms-one in which its contents co-exist, the other in which they follow one another. When we regard time as a homogeneous medium in which states of the mind develop we take it as abstracted from duration and already there, a medium given all at once--in short, we really abandon time and fall back unawares upon space. It may be, then, that time, so regarded, is a false concept arising from the intrusion of the idea of space into the field of pure consciousness; at least we must ask whether if time be homogeneous and space be homogeneous the two can be finally distinguished. Certainly things occupying space are marked out as external one to another, and states of consciousness are not; they become so only when we think of them as separated and spread out in the homogeneous medium we call time. The idea of space, then, seems to be fundamental, and 
the time that is conceived as without boundaries and homogeneous appears as no more than a phantom of space haunting our reflexion.

\section{Living time and mathematical time.}

Pure duration-we may call it living time--is the form taken by the process of our psychic states when the self does not divide itself, that is, does not separate its present condition from its past. But there is no need for it to abandon itself to the passing idea or sensation, for in that case it would cease to endure. Nor need it forget the states that are past; all that is required is that it should refrain from setting those states alongside the one that is actual, as one point may be set beside another. It must organize the present and the past together into a whole, as we organize the notes of a melody and melt them, as it were, one into another. For although we hear those notes in succession we nevertheless perceive them as one within the other; and we may well compare the whole they constitute to our own self, wherein parts, though they are distinct, are interpenetrating just because they are vitally connected. In the melody, if we interrupt the rhythm by dwelling too long on one note, we are made aware of our mistake not by the excessive length of the note but by the change in quality thus effected in the whole musical phrase.

We may obtain a clearer and more vivid idea of duration if we examine what takes place when our consciousness refrains from representing it symbolically. 
When we are made drowsy by the regular beat of a pendulum, is this effect produced by the last sound we hear, the last movement we perceive? Assuredly not; for then there would be no reason, we must suppose, why a single beat should not be equally efficacious. Are we to say, then, that it is produced by a remembrance of the sounds or movements that went before, set side by side with the last ? But if at another time we take the same remembrance and set it side by side with a sound or a movement, there is no such result. We are forced to admit that the different sounds blended one with another and acted not by their quantity as merely quantity, but by the quality which their quantity displayed, that is to say, by the rhythmic organization of their whole. How, in any other way, should we be able to understand the effect of slight but continuous stimulation? Were the sensation to continue unchanged the effect would remain always slight and indefinitely bearable. In truth, every repeated stimulus is organized with all those that went before, and the whole affects us like a musical phrase always seeming about to end, but always being altered in its totality by the addition of each new note.

There is evidently a great difference between the succession of material phenomena in homogeneous space, and the process of change in non-spatial, psychic phenomena, occurring as they do in heterogeneous duration. It is, in fact, the difference between the world of things and the world of mind. 
But assuredly we find very great difficulty in thinking of duration as it really is, in its original purity. This difficulty is owing to the fact that external things appear to endure like ourselves ; while time, as we have seen, looked at in this relation resembles a homogeneous medium. Not only may their moments be measured and juxtaposed like objects in space, but the movement in them that we perceive is, we may say, the palpable sign of a homogeneous and measurable duration. We measure the velocity of a movement, and in doing this we imply that time is a magnitude. Indeed, if duration properly so-called is not that which is measured by the clock, what is it that we measure? If we assume that the inner duration (that of which consciousness is interiorly aware) is no other than the blending of conscious states and the growing of the self, then, it will be said, the time the astronomer introduces into his formulae, the time measured into equal portions by our clocks, must be something quite different-a measurable and therefore an homogeneous magnitude. This however is not so, and close examination of it will remove one more illusion.

When with my eyes I follow on the clock-face the movement of the hand corresponding to the beats of the pendulum, I do not measure duration, as most of us think; I am only counting simultaneities-which is a very different affair. External to me in space there is never more than one position of the hand and of the pendulum; for nothing is left of the positions that once were. Within me a process of organization 
of conscious states goes on; and this constitutes true duration. It is because I endure in this fashion that I represent to myself what I speak of as former beats of the pendulum, when I am perceiving the present one. Therefore if, for the purpose of our argument, we set aside the self that thinks these successive beats there will never be in existence more than one beat; indeed there will be only one position of the pendulum. In short, there will be no duration. Set aside, on the other hand, the pendulum and its beats; then there will be nothing but the heterogeneous duration of the self, without moments that exclude one another, without any relation to number. Within the self there is succession without mutual externality; beyond the self, when the self is set aside, there is mutual externality and no succession. There is mutual externality, for the present beat is wholly separate from the previous one, which no longer exists ; and there is no succession, for succession has no existence except for a conscious looker-on, remembering the past, and setting beats or their symbols side by side in an auxiliary space. But a sort of exchange occurs between these two-succession without externality and externality without succession -an exchange not unlike that which happens when two fluids of different densities are separated by a membrane-the 'endosmosis' of the physicist. Just because in our conscious life successive phases, although they permeate one another, correspond one by one to the beats of the pendulum, and because those beats 
are clearly separate one from another, we habitually make the same distinction between the successive phases of consciousness. We allow our consciousness to be broken up, as it were, by the beats of the pendulum. And from this we derive the entirely mistaken notion of an inner duration that is homogeneous, that resembles space, that has identical moments which succeed but do not penetrate one another. Again, on the other hand, the beats of the pendulum which are really external one to another, and of which only one exists at a time, gain from the effect they have produced in consciousness an appearance of living duration. We make them into a whole by memory and arrange them in a series. To put it briefly, we make a fourth dimension of space for them, as it were, and call it time. This is homogeneous; and in it each movement of the pendulum is set side by side with those that have preceded it. Thus duration is made to take the deceptive form of a homogeneous medium ; the connecting link between space and duration being provided by simultaneity, which may be looked upon as the meeting-point of real time with space.

\section{The two aspects of the self.}

It is at its surface that our self is in contact with the external world. Our sensations, although they melt one into another, still keep something of that separateness, each from each, which characterizes their external causes. Consequently our superficial 
psychic life is easily thought of as spread out in a homogeneous medium. But as we penetrate more deeply into consciousness we discover that we were making for ourselves no more than a symbolical picture. In the deeper self, forming as it does one personality with the superficial,- - the self which obviously considers, makes decisions, is ardent for or against-states and changes permeate one another, and are profoundly altered when we separate them one from the other.

A careful psychology, then, will distinguish beneath the numerical multiplicity of conscious states a multiplicity that is qualitative; beneath homogeneous time, which is only the symbol of true duration, a duration whose heterogeneous moments are interpenetrating; beneath the surface self, whose states appear well defined, a self in which succession means mutual absorption and the making of an organized whole. Usually we content ourselves with the shadow of the self thrown upon the uniform background of space. The symbolic self, thus projected and separated into distinct parts, is much better fitted to the practical needs of social life and to language in particular; our mind dwells on it in preference, and we come to lose sight of the self that is fundamental. In other words, our sensations, perceptions, emotions and ideas have two aspects; one precise, clear, but impersonal, the other confused, always changing, and never expressed in language because language grasps it only at the price of an arrest of its movement, and adapts it to 
common forms only by making it public property and destroying its personal note.

When I go for my first walk in a town where I intend to live what I see about me makes two different impressions at once, of which one will last and the other will continually change. Day after day I see the same streets and houses and, knowing that they are the same, I speak of them by the same names and fancy that they look to me as they always did. But if after the lapse of years I recur to the impression these things gave me at first I am amazed to discover a remarkable but indescribable change. These houses and streets that I have seen every day seem to have borrowed from me something of my own conscious life; it appears that they have lived as I have, and, like me, have grown old. This is no mere illusion. If my impression to-day were precisely the same as that of yesterday then seeing and recognizing, learning and remembering, would be the same thing. We miss all this unless we are forewarned of it and examine ourselves, because our outer and social life is more to us practically than the life that is interior and personal. Without thinking about it we tend to solidify, as it were, our impressions, in order to speak of them in words. In consequence the feeling itself, always becoming and changing, is for us confused with its object, which is external and permanent, and, above all, with the word which stands for that object. Just as the moving duration of our self is fixed or solidified by being mentally projected into space, so 
our ever-changing impressions, moulding themselves upon the external object that is their cause, acquire its definite outlines and are arrested in its immobility.

The influence of language upon sensation is more profound than is usually believed. It not only makes us think that our sensation does not change, but it misleads us at times as to its nature. The mere word with its defined outline, ready-made for us and storing up in itself what is stable and common in the impressions of all men, the impersonal word, overpowers or conceals the fleeting and delicate impressions of the individual man. These impressions should have words new-minted ; but even so, as soon as they were coined they would give to the unstable sensation for which they were invented a share in their stability.

Feeling itself lives and grows, therefore it is for ever changing. How otherwise could it lead us step by step to resolutions? But for this, resolution would be immediate. Feeling lives, because the duration in which it arises has moments permeating each other. In dividing these moments, in symbolically translating time into space, we have taken life and colour from our feeling; we have come to stand in face of our own shadow. A novelist who should tear away the veil of our conventional self would reveal to us in this appearance of logic a fundamental absurdity, in this side-by-side array of simple states the interplay of a thousand impressions which, as soon as they are named, have ceased to be. Then we should praise 
him for knowing us better than we knew ourselves. But he does not ; and the very fact that he, too, paints our feeling for us on a background of space and sets out its elements in words shews that he in his turn gives us no better than a shadow. Yet he has painted his picture in a manner that leads us to divine the amazing and illogical character of its subject; he compels us to reflect upon its marvel, but it is by giving outward expression to something of the contradiction and interpenetration that are of its very essence. Stimulated by him we have for a brief instant drawn aside the curtain we had hung between what we are accustomed to think about ourselves and what we really are. He has taken us by the hand and led us into the presence of our own self.

Again, the beliefs which influence us most powerfully are often those we should find most difficulty in setting out in words or justifying by reasons. We value them because they have a colour matching that of our other ideas and because we detect in them a reflexion of ourselves. They live in us, in fact, as cells live in an organism; they change with us, as the cell changes with the organism. But unlike the cell, which occupies only one place in the organism, an idea truly our own pervades us through and through. Not all ideas, however, are in this sense our own. Many float on our surface, as scattered leaves float on the surface of a pond; and these we find always the same. They do not change with the changing mind; they remain as though external to it. Of such are the 
ideas coming to us ready-made, retained by us but never assimilated; of such, too, are those we have failed to cherish and allowed to wither in neglect.

\section{Freedom and necessity.}

It becomes evident from the foregoing discussion that the contradictions implicit in the problems of causation, freedom, and personality arise from presenting the concrete and living self as an association of elements separated, or at least separable, from each other, and setting these side by side in a homogeneous medium which may be called either time or space. To escape these contradictions we have but to substitute the true self for the artificial and symbolic self.

Our enquiry into the psychic process, as far as it has gone, shows us in the self a peculiar kind of activity. We see that in contact with the external world it accepts, in a measure, something of the clear-cut forms of that world, yet maintains always in its interior depths mobility, intensity, and qualitative multiplicity. We shall see too that the forms in which it expresses itself are new creations and are therefore incalculable beforehand. And we only put this in other words when we say that the self, essentially, is free, and that its action, when truly its own, must be regarded as a manifestation of the whole personality as it is at the moment. Any idea of determinism brought into this connexion reveals ignorance of the process of conscious life, which is duration. If we bear this in mind we shall find it impossible to deny 
freedom as the relation that the concrete self has to its act; but on the other hand we shall be compelled to recognize our inability to define it. We cannot analyse a process; we cannot break up duration. When we try to do so we make the process into a thing and translate duration in terms of space. We replace doing by the already done; and as we thus stereotype the self we may watch, if we please, spontaneity degraded to inertia and freedom crystallized into necessity. It is thus perfectly clear that a positive definition of freedom, for which analysis and its consequents are essential, must ensure to determinism the argumentative victory. Free activity is a fact that we know but cannot prove; and when once the problem of freedom is correctly stated we discover that real freedom presents no problem at all.

All this is in agreement with every man's experience of the real character of life; nevertheless it seems absurd to the ordinary scientific or psychological determinist. The determinist invokes against freedom certain definite facts, physical and psychological. He says that our actions are the necessary outcome of ideas and feelings and of the whole series of conscious states that has gone before. He says, too, that our freedom is incompatible with the fundamental properties of matter, and comes into direct conflict with the principle of the conservation of energy. From this it follows that there are two kinds of determinism and two ways of empirically proving universal necessity. It will be shown that these two are one ; in fact that 
even physical determinism rests upon a psychological hypothesis.

According to mechanical or rather kinetic theories, the universe may be resolved by the scientific imagination into particles which, by their elementary movements of vibration and change of place, give rise to all the physical phenomena our senses perceive; to chemical action, to heat, sound, electricity and so on, perhaps even to gravity itself. The matter of our own bodies is subject to the same laws; and in the nervous system, for instance, there is nothing but atoms and molecules in motion, repelling and attracting one another. Our conscious processes are the results of mechanical causes. And our own reaction to the external world is, in the last resort, only molecular reaction. Besides, since no exception is admitted to the principle of the conservation of energy, it is impossible to admit that any atom in the universe (of which the nervous system, after all, is but a part) is not determined in its movemerit by the total influence that other atoms bring to bear upon it. No more than a knowledge of the present position of all the atoms in a man's body and in the rest of the universe, so far as these affect it, is needed to enable a mathematician to calculate accurately the past present and future action of the man, just as he might predict a solar eclipse.

Accepting for the moment the scientific position thus assumed (although it is open in several directions to scientific criticism), we propose to shew that it does 
not involve the absolute determination of one conscious state by another, and also that the universality of the principle of the conservation of energy is inadmissible except as related to a psychological hypothesis.

Even if we allow that every atom in the brain is at every moment determined as to position, velocity and direction, it does not follow that our psychic life is subject to the same determination. Before that could be established we should have to prove that a strictly determined psychic state corresponds precisely with a definite state of the brain; and this has not been done. We are told of molecular movements taking place within the brain, consciousness then from time to time being set free, we know not how, and following their track as the phosphorescent glow follows in the wake of a vessel. Or we are to picture a musician playing out of sight behind the scenes, while the actor strikes the notes of a soundless keyboard; and then we are to imagine that consciousness comes from some mysterious region and is added to the molecular vibrations, as the music of the concealed piano is added to the movements of the actor. But nothing of this kind proves or ever will prove that the conscious fact is absolutely determined by the molecular vibration. We may find the reason for one movement in another movement, but we do not find there the reason for a conscious state. We only observe that this state does in fact accompany the movement, and not indeed invariably, except in some few cases that are generally admitted to be almost independent of the 
will. Yet physical determinism says that there is this accompaniment in every case.

We are aware that most of our actions can be explained by motives, but this does not prevent us from believing in our freedom. There are very simple psychic states which happen as accompaniments to well-marked physical phenomena, and most of our sensations seem bound up with well-marked molecular movements. For a man already sure that psychic states follow necessarily from circumstances this is quite enough. He then has no hesitation in picturing to himself the dramatic play of mind as a literal version of the play of material atoms in the organism.

But undoubtedly such freedom as remains to us, after making our life accord with the physical principle of the conservation of energy, is very small. Even if this principle does not regulate our thought it will at least determine our movements. Up to a point our interior life will still depend upon ourselves; but, looked at from the outside, it will be impossible to see how our activity differs from that of an automaton. Here we are driven to acknowledge that a scientific man who was not prejudiced beforehand against human freedom, and in whose mind the fact of freedom assumed a due importance, would be unlikely to think of extending that physical principle to all bodies in nature. To extend it to the human body seems to imply his prepossession by some psychological theory.

Further, it is well to avoid estimating too highly the 
share taken by this principle in the natural sciences. As it exists at present, it indicates an aspect of the evolution of some sciences; but we must not say either that it has been the chief factor in that evolution or that it is an indispensable postulate in all scientific investigation. No doubt, in mathematics what is given is given, and what is not given is not given ; in whatever order the same terms are added up the same result ensues; when we deal with a given quantity mathematically the permanence of that quantity throughout our operation is implied, in however many different ways we split it up. This is no more than the law of non-contradiction to which science must always be subject; it reveals nothing of the nature of that which we ought to take as given, or of what remains constant. It tells us that something cannot arise from nothing; but experience alone will tell us which are the manifestations of reality that must count for 'something' or for 'nothing' in the operations of science.

The principle of the conservation of energy applies, so far as we know, to all physical and chemical phenomena. But it cannot be denied that the study of physiological phenomena, and of nervous phenomena in particular, may well reveal to us besides 'kinetic' energy and 'potential' energy another kind differing from them by escaping the processes of our calculation. We should then see that systems based on the principle of the conservation of energy are not the only possible systems; and even that, in relation to reality as a 
whole, they play the same part as the chemist's atom plays in relation to bodies and their combinations. We must observe that in the most thorough-going of mechanical theories consciousness is taken as an epiphenomenon which under certain circumstances supervenes on molecular movements. But why, if these movements can produce sensation out of a zero of consciousness, should not consciousness produce movement either from a zero of physical energy, or by using that energy after a fashion of its own? We must observe, too, that every intelligible application of the principle refers to a system of which the points, after moving, can return to their original positions. This reversal of movement is at least thought of as possible, and as involving no change in the system as a whole or in its parts. Time makes no difference here. But in the realm of life we find a very different state of affairs. Here there is duration, and it seems to behave like a cause. The very idea of replacing things as they were at the end of a certain time seems to us absurd, not only because in no living being has any such reversal ever occurred, but because the hypothesis of reversal is meaningless in relation to conscious states. In fact the material point, as understood by the mechanician, is for ever in a present; but perhaps for all living bodies, and most certainly for all conscious beings, the past is truly real. To a system taken as conservative of its own energy past time brings neither gain nor loss; but to the living being it may bring gain, to the conscious being it unquestionably 
is gain. Surely we may say that the hypothesis of a conscious force, or free will, has much to be said for it-a force upon which time acts and which stores up duration, thereby showing that it is beyond the scope of the principle of the conservation of energy.

That a principle of mechanics has been elevated to the rank of an universal law is due, then, rather to a psychological mistake than to any requirement on the part of the positive sciences. We habitually see ourselves not directly but under forms transferred from the external world, and we are thus impelled to regard the duration lived by consciousness as the same as that which glides over material atoms without affecting them. So it comes about that we imagine the same motives acting a second or a third time on the same person, and picture them as producing, a second or a third time, the same effect. This is the psychological path to the establishment of the principle of the conservation of energy as an universal law. The difference between the outer and the inner worlds, which careful scrutiny reveals as all-important, is set aside. But physical science, properly so called, has nothing to do with this. In the confusion between concrete duration and abstract time we find evidence that the so-called physical determinism is at bottom no other than psychological.

\section{Psychological determinism.}

For the newer psychological determinism a state of consciousness, though regarded as a necessary outcome 
of states that went before, is now seen as no geometrical necessity but rather as a transition from the previous state, to be explained as though the first were a summons to the second, the difference of quality between the two nullifying the attempt to deduce one from the other a priori. No doubt there is a relation between an existing state of consciousness and the new state into which it passes. But the question remains whether the relation which explains the transition is the cause of the new state. The truth is that psychological determinism is compelled to represent the self as an assemblage of psychic states in which a prevailing influence is exerted by the most powerful, which carries the rest with it in its train. Co-existing psychic phenomena are thus distinguished one from another like objects in space. The feelings-desire, fear, temptation, and so on-are made into concrete selfexisting motives among which there may be a real struggle for mastery. And it is worthy of notice that the opponents of determinism are willing to follow their adversaries on to this ground. They also speak of contests among motives and associated ideas; and Fouillée, one of the ablest of them, even regards the idea of freedom itself as a motive that can overcome others. Both sides abandon themselves to a confusion, arising from the fact that language has not been built up in view of the need to convey fine shades in the changing colour of our inner states. When we try to describe and analyse a conscious state, the state, which is above all personal, is broken up into impersonal 
and mutually external parts, each of which suggests a class to which it belongs and a particular name that will match it. When, in place of the concrete phenomenon occurring in the mind, we put an artificial reconstitution of it according to the methods of philosophy, we fall into a confusion between an explanation of the fact and the fact itself.

- Undoubtedly, as we have said, the self comes superficially into contact with the external world, and its surface keeps, as it were, an impression of things in the world; it will therefore connect together in a sort of contiguity terms perceived by it as side by side. Links of this kind, simple and almost impersonal states, are not perceptibly out of harmony with a theory which treats them as though they were things. But the further we penetrate the processes of the self, leaving behind its surface relations, the further do its states depart from an apparent juxtaposition and begin to interweave one with another, to make a web of living, flowing, changing threads, each tinged with the colours of all the rest. Every one of us loves and hates after his own fashion, and in his love or hate mirrors his whole self. Yet for every one of us there is only the one word love or the one word hate, and in these words there is no more than an objective and impersonal aspect of emotions that stir differently the depths of every soul. Between mind and language there is no common measure.

Only when psychology is the dupe of language is it able to picture the mind as determined this way or 
that by this or that interior attraction or aversion, as though by powers brought to bear upon it. Every feeling, if it is profound, represents the whole mind because the whole content of the mind is mirrored in it. When the mind is said to be determined by any feeling it is, in fact, self-determined.

The outward sign of a state in which the whole personality is represented is a free act; because the self alone produces it, and in it all the self is expressed. We see then that, taken in this way, freedom is not absolute, as a certain libertarian doctrine pronounces it ; obviously it has degrees. Conscious states do not all dissolve in one another like raindrops in a pool. On the surface, where our life has dealings with space, independent deposits may be formed and float about. A hypnotic suggestion seems to possess a life of its own and invades the mind like a foreign force. A sudden rage provoked by a casual circumstance acts almost in the same way. Neither enters into the compacted mass of the self. And besides such as these almost independent elements are others, less simple, which yet always remain imperfectly unified with the self. Of this kind is the group of feelings and ideas arising from an education directed more to the memory than to judgement. This forms a parasitic self living as it were by the life of the self that is fundamental. Great numbers of men spend their existence in this way and die without ever knowing what true freedom is. But on the other hand, were the whole self to accept it, even the hypnotic 
suggestion would become possessed of the power to persuade; and if a sudden outburst of rage reflects the whole history of the man, it is no longer a fatal influence over him but the expression of himself. If education infringes upon our freedom it is not merely because it is authoritative, but because, whether authoritative or not, it fails to convey to us ideas that we can make truly our own. A decision to be free must spring from the whole self; and it will be more or less free as it springs from more or less of the real and deepest self.

Plainly, then, free acts are rare, even in men whose habit it is to govern themselves and think of what they do. We have seen in the course of our discussion that our own self is usually perceived by us against a background of space, that through the influence of language our changing states of mind come to take on the look of solid things, and that our living personality is thus crusted over by an aggregation of artificially defined states separated one from another and therefore deprived of their mobility. We have seen, too, that in our social dealings, and in our communication by speech with other men, we profit by accepting this state of things as a faithful representation of the true facts of life. We must note further that our everyday actions are evoked far less by our changing feelings than by the unchanging images to which these feelings cling-it is often very convenient to be a conscious automaton. Most of our own daily acts are done automatically; because external 
impressions summon responses from us which, although they are conscious and even intelligent, much resemble reflex acts. These are, in fact, a consolidated substratum for free activity, and fulfil the same office towards it as the functions of our body do towards all our conscious life. Indeed we must acknowledge that even in grave circumstances we not infrequently, from weakness or inertia, abrogate our liberty in favour of this pseudo-reflex process. But on the other hand, just when the quasi-automatic act is due, the profounder self sometimes rebels and takes a new decision, as though, beneath the superficial complex of arguments and advice and custom, another process had been going on, a gradual maturing and energizing of emotions and thoughts. And when we reflect upon what has happened we may discover that all the time this process was not so much unknown to us as unregarded. We find that in those ideas and those emotions we ourselves were alive, forcing a way to fuller expression; although we had, as it were, offered resistance to ourselves. Then, when we want to know why we changed our mind, we cannot see that we decided on our new course for any reason; we think perhaps that we decided against reason. But we must learn to recognize that sometimes this is the best of all reasons. The reasons we may muster superficially do not express our real selves; the act that might have followed them would not have been truly our own; the new decision, on the contrary, accords with all our deepest emotions thoughts, desires-in short, with what we really are 
in our profounder self. It is easy enough to shew that in everyday circumstances a man decides according to some determining motive. We must not look for evidence of our freedom there; we must look for it in some momentous crisis involving our reputation in the eyes of others and, more importantly, in our own. Then, if we decide and act in defiance of what men call a motive we are free; and our freedom is the greater the more manifest is the absence of a reason that can be put into words.

We are free when our whole personality is mirrored in our actions ; they should represent us in the fashion, so hard to describe, that the poem represents the poet. It must be granted that thus our character comes to dominate what we do. But why should we separate our character from our self, setting the thinking and feeling self apart from the acting self? We might as well ask whether we are free to change our character. It changes constantly. That which it acquires is not plastered on to it, but mingled with it. So we make the change our own, a change of ourselves.

\section{Of the foretelling of actions.}

When we say that a man will probably do so and so, we judge by what we know of his character. Sudden changes in character are not often seen and we can usually assert of any man that certain actions are like him and certain others unlike. Philosophers are agreed with regard to this. But the determinist declares that when we say the man will probably do 
so and so, we are only kept from being certain about it by the fact that we are acquainted not with all the conditions affecting him, but only with some of them. If we knew all we could foretell with certainty.

Let us imagine that I am a philosopher looking on while you are about to make an important and apparently free decision under momentous circumstances. If I knew all the conditions affecting you, could I predict unerringly the decision you will come to ? I answer that if I am to know all those conditions, and no detail is to escape me, then I must build up in my mind and live over again your history. And here we come to a crucial point. When I myself pass through a certain conscious state $I$ know it as it is, I know how intense and how important it is in relation to other states, but not by any kind of logical estimate or external comparison. Its intensity and importance are no other than its very self as I feel it. But if I try to tell you about it I have to use some sort of sign or symbol to indicate how intense it is or how important it is in relation to the past and the future, and so fix what share it shall have in the decision. In myself $I$ have no need of any such sign; the intensity of my feeling lies in the way I feel it. There are then two modes of getting at another man's conscious states-the dynamic mode, in which I experience them myself, and the static, in which I acquire an intellectual symbol of them. In the latter case there should be added something to shew the intensity of the states; and this must of course take 
on a quantitative character. One feeling will be stronger than another, and it will be necessary to reckon with its strength. But if $\mathrm{I}$ am to know how strong a certain feeling is in you I must either know what you will eventually do, as a playwright knows what his characters will do, and judge of the strength of your feelings by the final result they will produce in act; or I must somehow or other live through your states, not in imagination but in reality. And as we are discussing whether or not I can foretell what you will do the first hypothesis is inadmissible. I find myself compelled to be an actor playing your part in life beforehand; I am not a prophet able to discern what it will be. And I must play your part from the beginning and in every least detail; I cannot omit a single second of your history from it, nor can I alter the order of its events in the most minute particular. But if I am to experience your feelings as you have experienced and do experience them, if I am to think your thoughts and share your memories, even my body and all my relations in space and time must be the same as yours. But then, obviously, I am you, and I have reached that great moment when the action is taking place and there is no longer anything to foretell but only something to be done.

When a final act has been done its antecedents may be reckoned up, their value and relative importance measured, the complex interplay of many elements pictured. But to suppose that the final act can be predicted is to suppose that it exists before it has 
taken place. We cannot know the value of the antecedents without knowing the final act-the very thing we desire to foretell.

\section{Mathematical prediction.}

Science, unquestionably, gives us instances in which we predict the future, as, for instance, the occurrence of eclipses. But a prediction of this kind is not at all like the prediction of a free act. Indeed, that which makes possible the foretelling of an eclipse is precisely what hinders us from foretelling the free act. The future of the solar system and of the universe generally, although contemporaneous with your future or mine, has no likeness to it. And the unlikeness is manifest at once, if we picture to ourselves some super-Olympian god decreeing that every movement in the universe shall have its velocity doubled. Eclipses, and the equations by means of which we foretell them, would remain unaffected. Nothing would alter except the length of the interval between one event and another, and with that none of our calculations has anything to do. But our consciousness would be well aware of the shortening of those intervals. If, between the rising of the sun and its setting, our day were to give us but half the experience a day usually affords, we should most assuredly know it. Our interior progress, the storing up of our experience, would be diminished. The astronomer when he predicts the eclipse compresses several years, perhaps centuries, of mathematical time into a psychical duration of a few 
seconds. He establishes a series of relations of position between, let us say, the sun and the moon and the earth; but duration, properly so called, remains beyond the grasp of his calculation. Only a consciousness living through the intervals instead of merely considering their extremities could be aware of it. All real foreseeing is in fact seeing, and we can only see after this manner when we are able to diminish at will an interval of future time without altering the relation of its parts one to another ; and to reduce the interval would involve the impoverishment of the consciousness living that interval. When we turn then from astronomy to psychology and ask whether a free action can be foretold we confuse the time dealt with in the exact sciences, the time reducible to number and therefore calculable, with living duration in which so-called quantity is really quality, and which cannot be shortened by an instant without being altered through and through.

\section{Causality and duration.}

The determinist is driven to the last of his resources. Abandoning the hope of foretelling a state of consciousness or an act, he takes refuge in declaring that the facts of mind, like the facts of physical nature, are governed by laws. This implies on his part an omission of those characteristics of conscious states which elude symbolical representation. The special and peculiar character of these phenomena is thus ignored; but the determinist pronounces that, just because they are 
phenomena, they must be subject to the law of causality; and therefore either the act or state is bound up with antecedent acts and states and the same causes must always produce the same effects, or we must acknowledge a lawless exception to causality.

But in consciousness, if duration is what we think it is, the same cause never appears a second time. Identical conditions never recur in the depths of psychic life. We should beg the question if we were to deduce from an apparent likeness of two conscious states that the same cause produces there the same effect. Psychic elements have life, however superficial they may be; they are always becoming, and the same conscious state, by the mere fact of being repeated, is a new conscious state. If indeed a causal relation does hold good in the realm of consciousness it cannot have the smallest likeness to what we term causality in physical nature. Only for the physicist does the same cause produce the same effect ; for every psychologist not led astray by false analogies a profound inner state of consciousness has an effect once for all, never to be reproduced. And if we are told that this effect is inseparably bound up with that particular cause we must reply that the assertion means either that, given the antecedents, the action might have been foretold ; or that, once it has been done, no other action was under those conditions possible. But we have already shown the meaningless character of both these assertions, involving, as they do, a misunderstanding of true duration. Yet we fail over and over 
again to carry conviction by this reasoning to the mind of the determinist. His misapprehension is so profound and his prejudice so persistent that the only way to overcome them is to attack them in that from which they spring, the concept of cause. We may grant to empiricists that the principle of causality, were it taken as meaning only that physical phenomena once perceived can happen again and that a given phenomenon happening only after certain conditions will recur when those conditions are repeated, is derived from experience; but, since the question remains whether this regularity of succession occurs in consciousness also, such experience elsewhere proves nothing against freedom. Indeed when the principle of causality is used by empiricists as a refutation of freedom the word cause takes on a different meaningone given to it not by science or philosophy but by common sense. For common sense cause means more than the mere regular succession of phenomena; it suggests that, since the idea of the second phenomenon is implied in the idea of the first, the second phenomenon must, in some manner or another, be itself contained within the first. We could hardly expect anything else of common sense ; to distinguish between a linkage of phenomena and a linkage of ideas about phenomena is not within its purview. It glides only too easily from the one meaning to the other, and pictures the relation of cause and effect as a sort of pre-formation, in the cause, of the effect that is to come. 
In mathematics we are acquainted with some such process. We may say that any number of theorems are preformed or implicit in the definition of a circle. But here we have to do only with pure quantity, with geometrical properties that can be expressed in equations. Therefore we can see easily enough that the original equation, which expresses the fundamental property of the circle, may be transformed into any number of new equations virtually contained within it. In physical phenomena, on the other hand, we encounter quality as well as quantity, and we shall find a difficulty in declaring one phenomenon the equivalent of another. We evade the difficulty unawares by attributing the qualitative peculiarities of each to the impression it makes on us, and by taking for granted the existence, behind the variety of our sensations, of a homogeneous physical world.

If the development of the notion of cause, as involving necessary connexion, leads to some such conception of nature as that of Descartes or that of Spinoza, we may rest assured that in establishing the idea of the necessary determination of a phenomenon by those which it succeeds we are probably setting some mathematical mechanism behind their heterogeneous variety. It is not that common sense intuitively reaches scientific theories of matter or a Spinozistic mechanism, but that the more the effect seems wrapped up in the cause the more likely we are to regard it as we regard a mathematical consequence in relation to its principle, and so do away altogether 
with real duration and all that it involves. Just because I endure and change I do not necessarily act to-day as I acted yesterday, when under the same conditions. But things, irrespective of our perceiving them, do not seem to endure like us, and it is entirely reasonable to expect that in them the same cause should produce to-day as yesterday the same effect. Nevertheless phenomena succeed one another instead of happening all at once. So the notion of causality, although it very closely approaches that of identity, never appears to us to be identity unless we bring in the idea of a mathematical mechanism, or allow ourselves to be over-persuaded by some metaphysical subtlety. The more persistently we see the causal relation as one of necessary determination the more we insist that things do not endure like ourselves, and the clearer becomes the difference between a physical and a psychical series.

\section{The law of causality.}

We may obtain a clearer view of this law, or principle, by taking account of the psychological origin of our belief in the accepted relation of cause with effect.

Let us consider, first, whether the spectacle of exterior changes regularly following each other may not perhaps be able to create in us so strong a habit of associating certain antecedents with certain consequents that we come to erect our habit into an universal law. In visual experience, that which perhaps 
influences us the most, we may see cases of this regular sequence easy to follow, as for example when one billiard ball strikes another, or when fire makes the kettle boil. But in truth it is only in a limited class of facts that we are able actually to observe anything like this regular succession of phenomena, and there can be little doubt that long before man learnt to read them thus he found his profit in a recognition of causality. For the most part, in observing phenomena we see one phenomenon which we call the effect, and merely imagine another, the cause. We may even ask ourselves with advantage whether causality, in the sense we ordinarily give to the word, does not refer to things happening simultaneously rather than to a sequence of events.

We may rest assured that our faith in causality is based on experience, but the question is on what experience. Our answer to that question is that it is experience of the special kind that is identical with life itself. A habit is as a rule intermittently exercised. If our demand for causality is a habit it is one that, like the habit of breathing, never intermits, and is so deeply rooted in us that our mind, as soon as it becomes aware of it by reflexion, erects it into an unvarying law. The very moment we think of causality we are irresistibly referred to the experience we have within ourselves in translating resolve into act. We read our own vital process into the sequence or coincidence of phenomena.

Let us see whether the acquisition of our belief in 
causality does not, as a matter of fact, march pari passu with the advance in co-ordination between our sensations of touch and sight. When the eyes of the child open to light he must at first see a mere chaos of changing shapes and colours incessantly coming and going before him. By slow degrees he acquires tactile sensations, and learns to expect these sensations when certain visual impressions arise in his consciousness. It becomes inevitable that, in his mind, the external object which at first is visual should be supposed to produce the tactile impression. This is the case with all of us; our very character as active beings makes us look upon this relation as necessary. In short we live it before we think it. And as soon as we have thus established a fixed relation between the visual aspect of a thing and its possible contact with our body we naturally establish the same relation between the thing we see and bodies in general. Then, when we see one object touch another, we attribute to this contact the same dynamic meaning, and to the movement that results the same kind of determination, as experience reveals to us when the object provokes our personal activity. In its primary simplicity the law of causality has no other meaning than this. And we are left face to face with a cause which precedes the effect and is yet, after the manner of an active force, simultaneous with the effect it is supposed to produce.

Belief in causality is common to man and the higher animals. Man reflects upon it, and from this reflexion there arose the idea of a law of causality. 
Through his ever increasing preoccupation with mathematical necessity he has come to empty it of its primary dynamic element, the element he knows in his own experience of life. And argumentative confusion results when he shifts unconsciously from a conception of cause in which the dynamic element still persists to one from which it has been eliminated.

\section{Summary.}

Freedom then, we discover, is a certain relation between the concrete, enduring self and its action. The relation is indefinable for the simple reason that it is a process, not a thing. When we insist on analysing a process we unconsciously transform it into an object and make its duration seem extended in space. Instead of the fact in process, the process that is fact, we put the fact completed, and so bring to a standstill the living activity of the self. 


\section{CHAPTER IV.}

BODY AND SOUL.

\section{Common sense and philosophy.}

In apprehending the direction of the Bergsonian philosophy we learn to see that, without having recourse to other powers than those which serve us in our everyday life, we are able to penetrate beyond appearance and touch reality. It is in vain that we attempt either to guess at or to build up reality; our right course is to recognize that it is. Then, upon that which our intuition of things and events has already revealed to us we turn a reflective attention; and this is to philosophize. Therefore it is all important for us to begin by questioning and setting aside the theories whence issue those abstract conceptions which conduct us far from the thing we would interpret. Unless we criticise down to the very root everything of the nature of an accustomed formula of doctrine, we shall never attain the kind of thinking in which direct contact with reality may be won.

It always surprises the plain man when we tell him that the thing he sees and touches is regarded by many 
philosophers as existing only in and for his own mind. Naturally, he is quite sure that the thing has an existence independent of his mind. And if we tell him that it is entirely different from what he thinks it is-that it has neither the colour his eye sees nor the resistance his hand feels-he is quite as much surprised. Naturally again, the colour and resistance of the thing are for him in the thing; they are not states of his mind. For him the thing exists in itself and yet is in itself the picture as he perceives it. It is an image, but a self-existing image. This is the point of view of common sense.

Let us now strip ourselves for a moment of all theories concerning matter and spirit, and forget that we have ever heard any dispute about the reality or the ideality of the outer world. I find myself in the presence of images, in a wide sense of the word, images that I perceive when my senses are open to them, and do not perceive when they are closed. Among these images there is one distinguished for me from all the rest by the fact that I not only perceive it from without but also feel it from within. This image is my own body. I discover that feelings or 'affections' introduce themselves between the vibrations that are communicated to me from without and the responsive movement I produce from within-and that these feelings apparently have some bearing on the character of what I do. Each affection gives me in a special manner an invitation to act and opportunity to pause - perhaps to refrain from acting. And everywhere 
in nature I observe that those living beings which acquire the ability to change their place in the world acquire also, through the warning given in sensation, the ability to take precautions by means of which they may escape from danger. I discover, too, that my own consciousness is awake as feeling or sensation in all proceedings where I seem to take the initiative, and is not thus awake when my action becomes automatic and consciousness is no longer needed. Something new seems added here to the universe and its history. The vibrations I receive from without, instead of continuing mechanically as they do in traversing some merely material object, instead of transforming themselves into regular and necessary movements, are transformed in an irregular and, as it were, spontaneous manner. My body, looked at as belonging to the material world, is an image behaving like other images, receiving and returning movements; but somehow, and within limits, it seems to choose how it shall return what it receives. It is, in short, a centre of action; but as part of the material world it cannot beget a representation, that is, a mental picture, of it. Yet according to the ideas of many scientific men and philosophers (and in opposition to the view of ordinary men) the images of which our world is constituted actually originate in the image that I call my body. These men are in fact of opinion that the image I call my brain is the organ of representation. But if the image I call a disturbance of my brain really begot pictures of the external world it would somehow or 
other include them all in itself, and the representation of the whole material universe would be implied in the representation of this disturbance of my brain. Yet this is obviously absurd ; the brain is part of the material world, the material world is not part of the brain.

\section{The office of the body.}

The office of the body, then, is as it presents itself to us, to be a centre of action. It is so constituted as to exercise a real influence on objects by choosing, after it has received a stimulus from without, among different reactions that are materially possible. Throughout the animal series the nervous system is progressively developed and adapted for actions ever more freely chosen, less and less automatic, as we rise in the scale, but is in no way directed towards the production of images. And at any given moment the state of a brain indicates no more than a very small part of the total psychic state, in fact only that part able to translate itself into motor action. The man who could penetrate into a brain and watch what happens there would very likely see it full of sketched-out movements; there is no evidence that he would see anything else. He would have no more knowledge of what was going on in the corresponding consciousness than we should have of a play were we watching the comings and goings of the actors on the stage without hearing a word of it. If the play were no more than a pantomime the movements of the players would tell us nearly 
everything about it; if it were a comedy of life and manners they would give us next to nothing.

We must now enquire how it is that my perception of the world seems nevertheless to depend upon movements of the substance of my brain, and to change or cease with these. The image I call my body occupies the centre of the whole system of images I call my perception of the world. By it all others are conditioned for me. As to those images, they influence each other, but only in such a way as that the effect is proportioned to the cause. Here then are two coexistent systems of images; and these images I discover to be relatively invariable in the world and indefinitely variable in my perception. The same images can enter, it seems, at the same time, the system belonging to science and the world of consciousness. And now we see what the question between realism and idealism is. Subjective idealism derives the first system from the second; materialistic realism derives the second from the first. And both meet on the common ground of perception. The realist starts from the world as an aggregate of images always on the same plane, whose relations are governed by fixed laws, and whose essential character is the absence of a centre; but arrives at a recognition of perceptions -systems in which these same images seem dependent on one central image round about which they are ranged and by every alteration in which they are altered. But here precisely is the starting point of the idealist, from which he is driven only when he tries 
to connect the past with the present and to foretell the future. Then he has to replace all the images on one plane and regard them as varying no longer for him but for themselves. He must treat them as belonging to a system in which every change is the exact measure of its cause. The realist, in order to account for perception, must adopt some such hypothesis as that of the epiphenomenal consciousness, and so make perception a mysterious accident; and the idealist will have to assume some sort of preestablished harmony between things and mind, or at least between sense and understanding, thus making science a mysterious accident. The common postulate of both is that perception has a wholly speculative interest and that to perceive means above all to know. It is just this postulate that we dispute.

We have supposed that the body exercises a real influence on other images and is able to decide between possible steps. These steps, we shall maintain, are suggested to it by the question of greater or less advantage to be obtained somehow or other from the surrounding images. Somehow or other, then, these images must indicate the advantage to be derived from them. We observe that the appearance of objects, their shape and size, and even their colour, is changed as we approach them or withdraw from them. The intensity of a sound or of a smell is greater or less according to our distance from its source. So we come to the important point that distance stands for the degree in which other bodies are protected, as it were, against 
the action of my body and for the degree in which my body is protected against them. My perception, then, reveals its utilitarian character by sketching out, in the midst of the images of the world, the possible actions of my body. Matter should be regarded as the aggregate of images ; and perception of matter as the aspect of those images which is related to the eventual action of the central image, my body. In perception we detach from the world a part that has a practical interest for us, and set it in the foreground ; but that which we perceive is presented to us as it is, and this is why we can try to act upon it with a chance of success. To perceive, then, is not to know or to acquire knowledge; the office of perception is to give us the conditions necessary for action; it does not create images, but receives them.

What then is the relation between my perception and the molecular movements of matter in my brain? We are told, by those who say that these movements create for us a representation of the material world, that they are not images but something else from which representation miraculously issues. But there is no need to seek in these movements anything of the kind ; images themselves, they cannot create images ; what they do is to indicate, like a compass moved about, the relation of the central image, my body, to those that surround it ; and there is only a difference of degree, not of kind, between the perceptive function of the brain and the reflex functions of the spinal cord. Our perception certainly varies with the 
molecular movements of the brain; but since these movements themselves are not cut off from the rest of the movements in the material world, and are indeed inseparably bound up with them, perception does not depend upon the brain alone. The brain, like every other material thing, owes its existence to the place it occupies in the material universe.

If we consider a simple mass of protoplasm we see that it is irritable and contractile, and that it responds to external stimuli by physical and chemical reactions. We see divisions of physiological labour effected, as we rise in the animal scale, by the grouping of nervecells into a system, and may observe the reaction of the animal in more variety of movement. The brain differs from the spinal cord by increase of complexity, and there is a like difference between its functions and those of the cord. It becomes, as it were, a sort of central telephone exchange, permitting, delaying, or arresting communication. In its admirable and highly developed complexity it forms a centre where excitation from any part of the periphery may come into relation with this or that part of the motor mechanism, or may be dissipated in numberless reactions. It is an instrument of analysis and choice; but its office is limited to the transmission and division of movement. No more in the highest centres of the cortex than in the spinal medulla, or indeed than in the simple protoplasmic mass, do molecular movements work with a view to knowledge.

In the lower organisms there is no stimulation from 
an object except in immediate contact with it, and then reaction can hardly be delayed. Touch enables them at once to feel a danger and try to avoid it. We see that the more immediate the reaction has to be the more perception resembles a mere contact ; but, as reaction grows to be more uncertain and allows more opportunity for waiting, the distance increases at which the animal becomes sensible of the object of its interest. The 'zone of indetermination,' the place of hesitation and choice, is enlarged. In short, "perception is master of space in the exact measure in which action is master of time."

\section{Conscious perception.}

We must now ask ourselves why the perceptive relation of a living being to objects more or less far away from it takes the form of conscious perception, and why everything happens as though consciousness were born of the molecular movements of the brain substance.

Let us begin by simplifying artificially the conditions in which conscious perception occurs; let us put in place of our actual perception, always full of memories of the past, one that a full-grown consciousness might have if shut in by the present moment and exclusively occupied in the effort to conform itself to the external object. According to our view, such a perception, which would undoubtedly be impersonal, is fundamental in our knowledge of things, and individual accidents are grafted upon it. To see clearly what 
it is, it must be distinguished from that which, in every individual man, memory adds to or subtracts from it. It is something essentially different from memory, although in our experience it is always associated with memory.

Assuming this position, we pass to the consideration of perception apart from memory and of its relation with the material world. An image in that world may be without being perceived, and the distance between its presence there and its representation in us appears to measure the interval between matter and our conscious perception of it. It is ordinarily supposed that in perception there is more than there is in the object itself. Yet if this were the case the transition from matter to the perception of matter would be an insoluble mystery. But if the representation of an object is something less than its presence, the difficulty diminishes. The material object, as a present image, acts by all its points upon all points of all other images, but passes on all that it receives, and is in fact a road along which modifications set going throughout the whole universe are transmitted. In order to represent it some of its aspects must be obscured; it must be lessened by the greater part of itself, so that it may present itself as a detached picture. And, since living beings are centres of indetermination in a degree measured by the variety and dignity of their functions, it is reasonable to regard their mere existence as involving the suppression for them of everything in an object except that in which 
they find an interest. External influences in which they are not interested traverse them unarrested; the others, set apart and held, become perceptions just because they are set apart and held and lead us to react against them. It is as though, like mirrors, we reflected to the surface of things light emanating from them which, had we been (like things) clear panes of glass, would have passed through us unaffected.

We see now that between being and being consciously perceived there is for images only a difference of degree. Indeed it is not absurd to say that the instantaneous perception of an unconscious material point is indefinitely greater and more complete than our own. For in this point the influence of the whole material universe is assembled and passed on. Consciousness is comparatively poor, it attains only certain parts and certain aspects of those parts ; but in its poverty it prophesies of spirit, in the true sense of the word it is discernment.

The fact is that when we suppose perception to be a mere photography of things, in which an organ of perception plays the part of camera, and the brain is the dark room where by some chemical and physical process the picture is developed, we make the whole difficulty of the problem. To begin with, if there is such a mere photography the picture is both taken and developed everywhere in all the atoms in space. Every particle in the universe is acted upon by every other particle; but the action upon each by all the others passes through it without either loss or resistance, the photograph is invisible because there is 
no dark screen against which it can be thrown. In us, however, 'zones of indetermination' provide, so to speak, the screen, set up in such a manner as to allow the preservation of an outline of just those aspects of the picture which interest our action. But this goes beyond any comparison with photography. And since the brain substance itself is a collection of atoms, each affected by the entire universe, what we have to explain to ourselves is not how there comes to be any perception at all, but how there comes to be so little of it. Why have we not an image of the whole, not only of what interests us? Theoretically perception is unlimited; in actual fact it confines itself to shewing the amount of indetermination that circumstances admit of for our body. And the amount of indetermination in bodily movements, permitted by the structure of the cerebral substance, measures the range of our perception. Naturally then, everything goes on as though the molecular movements of the brain produced perception; which, as we have seen, is absurd. The molecular movements of the brain and conscious perception correspond strictly one with another, but their correspondence is due to their being both functions of the indetermination of the will.

By thus isolating perception from the complex of memories and affections that are mingled with it in actual life, we have been able to get a clearer view of its fundamental character. But we have obtained this view at the cost of an excessive simplification and must eventually replace in the problem those elements 
that we have hitherto purposely left out. When we come to reinstate memory in perception we shall not only correct a certain element of exaggeration in the view that we have obtained; we shall fix more precisely the meeting-point between consciousness and things, in fact between the spirit and the body. Remembered images must always mingle with present perception, for they are useful to us ; indeed the basis of our instantaneous intuition of things is a small affair compared with the additions given to it by memory. These are actually more useful than the intuition itself. They bring with them the whole series of events that followed similar intuitions in the past, and thus throw a fuller light on what we have to do. They may overcome, as it were, the real intuition of the moment and reduce its office to that of an occasion that gives body to remembrance. We have to bear in mind not only this but also the fact that in practice we measure degree of reality by degree of usefulness, and that it thus becomes our interest to consider as only signs of the real those immediate intuitions which are in fact parts of it. Perception and memory are interpenetrating as by a process of endosmosis, but they are different in kind. In examining perception as isolated from memory we discover a system of nascent acts with roots deep in reality; and we see that the reality of things is neither constructed nor reconstructed in perception, but touched and lived. So we establish its distinction from memory, which is the survival of past images. On the other hand, between 
perception and matter there is only a difference of degree, not of kind.

\section{Mind and matter.}

The outcome of our consideration of pure perception is that in matter there is not something different from perception but only something more than is given by it. Pure perception stands towards matter in the relation of part to whole, and in saying this we say that matter has no powers of a different kind from those that we perceive. The nervous system, for example,-a lump of matter-has certain qualities that we perceive, and very likely certain others that we do not perceive ; but they must all be physical, and therefore its office is no other than the receiving, inhibiting, or transmitting of movement. We cannot allow materialism either to suppose matter gifted with hidden mysterious powers equal to the production of consciousness, or to consider its perceived qualities as mere phosphorescences on the track of cerebral phenomena. Matter is in fact just what it appears to be ; its qualities are its own. And in maintaining this we correct also the error of spiritualism that despoils it of all the qualities given in our perception, and makes them subjective appearances-as though what was lost to matter must be gained by spirit. The qualities of matter of which it is deprived by both materialists and spiritualists must be replaced in it. They are neither representations of spirit nor an accidental clothing given to a mysterious entity in space. 
We take, in short, with regard to matter, the attitude of common sense, an attitude from which arises the common-sense belief in spirit. Philosophy, however, corrects that attitude in one respect. Owing to the fact that in practice memory cannot be separated from perception, that it brings the past into the present and shortens into a single intuition long periods of duration, we are compelled in actual experience to perceive matter in ourselves, not in all other matter. Hence the supreme importance of the problem of memory,--in principle a power independent of matter, though mingled with it in every act of perception. If indeed spirit is reality, it is in the phenomena of memory that by experience we shall find it.

\section{Memory : its two forms.}

We regard the body, then, as a conductor between objects acting upon it and those upon which it acts. Its office is to receive movements, and either to arrest them or to pass them on to motor mechanisms which are determined in reflex action, chosen in voluntary action. Everything occurs as though an independent memory amassed images as they come before it, and as though our body with its surroundings was but one among those images. We make as it were an instantaneous cross-section in the stream of becoming and our body occupies its centre. But it is only in the form of motor contrivances that the body can store up the action of the past. Yet we see that past impressions of another kind are somehow preserved; and we conclude 
that it must be in some other way. Examination shews us, in short, that the past survives under two distinct forms-in motor mechanisms and in independent recollections.

If I want to learn a sonnet by heart I read it with care and emphasis, and go over it again more or less often. At last the words are linked together into a continuous whole, and I tell myself that I know it by heart, that it is imprinted on my memory. Then I think over the process by which I learnt it, in its successive phases. Each time of reading comes back to my mind with its own peculiarities; I see it again among all its attendant circumstances and I distinguish it from the one that went before and the one that followed; it is a definite event in my own history. But again I tell myself that all the distinct readings are recollections and are imprinted on my memory. I use the same words for the recollection of the sonnet and for the recollection of the details of the process I went through in learning it. Do I mean the same thing? I do not. The memory of the sonnet as learnt by heart has all the characteristics of a habit. It is won by repetition of the same effort; it demands first an attention to each detail as it comes and then an assembling of the details into a complete action; and, like every bodily habit, it is stored up in a mechanism that can be set going as a whole, by an initial impulse, in a completed system of automatic movements following one another in the same order and in the same length of time. On the other hand 
the memory of each separate reading has not one of the marks of a habit ; its image was imprinted on my memory at once, and the other readings, just because they are other readings, form other recollections; the essence of each is that it has a date and can never recur. One of these memories imagines, the other repeats; one represents our past to us, the other acts it. And the latter, if it deserves the name of memory, does so not because it preserves bygone images but because it continues into the present moment their useful effect. The recording by true memory of facts and images that have a date and cannot be repeated takes place at every moment of duration. But just because learnt memories are more useful to us we notice them more; and, as the process of acquiring these memories resembles the process of habit that we know so well, we prefer to make it into our model of memory, to set it in the forefront and to regard spontaneous recollections-the true memory-as only the same thing in an early stage, the beginning of a lesson learnt by heart. We ignore the fundamental difference between that which has to be built up by repetition and that which is essentially incapable of being repeated. Spontaneous recollection is complete from the beginning, and keeps its place and date. But a learnt recollection, a habit-memory, passes out of time in the measure that it is better known; it becomes more and more foreign to our past life.

In practice these two extreme forms of memory, which we have separated for examination, work 
together and intermingle; and it is because the mixed phenomenon has been considered by philosophers to be simple that the true nature of memory has been misunderstood. Many are driven to assume that the nervous mechanism which serves as basis for the motor habit is also the basis of the conscious idea. So they devise the remarkable hypothesis of a storage in the brain of recollections, which become conscious in some miraculous way and carry us into the past by a method wholly unexplained. Others, recognizing the inadequacy of this hypothesis and the importance of consciousness, suppose that the brain is throughout an organ of representation.

On our part we must now consider these intermediate states, and distinguish in each the part belonging to nascent action and the brain, and the part of independent memory. Inasmuch as they are motor they must, in our way of seeing them, prolong a present perception; inasmuch as they are memory-images they must reproduce past perceptions. And the process by which we lay hold upon the past in the present is recognition, which we must now consider.

\section{Recognition.}

The progressive movement by which past and present come into contact with each other is the complex process of recognition. In a work of this kind we can only give a brief summary of the results of following, as Bergson does, the windings of that process.

It will be shewn that the recognition of a present 
object may be effected in two wholly different ways, but that in neither case does the brain act as an organ of representation or a storehouse of images. Sometimes the body responds to a recurring perception by a movement that has become automatic, and recognition is passive. Here it is explained by the motor apparatus that habit has formed in the body. At other times it is actively produced by memory-images emerging to encounter the present perception. Not every recognition implies the intervention of a memoryimage ; and, conversely, we may still be able to call up such images when we have lost the power of identifying perceptions with them. There is an automatic recognition mainly achieved through movements, and this is recognition by inattention; there is also that which calls for the intervention of memoryimages, and this is attentive recognition. In automatic recognition our perception is prolonged in movements, that we may derive useful effects from it, and we are thus taken away from the object we perceive ; in attentive recognition our movements carry us back to the object to dwell upon its features. Hence is explained the preponderant part played here by memory-images. But we must ask whether perception determines mechanically the appearance of the memories, or the memories spontaneously go out to meet the perception. On the answer given to this question hangs the nature of the relation philosophers must establish between memory and the brain. 


\section{Memory and the brain.}

In every perception some disturbance is conveyed by the nerves to the perceptive centres. If the further transmission of this movement to other brain centres really caused the uprising of images there, we might well say that memory is no more than a function of the brain. But if here, as everywhere else, movement produces no more than movement, if sense-stimulation only gives to the body an attitude wherein recollections may insert themselves, then, since the result of material vibrations goes no further than the motor adaptation, we are driven to look for memory somewhere else. And if this be so injuries to the brain will affect action alone; they will not destroy memory, as they would were recollection stored up in the injured part. We accept this hypothesis; but before we discuss it further we must consider the general relations of perception, attention and memory, and the way in which a memory may by degrees attach itself to a movement or an attitude.

In our view attention is rather an adjustment of the body than of the mind; we " see in this attitude of consciousness mainly the consciousness of an attitude." We may suppose that the movements accompanying voluntary attention are, in the main, movements of inhibition; but these are in fact only the negative condition for the actual movements of the attention. We have to explain the operation by which the mind, when fixed on an object the surroundings of which do not change, yet finds in it an increasing 
number of facts or things. The truth is that on movements of arrest accompanying attention more subtle movements are engrafted, which unite to retrace the features of the object ; thus the positive work of attention begins. And it is carried forward by memory, as this brings to bear upon the perception recollections resembling it. Memory thus enhances the perception, while the perception, enlarged by the process, draws to itself ever more and more of the wealth of memory.

Memory-images go out to meet the perception and, taking body from it, become actualized in space, so that we are no longer able to distinguish what is perception from what is memory. It has been experimentally shewn that in reading quickly the mind notes here and there the merest signs, and fills up the intervals between them with memory-images, which are thrown on the paper in place of the printed letters and may be mistaken for them. We remember more than we see. Clear perception is not unlike a circle in which the perception-image advancing towards the mind and the memory-image going forth into space pursue each other. There is no progress in a straight line by which the mind travels ever farther from the thing; reflective perception is a circuit in which any disturbance, issuing from the object and finding its way into the depths of the mind, always comes back to the thing from which it started. And, as the circuit enlarges to include further memories, attention recreates both the object perceived and the ever-expanding systems in space 
with which it may be bound up. In an effort of attention the whole mind is always concerned, but it may be carried out on different levels and may simplify or complicate itself as each level demands. According to the degree of tension in the mind and the level on which it works does the perception develop a greater or less number of images.

We should now enquire whether our hypothesis concerning the relation between memory and the brain is supported or contradicted by scientific knowledge. But the enquiry is elaborate and highly technical, and its results alone will be very briefly summarized here. All the arguments from fact which seem to favour the storage of memories in the substance of the brain are derived from localized disorders of memory. And for these to be valid there ought to be found characteristic injuries of the brain corresponding to particular losses of memory. This is not the case ; complete periods of a man's past life may be absolutely blotted out for him without any definite cerebral lesion; and where disorders of memory are associated with definite brain lesions we do not find that particular recollections are altogether extinguished, but that the faculty of remembering is more or less weakened throughout, as though the man found a certain difficulty in putting his recollections in touch with his present situation. We are led then to regard the office of the brain in regard to memory as that of ensuring this contact with the present situation, rather than of imprisoning recollections in its cells. 


\section{Past and present in consciousness.}

To represent as in a picture is not the same as to remember. A recollection, as we have seen, may become actualized and live in an image, but the image pure and simple is not related to the past unless I look for it in the past. Psychologists, seeking to establish community of kind between sensation and memory, are liable to ignore the fact that, although a recollected sensation grows more alive the more we consider it, the memory of the sensation is not the sensation itself at its beginning. The more I try to recall a pain I have experienced the more I approach really feeling it, but this is natural enough because, as we have seen, the development of a memory means its becoming materialized; we still have to decide whether the recollection of a pain, when it began, was really pain. But the argument is seen in its proper absurdity only when we ask whether as a sensation grows less it changes into a memory, which it should do if the two states are different only in degree and not in kind. We know it does not and we are entitled to say that memory differs from it in kind.

Between past and present, then, there is more than a difference of degree. But the present is no mathematical instant for me; my real present, of which I speak in speaking of a present perception, has duration. It spans something of my past and something of my future, and if I could describe its curve I should see that it points to the direction of my future. My present is both sensation and movement; in it movement 
is linked with sensation and prolongs this in action. It is sensori-motor and consists in my awareness of my body as a centre of action where impressions received through sensation select the path by which they are transformed into movements. Thus my body gives the actual state of my growing duration and my present is the very materiality of my existence.

My present, then, is my attitude towards the immediate future ; it is my impending action. That only of my past which can insert itself into the attitude to make itself useful can collaborate in the action. As soon as it does this it loses the character of pure memory and is merged in my present. When made actual in an image memory differs profoundly from pure memory. The only share in the past that the image of the present has is the memory from which it sprang - the memory which, as long as it was useless, was also powerless, unmixed with sensation, unattached to the present, and therefore not spatial. This memory is preserved as latent, but does not cease to exist while we are unaware of it. Our awareness is but the mark of the present, that is of the active; it is not the synonym of existence but only of immediate efficacy. Indeed we must confess that for us, who have bodily functions, the main business of our awareness is to superintend action and to cast light upon choice. So it casts light on the immediate antecedents of a chosen act and on those memories that may with practical advantage amalgamate with it; the rest it passes over. And once more we encounter the error we are 
always trying to correct-the error which leads us to regard consciousness, even when it is associated with bodily functions, as mainly addressed towards speculation and practical only by accident. As a consequence of this error we are surprised that it allows any information that it possesses to be overlooked, and come to regard what it does overlook as non-existent. Yet we all admit that the images actually present to our perception are not the sum total of the material universe. And a material object not perceived, an image not imagined, can only be a kind of unconscious mental state. When you speak of a town you are plainly thinking of so many perceptions not in your consciousness, and yet given outside it. How is it that existence outside consciousness is quite clear to us in regard to objects, but obscure in regard to our memories? It is as though we supposed that while space indefinitely preserves things set in it side by side, time as it advances consumes the states succeeding each other within it. This is in part because space supplies us with a sketch of our immediate future and, since that future stretches out indefinitely, remains indefinitely open. The horizon about our perception seems to us, as a matter of course, surrounded by wider and wider circles; and so our actual perception, inasmuch as it is in space, is always related to an unlimited experience containing it which, although absent from our consciousness, nevertheless appears to be actually given. On the other hand, while we feel ourselves dependent on these objects of which we are unaware, 
our memories of the past seem so much lumber that we prefer to imagine ourselves without. The same practical instinct which leads us to set space open before us prompts us to close time behind us. In our interior life that only seems real which begins with the present moment, and a memory reappearing seems to call for explanation. But as a matter of fact the connexion of this memory with our present state is strictly comparable to the connexion of objects we do not perceive with those we do perceive. In both cases the unconscious plays a similar part.

We are misled by our habit of laying stress on the differences and blurring the resemblances between the series of objects set together in space and the series of states developed one after another in time. In the first series, one term conditions another in a way which allows every new term to be foreseen. But in the succession of my memories I seem to detect caprice. Their order is contingent, not necessary. The order of objects in space seems to me a chain in which my present perception is one link-a link that gives its own actuality to the rest of the chain. Only a close inspection reveals the fact that memories also constitute a chain, and that our character, which is in all our decisions, actually synthesizes all our past states. In truth our past life exists for us more than the outer world; we perceive only a small part of the world, but use the whole of the experience we have lived. 


\section{Memory and character.}

We have considered two distinct memories. One of these is established in the body and enables us to adapt ourselves to the present situation. We may say that in truth it is not so much memory as habit; it acts bygone experience but does not picture it. The other is true memory; it conserves our history; all our states are ranged in it according to the order of their occurrence, each stamped with its place and date. This memory moves in the past and not, like the other, in the present.

We must now try to shew how these two forms of memory are connected. If we recognize that we never perceive anything but an immediate past, and that our consciousness of the present is already memory, it is not difficult to see them cohere. The bodily memory is quasi-instantaneous, and the true memory of the past serves it as base. It is, as it were, a pointed end, ever moving, which true memory inserts and guides in the shifting plane of experience; and the sensori-motor apparatus, as organized by habit, provides for the true memories, that would otherwise be ineffective and therefore unconscious, the means of taking on a body, in short of becoming present and conscious. For a recollection to appear in consciousness it must come down from the heights of pure memory to the point where action is taking place.

In the effective working of this partnership between two complementary memories, in the precision with which they insert themselves the one into the other, 
we recognize the well-balanced mind of a man nicely adapted to life. The man of action is characterized by the readiness he displays in bringing to bear upon a given situation recollections which will cast light upon it. But this very readiness may absolutely bar out memories which are of no use in regard to that situation. It is the mark of the lower animals to answer to a stimulus by an immediate reaction which carries on that stimulus, and thus live only in the present; the man who lives in this way is a man of impulse. And the man who, for the mere pleasure of it, lives in the past, for whom memories come forth into the light of his awareness without bringing any profit for the present situation, is a dreamer. Between these two, the man of impulse and the dreamer, lies that fortunate disposition constituted by a memory flexible enough to adapt itself precisely to every demand of the present, but possessed of power to resist in moments of emergency every distracting appeal.

\section{Intellection. ${ }^{1}$}

There are features in every representation which it has in common with previous states of mind or which resemble those of some previous states. But when a man recalls a memory it is not as though he put his hand into a heap of memories and pulled out the one he wants to look at. How could he hit upon just that

1 The substance of what follows under this heading represents the purport of a paper by M. Bergson which appeared in the Revue Philosophique, Jan. 1902, pp. I-27, entitled L'Effort intellectuel. 
which is adapted to his present purpose ? We must employ a more fitting metaphor, and think of the mind developing itself on innumerable planes, like sections of a cone, growing larger and larger as they become more remote from the point where it inserts itself into an act. During the process of intellection we move through the various sections of the cone, now embracing a wide horizon of images, now contracting ourselves to look at a particular image germane to the action we are preparing. In the effort to recall a memory, the mind compels the image that it needs to stand out in relief from the mass of interpenetrating elements of representation. The search for what is needed is often carried on automatically or with little trouble; but sometimes, as in the higher tasks of mind, it is complicated and difficult. When we go about our daily life, meeting trivial questions with stereotyped replies, confined within a familiar circle of ideas, automatic intellection meets our needs. But in its higher forms intellection is very different, for instance in inventive work, artistic or mechanical. The process here is much more instructive, and before considering it we must discuss the ordinary forms of intellectual effort.

If we examine what occurs when we try to follow another man in an arithmetical calculation, we shall find that it conveys nothing to us unless we do it ourselves. When we read a bock its passages have no meaning for us unless we recreate it for ourselves and express for ourselves its truth. When we follow and 
understand a long analysis it does not mean that we follow the images step by step and fix upon each image, as it comes, the label of an idea; we start from the idea that we have divined and attach the images to this. The fact has been proved experimentally beyond all doubt.

We misunderstand the process of recognition if we think that we begin by hearing and seeing in order that afterwards, when perception has become distinct, we may bring to this perception a memory that has affinity with it. The truth is that perception becomes distinct only through the help of what memory brings. All that comes to us by hearing or by seeing is really no more than what is sufficient to direct us to a corresponding plane in consciousness where other images may be found that are congruous with those given in perception. And it is where this congruity is perfect that we find intellection attaining its highest rank. Ordinary perception, then, is merely an appeal to memory, suggesting a diagrammatic representation which, when it is aided by attention, we transform into the concrete image of the object.

We may now consider the process of higher intellection. When we try to solve a problem we place ourselves in imagination in the solution itself, and then go back to make our way by intellectual steps to the goal we have already intuitively reached.

Let us suppose again that an author is making the plan of his novel, a dramatist creating the types and situations of a play, a musician, a poet, each at his 
own work-for all these the point of departure is something general. It is an impression, a feeling, to be developed; it is a theme that will be set out in some sequence of events, some description of conflicts of emotion or of the grouping of a social milieu. The artist begins with something abstract which he seeks to endow with the colour and the movement of life. He works upon a dynamic scheme, and no artistic result is obtained until he has transfigured the abstract outlines of his scheme into vivid images. While the work proceeds the scheme may vary; it is often changed by the influence of that with which it is being clothed ; sometimes nothing remains of it in the completed work. An inventor of a machine may give up something he set out to obtain, or he may obtain something else, as he carries out his plan into detail. So the created persons in the novel or the drama have their own effect on the idea or the feeling they were called into being to express. And in this contingency the spontaneous, the unforeseen, has a large part.

In such intellectual work one representation is carried through wider and wider planes of consciousness as it passes from the abstract to the concrete, from the scheme or diagram to the image. The work of invention is a real conflict, in which battles are fought among the elements to be organized.

\section{Parallelism.}

The scientific opinion with regard to the phenomena we have been considering, which not long ago was 
commonly held, is as simple as it is at bottom absurd and inadequate. A part of matter called our body is said to receive vibrations from external matter and then to conduct them from its surface to the brain, where it magically transforms them into conscious impressions. These are forthwith projected into space and come to overlie the objects from which the vibrations proceeded. The relation between objects and consciousness is taken to be a fact which defies analysis. Brain and consciousness work on parallel lines-this is all that we can say. That some scientific men should even now be satisfied with this theory is mainly due to its practical convenience for science, but in part to the fact that philosophers have not supplied them with another.

At bottom the theory of parallelism is not based on observed facts but on a specious metaphysical hypothesis. Its origin may be traced to the metaphysic of the seventeenth century which, in its turn, rests on the scientific discoveries of the Renaissance. After Galileo and Kepler thinkers were led to hope that the whole world might be subdued to calculation, and the acts of man foreseen as though they were akin to astronomical phenomena or to a complicated machine. But neither our present knowledge of psychic life nor our knowledge of the material world is covered by this theory.

Observation and experience, and therefore science itself, do not allow us to claim more than that there is a certain correspondence between brain and con- 
sciousness. Nothing assures us that the brain follows all the details of consciousness or that consciousness is produced by the action of the brain. The extent of the correspondence that exists is an entirely empirical problem which lies open to a more and more closely approximate solution. It does not follow that because two things are mutually dependent they are equivalent. Because a certain bolt is necessary in a machine, and because the machine stops working when it is taken away, we do not say that the bolt is the equivalent of the machine. And indeed facts, dispassionately examined, seem to show that the relation of the physical to the psychical is that of the bolt to the machine. Experience shows us that the mental and physical are interdependent, that a certain cerebral substratum is required for a psychical state, but no more. Even into the most complicated psychic state something of movement enters, although usually we have no interest in taking note of the elements of nascent action taking part in it. But if we examine carefully the process of our consciousness when we are trying to grasp our own thoughts, in order to communicate them to some one else, we discover the important part that movement plays. It is this same motor accompaniment which we might indeed perceive could we be spectators of the molecular changes in our brain; we should never find there the thought itself.

The parallelist may ask us where recollections are stored, if not in the brain. He usually supposes that memories are somehow hung on the brain, as though a 
telephonic conversation should remain hung on the wire. It is really absurd to put the question where, that is to say to use a spatial term, in the case of anything but an object in space; and there is a psychological error in making the brain a storehouse of the past and picturing to oneself a particular region in it where the past, when it has become past, is housed. To do this is to attribute a scientific value to a distinction wholly practical; there is no precise moment when the present becomes the past nor, consequently, when perception becomes memory. Let us suppose that I pronounce aloud this word 'memory'; I have then present in my mind not only the beginning, the middle and the end of the word, but all the words which have preceded it in the sentence to which it belongs. If it were not so I should have lost the thread of my speech. And if I had punctuated my speech in a different way my sentence might have begun further back; it might have embraced the whole of the preceding sentence, and my 'present' would have expanded even further within the 'past.' Let us carry this reasoning to its extreme ; let us supposewhat this time is impossible-that my speech should last year after year from the dawn of my consciousness, that it should consist entirely of one sentence, and that my consciousness should be sufficiently detached from the future, sufficiently disinterested in regard to action, to be able to devote itself to embracing the continuous expansion of the meaning of the sentence. In such a case I should see no more difficulty in the 
integral preservation of the whole past than I see now in regard to the preservation of the first two syllables of the word memory when I pronounce the last. In fact I am compelled to think of our whole psychic existence as something like this one sentence carried on since the awakening of my consciousness, a sentence sprinkled with commas but never divided by full stops. And I believe also, and in consequence, that my whole past survives in me, subconscious-that is to say present to my consciousness in such a fashion that my consciousness, in order to discover it, has no need to go beyond itself nor to add anything foreign to itself. In order to perceive distinctly all that it possesses, or rather all that it is, it would only have to sweep away one obstacle, to lift one veil. But the obstacle, the veil, is of infinite value to us. Our brain does us the service of keeping our attention fixed upon life-upon life that looks towards that which is to come. For life turns towards the past only in the degree in which that past may serve to enlighten and prepare the future. To live is, for the spirit, above all to concentrate itself on the act that is to be done. It is to insert itself into things through the medium of a mechanism which shall extract from consciousness all that is useful for the coming action, and keep in shadow the greater part of the rest. Such is the office of the brain in the work of memory; it does not preserve the past, it first conceals it and then allows to appear what is practically useful. And such also is the office of the brain in regard to mind in 
general. The mind is wider than the brain in every direction, and the brain's activity corresponds to no more than an infinitesimal part of the activity of the mind. ${ }^{1}$

1 The substance of the last paragraph is taken from ' $L$ ' $\hat{A}$ me et le Corps,' a lecture given by Bergson in Paris, and published with other papers in Le Materialisme actuel, Flammarion, Paris, I9I3. 


\section{CHAPTER V.}

\section{LIFE.}

ONE of the most conspicuous of the characteristic qualities of Bergson's thought, as is often remarked, is that, despite his emancipation from accepted formulas, it maintains a vigorous unity. Throughout his writings, in fact, he uses a small number of dominant ideas, which he applies to different aspects of reality as one might apply a master key to the locks of different doors. To the reader who has been trained in other manners of thought his point of view is at first both foreign and bewildering. But as, studying further, he learns to enter into the mind of the philosopher the outcome of the method reveals itself as above all things profoundly simple, so profound and so simple that there is often a difficulty in putting it into words. This is no doubt why, like Spinoza (as Bergson himself observes), he speaks so much and has been speaking all his life. And when we attempt to represent his thought to ourselves we should endeavour to picture it as a whole, and not to compress parts of it into formulas. The reader should look at it, as we have tried here to do, from different sides, and should 
examine different complexes of reality and different problems in its light. He should live with it, make of it a friend, so that it will no longer seem to him strange, and then its wide and deep simplicity will become clear to him. An intimate sympathy with the thinker will lead in time to that sympathy between ourselves and life which he himself enjoys, and which we must acknowledge as the meaning and ultimate aim of all that is worthy to be called philosophy.

In the foregoing chapters we have tried to give the main ideas of this philosophy in regard to the self, to the freedom of man, and to the relation between spirit and matter. In this chapter we shall make use of the same ideas in regard to life in its evolution and in the ever-new creation which is the very self of the universe as of the real man-whose place we hope to indicate in relation to that vast whole.

\section{Mechanism and finalism.}

Let us suppose that we wish to copy Leonardo's La Gioconda in mosaic. The smaller, more numerous and more varied in colour the tesserae are, the more closely we shall approximate to the picture. But to reproduce it so that the copy will resemble exactly the undivided whole of the artist's conception we should need an infinite number of tesserae, infinitely small, infinitely various in colour and tone. Let us suppose now that our eyes forced us to see the picture as though it were a mosaic and that our mind was of 


\section{LIFE}

the sort that could not explain it except as being a thing made up of tesserae, an assemblage of small pieces; we should then speak of it not as the product of an indivisible intuitive act but as that assemblage of little bits. We should, in fact, be dominated by a mechanistic hypothesis. Then, if we decided that the artist had worked according to some plan we should be confessing ourselves to be finalists. In either case the real process would escape us ; we should be decomposing the picture before us into myriads of tesserae which, when recomposed, presented to our eyes an astonishing order.

When we consider some bodily organ in the same fashion, for example the eye, we may regard it in its complex structure as made up of innumerable cells marvellously arranged. But we can look upon it as an artistic whole of vision. And then the process by which nature produces an eye may be compared with the simple undivided movement made when we raise a hand. Mechanism would distinguish here only the positions of the hand, finalism would reckon with their order; but both would ignore the movement, the real character of the act. Now this movement, which is one, is more than the successive positions and the order in which they occur; it gives not only these but also that which is not order and is not position, essential mobility. Yet we must confess that there is something in the positions and their order which, in a sense, is more than the movement; there is, in short, the mental work of assembling those positions and the intelligence 
needed to conceive the order. So, in vision there is more than the cellular structure and its co-ordination. But in another sense both mechanism and finalism go too far in supposing that an infinite number of cells have been gathered together to minister to the one act of vision. The making of an eye gives no more trouble to life than turning my head or moving my arm gives to me. The simple living act has divided itself into an infinite complexity of elements, which we then discover to be co-ordinated to one idea. All this may sound obscure, but its obscurity is due to the fact that the natural way in which we think of organization is as resembling our own process of manufacture. When we manufacture a thing we gather pieces of matter together, cut them out according to a pattern in our mind, and adjust them so that they will work together as one. We think of the work for which the thing is destined and arrange its parts round the idea of that work as round a centre. In manufacturing we proceed from the many to the one. Organization works from within outwards, from centre to periphery. Our human work is the more effective the greater the quantity of matter we deal with; it is emphatically a work of assemblage and concentration. But the work of organization calls at the outset for the least possible quantity of matter, as though it entered the world of things at a mathematical point. One of the smallest cells in the organism, and no more than a small part of that cell, sets going the process by which man comes through organization to birth. 
Moreover, in the thing we manufacture there is only what we put into it ; its parts are there, and the way we have put them together. The whole thing represents the whole work, and to every part of the work corresponds a part of the thing.

This brings us to an important difference between the point of view of positive science and the point of view of philosophy. For science the organized body is and must be a manufactured body, a machine. The cells are its parts, the organism is their gathering together, and the special and particular efforts which have organized the parts will be looked upon as real parts of the effort that has organized the whole. But for philosophy the parts of the machine do not correspond to parts of the work ; the matter of the machine does not represent an assemblage of means that are used; it represents a number of hindrances overcome. By right we should, through our power of vision, see everything at once; but this would not suit, would not be useful to, a being that must act upon objects. The vision needed by such a being must, as it were, cut for him, through the immeasurable multitude of things, a canal to those things upon which he will act. We can no more explain the making of an eye by a process of bringing together its cells, its rods and cones and so forth, than we can explain the cutting of a canal by the piles of earth beside it. According to the mechanistic theory the earth was brought there from a distance, cart-load by cart-load; the finalist would say also that the men who brought it had worked 
according to a plan. Neither would have hit upon the truth.

As the undivided act that constitutes vision moves further and further into matter, the number of coordinated elements in its organ increases. But their order is at all stages complete. This comes of the fact that the real process through which the organ comes into being is not divided into parts. Neither mechanism nor finalism reckons with this fact, and, when we wonder at the complex structure of an eye, there always lurks in our mind the notion that only a part of its co-ordination might have existed, and that its completeness is something superadded as a peculiar favour. When we are finalists we think of this favour as conferred upon us at a stroke by the 'final cause'; when we are mechanists we think it is procured bit by bit. In truth the cause produces its effect in no other way than as an achievement one and complete. This cause, ever advancing in the path of vision, may produce the sensitive spot of pigment in some lowly organism or any variety of rudimentary eye, just as it may produce the complex and far-reaching eye of the bird; but in all these there is an equal co-ordination. Hence in animals biologically remote from each other we find that where vision has advanced to the same degree the same organ exists. Both have eyes of the same kind, because the kind of eye is but a measure of the height attained by the function of seeing.

We must not, however, regard the advance towards this height as involving the idea of finality, an end to 
be reached. It is due to the impetus original to life, is implied in the movement of life and, consequently, is found, as we have said, in paths of its evolution far apart one from another. Life, in short, is above all a tendency to act on matter, and its action has in some degree a contingent character; there is in it at least, yet always, the beginnings of choice. And for choice to be exercised there must no doubt be various possibilities for action, indicated somehow before the action takes place. Vision is essential to this indication of possibility, and it exists therefore in its various degrees in all sorts of animals, and is accompanied by the same elaboration of structure wherever it reaches the same degree of intensity.

\section{The impetus of life.}

The biologist in his classification first associates together animals or plants roughly resembling each other, the mammalia, for example, or the cryptogams; he then divides the large group into smaller and yet smaller groups where there is an increasing likeness between the members; and throughout the process of his classification the characters of the larger group are general themes of which every lesser group gives its own variation. The same holds good between parent and offspring, both animal and vegetal. There are but slight differences, no doubt, between the parent and the descendant, and we might hesitate to say that material stuff is adaptable enough to be transformed into creatures so far apart from one 
another as the lion and the lizard, the bird and fish, the oak and the mosses at its feet. But the series of transformations by which embryos hardly distinguishable one from another develop into animals amazingly different is fairly comparable with the changes through which one kind of animal is evolved from another. One cell, the outcome of the union of two, the male and the female, performs this astonishing piece of work by a process of division, and this happens every day ; the most complicated organic elaboration is a result of a simple beginning, and the evidence of palaeontology, fragmentary though it be, bears out what we should be led to expect from what is going on under our eyes.

Let us, then, consent to regard life as a real activity, a movement made visible in bodies successively organized by it, travelling from generation to generation, becoming divided among different kinds of organisms and into different individual beings, but in no way losing force, indeed growing more intense as it goes on. It moves like a current conducted from germ to germ through the mediation of the full-grown organism. As we watch it this progress looks like an underground root-stock from which one plant after another may arise. The essential thing is the continuity of movement in the advance by which each separate organism is sustained.

We can hardly help recognizing the likeness between this organic evolution, with its underlying continuity of life, and the evolution of a consciousness, in which 
the germinal past, forcing a way into the present, brings about the appearance of a novel form of consciousness. We shall not be concerned to deny the fact that the origin of every living species is due to causes; but, as we have seen in relation to our own expression of ourselves in act, this means no more than that if we could know every detail of all the causes, we should see how the character of any existing species had been brought about. To foretell the species, as to foretell my full expression of myself in act, would be impossible. Like every free act of my own, every species is unique; it has never occurred before and it will never occur again. Therefore it can never be predicted, as we can predict, for example, an eclipse or any event included within a system of parts supposed to be unchanging. Only in a system where changes are but changes of position, and in which it is not absurd to picture the change reversed and things replaced as they were before, is such calculation feasible. We can never predict a perfectly new situation which contributes from itself something of its own novelty to the elements or partial views we are able to mark out in it ; we can only say that, after our own fashion, we can explain it to ourselves by means of those partial views. And it is important for us to notice that all this is valid in relation not only to the origin of species but also to the origin of every new individual and indeed of every moment in a living organism. It is true that variation must attain a certain amount and range before we can speak of a new species, but in 
every living creature variation is always going on. Life, like our own mind, is for ever creating something new-

Seine Welt bildet der Künstler, die nie war und nie wieder sein wird.

\section{Intellect and evolution.}

Intellect, very naturally, rebels against this idea. To foresee what will happen, to prepare us for action that we may know what we are going to do and what will happen in consequence, is the proper business of the intellect. In ordinary life our intellect is occupied in finding that which is like what we already know, and thus enabling common sense to provide for or against the future. Both as practical men and as scientific men we are concerned only with that which seems to repeat itself. The scientific man cuts up every original event with which he deals into phenomena more or less closely reproducing past phenomena. Whatever in it cannot thus be analysed, whatever in short is theoretically irreversible and irreducible, he is obliged to neglect. So it comes about that, trained as we are in practical life or science or both, we must resist the natural disposition of the intellect if we are ever to lay hold upon the original and essential character of life ; for this, assuredly, is both irreducible and irreversible. We must, in short, seek the discipline of philosophy.

Intellect, as we possess it, has undoubtedly been evolved by an ascending progress through the animal 
kingdom up to man. It has been an adjunct to the power of acting, an ever more flexible and exact adaptation of consciousness to the surroundings of the conscious and acting being. In a strict sense intellect has for its peculiar office the perfecting of the adaptation of the body to external things, and the representation in it of the relations between those things. It is at ease among such things, especially among those which supply man with instruments for practical use. Solid objects have served as pattern for its concepts, and in the main have suggested its logic. In geometry it is triumphant, and there the close alliance of logical thinking with material things is most plainly shewn. But it is a stranger to life. Pure logical thought is absolutely incapable of grasping creative movement. We have created logical thought-life has created intellect. And the character of pure intellect is determined by its primary use, that of an adjunct to our action on particular things. We cannot expect that the part should be equal to the whole, or that a power directed towards action should be capable of comprehending the whole life, in which action on things is itself only a part, although a highly important and, in us, initially dominant part.

We are born artisans, workers upon things, and our bent is geometrical. We work at the same time by intention and by calculation, by using means and thinking out plans; and we can hardly avoid thinking of nature either as some great machine regulated by calculable laws or as the result of a plan-influenced 
as we are by the vital necessities of our action. Radical finalism and radical mechanism are both congenial to us. But both obstruct our view of the real course in which life develops and of its unforeseeable creation of new forms. As artisans and geometricians we have no room for what cannot be foreseen. If we were artists we should welcome it; in so far as we are artists we do. For the artist the very breath of life is creation, and in the depths of his heart he cherishes a belief in the spontaneity of existence. But art divested of the thought of usefulness is, like pure speculation, a luxury.

It is only when we leave behind us the state of bondage to primary utilities and the rule of mechanism and finalism over thought, that reality is made known to us as an unfailing fountain of true novelty, which has no sooner emerged into the present than it is submerged in the past; there, and there only, to be examined by the intellect as a thing fashioned and complete. As long as we are in that bondage, we extend to life in general the same treatment and the same considerations that, uncorrected, we give to our own selves. It is easy enough, as we have seen, to find preceding events of any act of ours which may seem to have brought it about as a mechanical result; it is equally easy to regard it as the final outcome of an intention or a plan. Thus we may detect everywhere in the development of our own life either mechanism or finality. But again, as we have seen, no action of ours that is truly our own and expresses what we 
fully and truly are could ever have been foretold, even though, when it has been done, we can trace what has, as we say, led to its being what it is. It may realize an intention but, just because it is new and present and is no recommencing or rearranging of the past, it is not the same as the intention. When we explain by finalism or mechanism either our own development or the evolution of nature we only take out from reality elements with which the intellect can deal. In both cases real movement and new creation are overlooked. It is the aim of the Bergsonian philosophy to reinstate them in their full importance.

\section{Adaptation and the struggle for life.}

This philosophy represents the organized world as a connected whole, imperfectly harmonized, where each species, and indeed each member of a species, uses in its own interests a certain impulsive energy derived from the general impetus of life. Hence what is known as the struggle for life-conflict among the forms of life. Yet the original impetus is common to all forms, and as we mount higher in the scale of life we discover that the various tendencies conflicting at a lower stage are becoming complementary. In the world of organized beings the state in which differences become fully complementary is shown to us rather in tendency than in fulfilment. And this tendency comes not from a common interest or aspiration but from the oneness of the vital impulse that is behind us. It is useless to attempt to attribute to life an end, as we 
conceive an end, that is, a pre-existing model to be realized. This would be to believe that the totality of life is given, and that its future is enclosed within its present. We should be looking at life then as though it went to work like our own intellect; we should be seeing it as it were motionless and in pieces, an affair outside time instead of one essentially of growth and enduring in time. We must regard the future as expanding the present, not as contained in it like a prearranged end; and then it will explain the present as much as the present explains it, or even more; and be seen as an end-though not prearranged-even more than as a result. Thus we come to terms even with finalism, but in our own sense and, as we shall see, with a further reach.

Life, then, we take as continuing a single and original impetus which divides into many different lines of evolution. There have been additions that are so many creations; and tendencies have been set apart one from another when they could no longer increase in the same organism without becoming destructive or obstructive one of another. We are able to imagine a process of evolution occurring in one individual being, in the course of successive transformations through the ages. We can also imagine a process in which many beings are extended in a single series like a straight line. But in actual fact evolution has occurred through a process in which myriads of beings have taken part on divergent lines, lines from which every now and then new divergent paths radiate, and so on 
indefinitely. And if, as we think, the real causes at work are psychical in character there should be about all beings something in common, however far apart they may have travelled. What is common to them should be manifest in some way or another-let us say by the fact of different animals of different species having organs that we recognize as of the same kind. If this be so we are justified in saying that the greater the biological distance between the two species the less applicable is any mechanical explanation of the fact. This explanation would require an incredible coincidence between two series of accidents along two different lines of evolution. On the other hand, the likeness between two organs existing in two species highly developed along diverging lines is in our view natural enough, since along every line there is something of the original impulse in which they share. The more complex the structure of the organ the more cogent is this reasoning.

\section{Creative evolution.}

If life had travelled in one line, as a cannon ball does, its evolutionary movement would be easy enough to trace. But it behaves much more like an explosive shell of which every fragment is explosive too, and so on for an immeasurable time. We have before us for examination no more than the small pieces produced by the latest explosions; we start from these and retrace what has happened, step by step, until we reach the initial movement. The living shell has 
broken into individuals and species. And the manner in which it divides is determined, in our view, partly by the resistance of the material it encounters and partly by the explosive force inherent in itself.

The first entry of life into matter seems to have been a kind of gentle insinuation, a flexible adaptation to the characters and powers of material elements. It seems as though these elements were coaxed or persuaded from their ordinary habits into other habits new and strange to them, but at first as little removed as possible from those of which they were originally possessed. They were drawn gradually aside from their own path to enter upon another-the path of life. A mass of protoplasm is a creature of extreme simplicity, even in the amoeba of to-day. The first forms in which it appeared were most likely still less differentiated than the amoeba, although unquestionably they must have possessed enormously greater powers of growth. It may be that the next stage of things presented an obstacle, to overcome which aeons of ingenious striving were necessary. Protoplasm in its growth soon reaches a condition in which it must divide instead of continuing to grow as one. But for organization many protoplasmic parts must be associated together, and the power of life brought this about. Organisms were formed which, although complex and in a way discontinuous, carried on active life as one living mass might carry it on if it could have attained so great a size.

But we must look deeper for the true cause of organic 
division. In life there is " an unstable balance of tendencies" and hence through its mere advance it creates diverging paths among which its total impetus is divided. If we consider our own growth from childhood, the evolution of the tendency proper to ourselves which we call our character, we shall see that many personalities, so to speak, remained at that time fused or interwoven together just because they were undeveloped. The line of our progress was not as yet decided. Along the road by which we passed from childhood to adult life we discarded this or that possibility of character, of occupation, of talent to be used. To be what we are we have had to throw away what we might have been. Nature, too, includes a multitude of tendencies and possibilities, but it is not necessary for her to abandon them by the way-side; she has a myriad lives, she has many species, differing widely one from another, in which her tendencies may be displayed. In the evolution of life there have been two or three great highways. We can see also that there have been attempts to pass along blind alleys. Further, we can distinguish among the highways one, and only one, great enough for the free expansion of life. It is a main stream upon which we men are borne, a main stream that carries our societies of men. If we compare these with the far better ordered societies in the insect world, we see that the avenue to progress is closed there by the very perfection of its achieved result. In our societies there is conflict, disunion, the clash of ideals-in short instability; but 
an instability ever affording opportunities for new advance. Imagination points to a society that is always advancing, yet is always well-balanced and free from strife. Here and now we cannot look for it.

We may reasonably expect that societies developed along such different ways of life should manifest different characters of life, yet characters which, because they are derived from the one life and its common impetus, are all more or less obscurely complementary to each other. And so, perhaps, if we examine these dissociated characters or tendencies and bring them together in thought, or still better in our own life, we shall draw near to-even perhaps imitatethe original and undivided motor principle. Looked at in this way evolution does not appear to us as an affair of progressive adaptation to environment-an affair, in short, of mechanism-nor does it seem the ordered carrying out of a definite, pre-arranged and final plan.

This becomes more clearly evident when we consider the question, to which we have already alluded, concerning the appearance of identical organs in the course of divergent and widely separated lines of evolution. How, let us ask ourselves, can these be formed by any gradual and successive accumulation of casual variations, as is necessary according to the Darwinian hypothesis? In the very complex organ to which we referred-the eye-the smallest variation involves the concurrence of many physical and chemical causes. The accumulation of the variations required to produce 
an eye demands the concurrence of an enormous number of such causes. Why should accidental variations happen in the same way and the same order at different places and at different times? We cannot suppose that they do. And the Darwinian would most likely say that the same results may occur in consequence of different causes; in short, that there are more roads than one to the same place. But this will not serve ; for though the principle of mechanism gives us the same causes as always producing the same effects, yet does not imply that the same effects must have the same causes, in such a case as this, where the causes are distinguishable in the effect and indeed are its very elements, it does imply this consequence. It is not surprising that you and I, starting from different villages and wandering over a Highland moor, should meet at last. But that in our walk we should follow paths which if laid one upon another would coincide exactly is a supposition hardly to be entertained. And if we were to botanize on the way and so complicate our wanderings, making our paths indefinitely various and intricate, such a coincidence would be altogether beyond belief. Yet no complication of such paths can match the complication of an eye, where myriads of cells, each complicated in itself, each a kind of organism, are arranged in a definite order.

There is, however, another hypothesis ; let us consider this. We are carried now beyond mere natural elimination of that which is not adapted to survive ; we are introduced to a direct influence of external 
conditions shaping living beings into correspondence with themselves. Now, like effects are to be explained by likeness of cause. This has every look of pure mechanism; but, as a matter of fact, we are misled by a use of the word adaptation in two different senses at the same time. There is an adaptation that means mechanical adjustment, as when milk or water both take the shape of the vessel I put them in. But, when we speak of an organism as adapted to its surroundings, we must recognize that there is no likeness whatever between those surroundings and the vessel into which I pour the milk or the water. The environment of life is not a mould whose form it takes. Life creates its own form, accommodated no doubt to its surroundings but overcoming their disadvantages and making use of them where they are useful. Now adaptation such as this is not copying or repeating, it is responding -as an intelligent activity responds to a problem in providing its solution. Here we come again to finalism. And science passes lightly from finalism to mechanism, with a practical leaning to the former and a speculative attraction to the latter.

Let us consider now, in relation to the eye, the Darwinian hypothesis involving the chance occurrence of small variations and their gradual accumulation. We must remember in this connexion that no organ will be of any use, during the course of this process, unless it works. It is useless for the retina of an eye to be developed unless the optic centres develop also coincidently with it; it is probably even worse than 
useless, as hindering the vision there might be through an organ more simple yet complete. And, if there is a coincident development throughout the organic apparatus, how do the necessary accidental variations contrive to come about together at the same time, so that while the organ is developing it may still work? The difficulty was apparent to Darwin himself and was the reason why he regarded these necessary but accidental variations as minute. A minute variation, he argued, will not hinder the working of the organ and can be stored up until other minute variations arise elsewhere to co-operate with it. Undoubtedly ; but the point is that until those co-operating variations do occur it is of no use, and cannot therefore be selected to survive. And when we come to remark, let us say, the likeness between an elephant's eye and a mollusc's, such as the common pecten, our difficulties increase upon us. If they are manifold in the case of an eye developed on the line of evolution where the mammalian stands, what must they be when we find them duplicated along another line?

We turn then to the hypothesis of sudden variations of a larger size, a mutation that takes place not insensibly but by leaps. Obviously some difficulties are diminished here; an elementary variation may now be large enough to be of use and therefore to be preserved; moreover, if such variations are accidental there are at least fewer of them to be reckoned with. Nevertheless another and a very serious difficulty arises. A sudden change in any part of the visual apparatus, 
unless it is very small, will make sight impossible. How is it that all the parts change at one and the same leap yet keep their mutual relations? Doubtless many unfavourable and incoordinated variations may have occurred and been eliminated; doubtless, too, only a useful combination has survived. But how was such a combination produced? And if it was once produced by chance, is it likely that chance should give the same amazing result time after time in the history of species, each result so related to the past as to advance yet farther in like manner? Moreover, what can we say when we find that this 'accidental' process, growing more and more intricate and complicated as it goes on, has been at work along two lines of evolution that are wide apart? We are told in this case, as we were told by Darwin in regard to his own hypothesis, that there is a correlation of changes in these matters. Hair and teeth, for example, are often modified together. But then hair and teeth belong to the same tissue-system, and the correlative changes in them that have been noted are by way of impoverishment or suppression, not by way of addition. The changes which occur in the eye are not correlative in this sense; a whole group of changes not only occur at the same time, are not only associated in a common origin, but are also co-ordinated in such a way as to enable the eye to do its work, and to do it even better than before. We discover, then, that the word correlation, like the word adaptation, is used in two senses by the biologist, and that these senses are 
interchanged. Yet whatever may be permitted in regard to the more fluent functions of the vegetable kingdom, in regard to an organ like the eye careful distinctions are essential, and they are not made by the biologist.

We must examine now, in its bearing on this problem of the eye, the hypothesis that variations are produced by external circumstances. Light, no doubt, is a physical cause with definite physical effects. Therefore, we are told, it has brought about a continuous variation in one direction. In short, it has worked upon living matter in such a way as to change its structure and adapt that structure to its own character and demands. When we say that one eye is more complex and efficient than another we mean that light has found living matter there peculiarly capable of being impressed by it, shaped after its likeness. Again we must remind ourselves of the difference between receiving an imprint and the positive reaction bringing about the solution of a problem. And once more we must refer to the two senses of the word adaptation; although in passing we must confess that nature herself has started us in the way of this confusion, for undoubtedly in the earliest stages of development there is very frequently a process of passive adaptation (as in the pigment-spot of the lower organisms) where an organ of active response is later built up. Yet again, we should distinguish. We may pass from one thing to another by degrees, but it does not follow that the things themselves are of the 
same kind. The process of life is, as we have said, primarily one of insinuation ; that there are many steps between a pigment-spot and the eye of a bird leaves untouched the fact that there is between the two the same fundamental difference as between the photograph and the camera. Certainly the elementary photograph has provoked the development of the camera as we have it now; but it has not done so by acting as a physical force and by mechanical means. Organized matter seems to have a power of its own, through which it constructs wonderfully complicated machines to make use of the simple stimulus that it receives. To this pass we are inevitably brought by reasoning on such lines, a pass which we are supposed to be in a position to avoid, by an appeal to physics and chemistry and the power of a physical cause to dominate organic matter.

Must we then fall back upon Lamarck's doctrine that a living being may institute a modification through the use or disuse of an organ in an effort to adapt itself to circumstances, and that its descendants may inherit a modification thus acquired? Here we may indeed admit the existence of a psychical principle in development, although we are not compelled to do so. And certainly the doctrine seems able to account for the building up, let us say, of the two eyes of the mammalian and the mollusc. A similar effort to make use of similar circumstances may well have a similar result ; and if there is only one way of meeting those circumstances to advantage we may go so far 
as to say that they must have a similar result. We must ask ourselves, however, whether the effort of the organism does not mean something more profoundly psychical than biologists of any school are willing to admit. For it is impossible to believe that what we ordinarily call an effort could not merely vary the size or the strength of an organ, but both enormously increase and exactly co-ordinate its complications. For this, an internal activity of a very different order must be required; we must seek for this activity beyond the effort itself.

In regard to the transmission of acquired modifications, a distinction may be proposed between inherited deviation and inherited character. When an organism acquires a new character it deviates from its previous and inherited form. If this deviation neither involves the production of a substance that will alter the germ-plasm nor affects the nutrition of the germplasm in such a manner as to deprive it of some of its constituents, it will not affect the descendants of that organism. This is most likely the usual state of affairs. If, on the other hand, the germ-plasm is chemically changed, this might really lead to a repetition in the offspring of the original modification of the parent; but it is far more likely to do something else. The offspring will then inherit deviation but not character. Experiment, so far, has not settled either way the question of the inheritance of acquired characters; but we are certainly entitled to say that it is the exception, not the rule. And, applying this 
to the special problem of the development of the eye, with the enormous number of modifications, all tending the same way, which would need to be amassed before the eye of the mammalian and the mollusc could be developed from the pigment-spot of the infusorian, we see plainly that Neo-Lamarckism is no more fitted to solve the problem than is any other evolutionary theory.

Unquestionably, however, every one of these theories has its measure of validity, which it is the special business of philosophy to discern.

We recognize that the Neo-Darwinian doctrine is correct in maintaining that the inherent characters of the germ carried by the individual organism, and not the conduct or experience of that organism, are the essential causes of variation. But we cannot regard the differences of character in the germ as purely accidental and individual; rather we would maintain that they are brought about through the development of an impulse, transmitted from germ to germ, which may well appear in the same way in many species or many individuals. In fact the doctrine of mutations, which imputes to species the manifestation at times of a tendency to change affecting the whole species, introduces into the Darwinian doctrine a new modification pointing rather to such an hypothesis as Eimer's, which regards variations of character as going on from generation to generation in certain particular directions. But we cannot agree with Eimer that physical and chemical causes are sufficient 
to produce what we see produced in the organic world. We demand, in short, a psychical cause ; and here we discover validity in the doctrine of some of the NeoLamarckians. They, however, are at fault in regarding the psychical cause as no more than the conscious striving of the individual being. For they thus restrict it to a few instances confined to the animal world, and omit the plants altogether. Moreover, the criticism we have just passed upon the whole doctrine compels us to recognize that inherited change, definite in direction and cumulative, bringing about enormously complicated organs, points to an effort common to most individuals of the same species, and carried on in the germs rather than by the organisms containing them.

That the life impetus must adapt itself to circumstances as a necessary condition of its successful evolution is unquestionable, but to regard these circumstances as powers which are the actual directing causes of evolution is quite another matter. The fact is that adaptation to circumstances explains the windings in the path of the evolutionary movement but not its main direction, and above all not itself. A railway track must be adapted to the exigencies of the country through which it passes. Its gradients will be slight or steep ; it will have its tunnels, its embankments or its bridges. Everywhere the ground on which its rails and sleepers are laid will be its necessary support; but never will these things either give its direction or be the cause of its existence. Indeed, our 
illustration carries us but part of our way, for the path of evolution is not single and its many tracks are without definite aim or end. It maintains an inventive character even while adjusting itself to the most potent or most rigid of circumstances. No plan is laid down beforehand for the evolution of life to follow; it is a creation always being renewed.

We encounter here the primary error of the finalists, but we must go on to notice another, even more significant and important. As the building of a cathedral advances, as pillar after pillar is placed and walls rise course by course, the harmony of parts becomes ever more apparent and the idea of the architect clearer to our minds. And this is precisely what we should expect, since the architect undoubtedly planned it all from the beginning. But we do not find that life as it advances in its evolution manifests a greater harmony, a closer union in idea; in fact we find precisely the opposite. And this is what we should expect if the unity of life consists in the impetus driving forward its evolution, an impetus which scatters and divides as the evolution progresses. The manifestations of life are in some aspects complementary to each other, a fact due to their community of origin. But they are also not only incompatible one with another, but antagonistic. Discord rather than harmony increases as new species are developed. And this is not all ; for there is arrest of species, there is even degradation. Evolution is not necessarily an advance. Life in a species may stand still or even retrogress. Unques- 
tionably there is progress along the main lines of evolution, where forms of life more and more complex are produced; but elsewhere there are multitudes of minor intercrossing paths. The man who would link all the particulars of organic life as parts of a general plan does well to remain in his study and construct them after a diagrammatic fashion. In nature, as nature truly is, he will meet with disappointment. Yet nature is both more and better than he dreams. After all, a plan sets to creative work a term; and for life in its creative evolution the doors of the future are set wide. The initial impetus of life is a movement giving a rich and fecund unity to its advance, far beyond any that the most ingenious mind could conceive. And it is well for the finalist in his study to remember that mind, however ingenious, is and must remain only one among the treasures this movement has produced.

In our further discussion we shall dwell chiefly on the main lines of evolution, and especially on that which leads to man. That with which we are most concerned is our own relation to the animal kingdom and the relation of that kingdom to the organized whole.

\section{The direction of developing life.}

Strictly speaking, no definite characteristic distinguishes vegetable from animal life; and biologists have maintained that the distinction between them is a matter of artifice. We should have to acknowledge that this is true were definition of living beings the 
same as definition in physical science. But there certainly is no living being anywhere that does not include in some degree or other the essential characters of most other beings. The real difference between one and another is a difference of proportion and emphasis ; and by giving due weight to this we may define and distinguish animals and plants and, moreover, discover that they represent two diverging paths of life.

To begin with, we find the plant procuring from air and earth and water everything necessary to support life, whereas the animal cannot feed on the elements thus presented until the plants have fixed them in organic substances. Yet there are some plants that are insectivorous; and the fungi feed like animals on organic substances. Thus we see that this difference will not provide us with a static definition telling us at once whether a particular organism is animal or plant. What it does is to give us the starting point of a dynamic definition marking the divergent paths along which the two great divisions pursue their course. The fungi occupy a remarkable position. Their distribution is very wide, in number they are abundant; but their tissue-structure is embryonic in character, and we may say that, as it were, they never come to birth as true children of the vegetable world. The insectivorous plants, on the other hand, are both formed and nourished like other plants; and only seem to have developed the insectivorous habit in circumstances of unusual difficulty in regard to the provision of other food. It is reasonable, then, to 
maintain that, if we give due consideration to the tendency or path along which evolution has been able to continue for an indefinite length, we may distinguish plants from animals by their power of building up living matter from unorganized mineral elements.

We turn now to another difference, even more suggestive for our thought. Just because the animal cannot feed on the mineral elements abundant everywhere, it must be able to seek the food provided in plants or other animals by moving, either from place to place, or by extension in some such form as the pseudopodia of the amoeba. The animal in its primitive form is a protoplasmic mass having ample freedom for movement and change of shape; but the vegetable cell is covered by a membrane which prevents both. No doubt there is movement in plants -in leaves, tendrils, and so on ; and vegetable protoplasm circulates within its sheath. No doubt, too, many animals, particularly the parasites, are more or less fixed in one place. It would therefore be an error to use fixity and mobility as test characters to decide between the plant and animal. We are, however, entitled to say that where we find fixity in an animal it appears as a rule like a torpor, the result of an arrest of evolution. And where we see movements in plants we must note that they are usually only of parts of the plant, and in any case are neither as frequent nor as various as the movements of the animal. They have the look of a chance awakening in an organism ordinarily asleep. The two opposite 
tendencies of movement and fixity are obviously indications of the two paths along which the different kingdoms have arisen. Yet even these, which we might almost use as defining the animal and the plant, point us to tendencies that are still deeper seated and have yet more significance.

\section{Mobility and consciousness.}

Although the consciousness of the higher living beings appears to be definitely associated with a highly organized nervous system and brain, and although the better developed is the nervous system the more defined and numerous are the possibilities of movement and the clearer the accompanying consciousness, the existence of a nervous system is not necessary to mobility or to consciousness. In the lowest animal organism there is a diffused undifferentiated activity, an undivided labour, a function embracing all functions, which the gradual elaboration of a nervous system, as of other bodily structures, divides and intensifies in its different directions of power. Just as a stomach is no necessary condition of the digestion and assimilation of food, so is a brain no necessary condition of animal consciousness. The function which the lower organisms possess as diffused and undifferentiated is, in the nervous system, made both more precise and more intense through the dual form given to it by a division into reflex and voluntary activity. Two different mechanisms have been developed in the vertebrates; the one in the spinal cord and medulla, 
through which true reflex movements are effected, the other in the brain, where a complicated system of cross-ways and motor mechanisms provides an organ of indefinite choice. There are, however, organisms in which nervous elements are not yet definitely ordered, still less made into a system, and here we find that, by a sort of division, both reflex and voluntary activities come about, but without either the mechanical sureness of the truly reflex or the intelligent suspense and choice of the truly voluntary. Here, no doubt, is a process of reaction but vaguely conscious. In fact we may say that the consciousness of any organism is proportionate to its capacity for free movement. How shall we regard this consciousness, then, in its connexion with movement ? It is certainly a cause of movement, for it directs change of place; but it is also a result of movement, for undoubtedly when all motor activity stops it falls asleep. Certain organisms, in which the nervous systems have so far degenerated as almost to disappear, have become fixed and parasitic. In such a case consciousness is probably more faint than it is in animals where differentiation through the establishment of nervous centres has never taken place and movement has persisted.

The plant presents us with the spectacle of movement arrested from the beginning by the cellulose skin enclosing its protoplasm, and in large measure shielding it from stimulation by influences from without. It is thus left to slumber undisturbed. Yet, just as the animal may sink into parasitism, so the plant, in so far 
as it gains some power to move, may awaken from its sleep. But unmistakably the paths which evolution has followed in the production of the animal and vegetable kingdoms are marked respectively by consciousness and unconsciousness. In order to find consciousness at its best in the animal we must look to the highest kind of animal ; but, on the other hand, we must search among the lowest plants as the one likely place in which to find signs of the possession of even a rudimentary consciousness. And it is there, in unicellular organisms, that life seems to waver between the animal and the plant.

\section{Plant and animal.}

Most likely the earliest organisms shared the characteristics of both kingdoms in something like equal proportions; the divergence of the two is a readjustment of proportion. Even now, as we have seen, the plant-cell is not so profoundly torpid as to be incapable of being roused, nor is the animal so safe in its activity that it can never sink into permanent unconsciousness. Nevertheless, on the whole the two original tendencies became dissociated in their advance. Each organism seeks that which is useful to it; and animals and plants have found different kinds of convenience in acquiring the necessary food. Both have found a way, so to speak, of least resistance in the expenditure of work. The plant has no need of the selecting and guiding power of the animal ; for this it substitutes a power to use the energy of the sun in splitting up 
carbonic acid to obtain the carbon it requires. It has no need of the nervous sensitiveness of the animal ; for this it substitutes the sensibility of its chlorophyll to light. Here indeed is a 'nervous system' totally different from that of the animal, yet representing it. The one impetus of life has in the animal led to its nerves and nerve centres and in the plant to the elaboration of the work of chlorophyll.

We must now try to penetrate further into the problem. The picture of life as we see it in its evolutionary history justifies us, we believe, in attributing to it, or at least discerning in it, an effort to introduce, in relation to the necessity that obtains among physical forces, as high a degree of indetermination as possible. In this effort energy is not created-that is, such energy as can be apprehended or measured scientifically. What happens is that the energy already existing is put to the best use ; and this is effected by so accumulating in living matter the energy of non-living matter as to constitute a reserve of it whence it can be released as the energy stored in a cartridge is released by the firing of the gun. The sun is the chief source of the energy used upon the earth. Life, then, in face of physical processes, had to devise some kind of receptacle in which the solar energy should be stored, so that it could be used when, where, and how it was needed. Substances on which animals feed do in effect perform this office. Chemically they are unstable like explosives and are ready to liberate the energy they contain. In its early stages life seems to have made 
the explosive and brought about the explosion together, so that the solar radiant energy, directly stored in an organism, was spent by it in free movements of locomotion. We see something like this now in, for example, the Euglena, an infusorian which possesses the chlorophyll of the plant and the free movement of the animal-although in this case the power to evolve has been lost. As evolution progressed the two tendencies were respectively accentuated along different lines. Probably this was a necessary condition of all considerable advance. In any case we see before us the fact that the plants emphasize the principle of making the explosive and the animals that of its explosion. And, since the animal unquestionably has advanced the further of the two, we may reasonably say that it was for the sake of the explosion that the explosive was made, and that the animal shows on the whole the main direction of the impulse of life.

\section{Animal life and the nervous system.}

In the earliest stages of animal life the direction of explosions seems to be a matter of chance. An amoeba is of no particular shape and its pseudopodia may be formed on any part of its surface. But in animals of a higher kind definite directions of energy are shewn in the very outlines of the body; and these directions are more precisely indicated in ordered systems of nervous elements, which have themselves been gradually differentiated from the general living mass. These nervous elements may be regarded as specially capable 
of acting as releasing agents. They, more particularly, will suddenly set free a store of energy. But every cell must use up energy to maintain its physiological balance. The plant cell does nothing else, but the animal cell, although it must do the same, has the further function of using up energy in promoting movement of the organism from place to place. And in those animals in which a nervous system exists the rest of the body seems to be occupied in serving the needs of the locomotive apparatus, by making ready for it and passing on the energy required.

In the higher animals food is used to make good the wear and tear of tissues, to supply the requisite amount of heat, and thus to keep going the organism of which the nervous system is a part and by which it is sustained. But unless the organism provided energy to be spent in the motor apparatus and elsewhere the nervous elements would have no part to play. It is not unreasonable to suppose that this is the main and ultimate destiny of food, however much may be expended or even wasted in attaining to this end. The rest of the organism may in short be regarded as subsidiary to a sensori-motor system, that is to say, to the cerebrospinal nervous system, the various organs of sense into which it extends, and the muscles it controls. The function of the body generally is to provide a sphere for the operation of the nervous system, and energy with which it can deal. The greater the perfection of the nervous function the more the other functions of the body must both develop and demand for their 
own sustenance. Hence the complexity of functions in the higher organisms appears to have no limit, and revolves as it were in a circle; but the centre of that circle is the nervous system, extended between the organs of sense and the motor apparatus. The function of the nervous system is to further indetermination; and in the highest organisms, where its elements are placed end to end in such a manner as to provide at the extremity of each a multitude of open ways affording a multitude of possibilities for action, it is an apparatus of indetermination.

\section{Freedom and automatism.}

We must bear in mind the fact that the effort manifest in the process of evolution has its limits and inadequacy. When the finalist pictures the living world as though it were a machine in which all parts have been adjusted with a view to its effective working, he misapprehends this fact or ignores it. Often the effort is abortive or arrested ; it is brought to nought by opposing forces, turned aside or entirely taken up in some minor result. At its best, where it seems to have overcome both outward and inward resistance, it is at the mercy of the body it has assumed. Human freedom itself, in the very action through which it asserts itself, produces habits that will suppress it unless it is revised by continual effort. Automatism dogs our steps; the formula crystallizes the living thought that gave it birth, the idea is oppressed by the word, the spirit overwhelmed by the letter. Behind 
all this lies the ineradicable difference between life, which is movement itself, and its manifestations, which it for ever leaves behind. Evolution in general presses ahead in a direct line, but every special manifestation of it turns round upon itself. Then these special manifestations so successfully feign immobility as to induce us to regard each of them as a thing not a progress, and to forget that they do but mark the outline of a movement that goes on. Yet sometimes revelation touches us. The love of animals and the care of plants for offspring may bring it home to us ; in these we may approach perhaps the secret heart of life, the movement carried on from one bearer of life to another.

There is a contrast, then, between life in general and the forms in which it shows itself. When we look at life as a passing from one species to another we see it as an action continually growing ; but in each separate species the effort after continual growth is, as we have said, turned round upon itself, and the species seeks its immediate advantage by the least possible expenditure of effort. The fact that a particular form can live implies that it is adjusted to its circumstances and is so far a success to be credited to life. But when we look at the progress of life beyond that species this very success in relation to surroundings is seen to be a failure relative to the main advance. Animal life has taken four chief directions; two, as we shall see, have come to an abrupt end, and in the other two the result has usually been inadequate to the expenditure of effort. Taking this point of view, comparative 
failure seems to be the rule, success rare and always incomplete.

\section{Obstacles to mobility.}

At an early stage a danger not unlike that which checked the mobility of the plant beset animal life. A large number of animals were in fact arrested by it. Palaeontology shows us that more of the early molluscs possessed a shell than do those of to-day, and that most arthropods were crustaceans, while even the fishes of the remoter periods had a very hard bony sheath. It is probable that this imprisoning armour came about by way of defence against other animals. The way of least resistance which tempted certain primitive organisms from the vegetative path and led them to take their food ready made, instead of manufacturing it themselves from inorganic material, also led mobile animals to hunt for the less mobile and for those that were soft-bodied and defenceless. And the more capable of movement the first kind became the greater was the danger to the second in remaining unprotected. The consequence was a wide-spread arrest of progress, through the development of shells, carapaces, breast-plates and so forth. Just as the plant when its cells became enveloped in a membrane of cellulose doomed itself to sleep, so the animal lulled its consciousness more or less when enclosed within a shell. In this partial torpor some creatures, notably the echinoderms, now exist. But the vertebrates and the arthropods found another way. The spirit of 
adventure was dominant in them, and they took their risks. The higher interests of animal life were certainly better favoured by increased power of movement and a consequent ability not only to escape from an enemy but to choose the place, time and direction of an attack. We may regard change in any species as no doubt effected in the direction of its own interest and of an economy of effort, but we must look beyond this to the primordial impulse by which life drives its way, dividing and scattering-sometimes arrested but at some place or places moving vigorously on. The vertebrates and the arthropods found their way of advance in the elaboration of a sensori-motor system ; they found through this, after what we may fairly call many experiments and not a few errors of excess, not only definition and elasticity but a great variety of movement. And they found all these by different methods and through a different bodily scheme. The structure of the arthropods causes their motor activity to be distributed among several or even many appendages, each having a special function; but in the vertebrates there are only two pairs of appendages, and these have functions of far greater variety and less dependence on their peculiar form, this independence culminating in the human hand. And we surmise the existence of two vital powers, once blended together, and separating, or rather being altered in emphasis and proportion, which are being manifested along these two different lines of advance. 


\section{Intellect and instinct.}

What these powers are, how we shall define them, is only to be discovered by an examination of the species in which their development is most clearly displayed, that is to say, at the highest point evolution has attained along these two paths. We may take success as the mark of superiority, and as involving fitness to grow under many different circumstances, to overcome many kinds of difficulty, and to take possession of or occupy a very wide range of territory. Among the vertebrates man assuredly is in this sense the most successful. The insects, and especially some of the hymenoptera, have succeeded best along the other path. Intellect has reached the highest point in man, instinct in the bees and ants. Plants, the arthropods, and the vertebrates display to us the three great elements coincident in the common vital impetus which gave origin to them all, and dissociated, or differently accentuated or proportioned, along the three lines of growth. Most philosophies have erred, after the manner of Aristotle, in regarding the different characters manifested in vegetative, instinctive and rational life as successive stages or degrees of the development of one tendency. But it is neither in intensity nor degree that these characters differ; it is in kind. Yet instinct and intellect shew traces of a common origin, and neither is ever entirely separate from the other. Just as the two tendencies of plant and animal have never been wholly divided and are but manifested in different proportions, so it is with intellect 
and instinct. We may always find some instinct associated with every intelligent operation, and, surrounding every operation of instinct, there is, as it were, an atmosphere of intelligence. To this in fact is due in the main the confusion with regard to the difference of kind. Because instinct in an animal is accompanied by some intelligence it is supposed to differ from a developed intellect only by a lack of complexity or of perfection; the truth being that just because the two are really different they complement one another.

We must consider this important subject closely ; and to facilitate our examination we will divide the two tendencies, as nature never does divide them, and give them definite outlines, where nature blends one with another. We shall also look upon them chiefly as they are displayed in their two different ways of acting upon matter. The lesson taught by human history, and by remains that have come down to us from the times before history, is that the intellect of man is primarily directed towards making tools for practical use, and has developed in the direction of making tools with which to make other tools and of diversifying to an indefinite extent the processes by which they are made. Man, however, is not the only animal possessing tools or instruments. The important thing to bear in mind is that the tools of the lower animals are parts of their own bodies and are directed less by intellect than by instinct. We must not say that every instinct is an affair of managing an organic tool ; yet we may lay 
down this definition for the purposes of our discussion, as indicating the main character and the ideal goal to which instinct tends. After all, the process by which a living being comes to be organized passes by insensible gradations into the instinctive processes by which it lives. In the development of the chick within the egg, the activity that leads to the production of beak and feathers and the horny tip with which the chick will break the shell seems to differ but slightly, if at all, from the activity that does break the shell. Yet we call this instinct and the other growth. Where instinct comes to its highest development and social labours are divided among different cooperating individuals with different instincts, as in the bees and ants, the structure of those individuals alters to correspond, as though the activity of instinct were directed towards shaping living structures into fitness for specialized movements. We see, then, that whereas intellect at its extreme is the power to make and use artificial, unorganized tools, instinct at its extreme is shewn as the power to use and even to construct living and organized tools.

Neither of these methods is without its disadvantages. The instrument that grows is amazingly simple in use, although highly complicated in its details. It is always at hand, always in perfect order and ready for use. But it remains the same for every individual that uses it; change in it means a change of the whole species to which the individual belongs. Instinct, then, is tied to its instrument; its manner of working is limited to the 
manner of the instrument. But the tools that men make through the exercise of the intellect are imperfect; in their use they demand conscious effort and adjustment. They fail, they get out of order; but when they fail or get out of order they may be thrown aside, mended, replaced by other and better instruments. Moreover, although in regard to the immediate wants of him who uses them they are less successful than the tool the insect grows, they are far more influential in the education or development of the user. They demand of him initiative, ingenuity; they stir him to imaginative construction or reconstruction. In their very failure they open out before him vistas of new possibility. At a stage where intellect has attained the ability to make machinery which makes tools or fabrics all this is apparent; but in the earliest stage it is difficult to say whether the natural or the manufactured tool will best serve its owner in the effort to secure food and a safe standing in the world.

It is likely enough that if we could investigate the facts of the remote past we should see that instinct was once less separate from intelligence than it is in insects of the present day, and that intellect was nearer instinct than it is now in vertebrate animals; that, in short, the life impetus was in this respect far less differentiated, far less definitely controlled by the material into which it was making its way. If the energy of life had no limits it might perhaps have developed both powers together, and up to their highest point, in one and the same living creature. But the whole of our study of the 
evolutionary process, so far, has shewn us that it is not without limits and that the initial impulse is rapidly exhausted in manifestation. In regard to methods of acting on the world of matter choice was forced upon it. It could produce the desired effect at once in creating for itself an organized tool, an instrument perfectly fulfilling the needs of a narrowly specialized activity; or it could produce out of unorganized matter an organism which should manufacture tools for itself. To do both at once in perfection seems to have been beyond its strength.

In the arthropods we see instinct triumphant in the highest success; here life seems to have abandoned the struggle to advance at all in the direction of intelligence. But in most vertebrate animals a certain degree of effort after intellectual advance still goes on. Their intellect does not enable them to manufacture tools, but it does enable them to vary more or less indefinitely the operations of instinct. In man alone intellect attains success; the very poverty of his means of defence against enemies and his weakness in regard to his natural appetites bear witness to the triumph of intelligence over the safeguards of instinct. Man is the great adventurer; he has embarked on a life full of risks and strewn with failures, but the very field of enterprise and ampler growth, just because the kind of knowledge with which intellect provides him is wholly different from that accompanying instinct. This point we must now consider in some detail.

Instinct may be more or less conscious ; it may even 
be unconscious. But we must observe that there are, in fact, two different kinds of unconsciousness, one in which there really is no consciousness, as in the drops of rain that fall upon the earth and are unaware of their fall, the other in which there really is consciousness, but inhibited or neutralized, as with regard to the elaborate adjustments of balance we effect when we walk from one place to another. In the first case there is literally nothing; in the second, the carrying out of the action is so exactly fitted to the idea of it that there is no need for it to be represented in consciousness. Only when the act is badly done or being learnt does consciousness appear in relation to it. Consciousness, in fact, means hesitation or choice. We may reasonably say, then, that the working of intellect is likely to further the manifestation of consciousness, and the working of instinct to further some degree or other of unconsciousness. When a wasp uses the tool organized by nature-that is, its stingupon material supplied by nature-a caterpillar--with the result sought by nature, choice plays little part; and such consciousness as belongs to the idea thus carried out is neutralized by an action perfectly adjusted and automatically performed. Where there is consciousness it is related not so much to the successes of instinct as to its failures. And failure or incomplete success is the characteristic note of intellect; a conflict with obstacles, a choice among expedients, is of its very essence. It is never satisfied with what it has, for everything it gains does but 
open out a way to more. And this is not all; the main difference between instinct and intelligence is yet to seek.

We have said that instinct is beyond everything else the power to use organized tools. We must say then that in the insect there is some kind of inborn knowledge of the tool and of the object to which it is applied. With this power, then, there goes the inborn knowledge of a thing. Intellect, on the other hand, gives power to make artificial tools, and the business of intelligence is to apply tools to a great variety of circumstances and adapt them to any sort of change. It is concerned in short with the relation between a given state of things and the means of making use of it. It is characterized, then, by a tendency to establish relations, which implies a natural knowledge of widespread general relations as material that the particular intellect analyses or divides into special relations. The advantage of this kind of knowledge over that of instinct is plain ; so also is its disadvantage. It is not limited to what is only practically useful, although it was for practical usefulness that it began to be ; it may carry a man beyond the necessities of nature, and enable him, as it were, to outgrow himself. But just because the character of intelligence is that of a form into which anything may be inserted it may lose itself in unreality. Instinct, however, tied to the definite material thing, cannot go in search of other objects and is incapable of 'speculation.' We reach, then, this important conclusion: "There are things which intelligence only 
is capable of seeking, but which, unaided, it cannot find; instinct alone could find these things but will never go in search of them."

\section{Life and intuition.}

If the consciousness, sleeping in instinct, were to awaken, if instead of passing outward into act it were to turn inward into knowledge, and if we could put questions to it and it could answer, the deepest secrets of life would be revealed.

In a certain degree this becomes possible when consciousness, using intellect at its greatest height and clarity, sets itself free from the necessities of action and turns to look into its own depths. Then the latent powers of intuition slumbering within it come to light.

Animal instinct, like the vital qualities of the cell, attains a clear knowledge only of that which interests itself, all else being left in shadow. Here life follows the same method as consciousness in general and as memory in particular. Unawares, we carry with us our whole past, and from this past our memory picks out those recollections which bear upon the actual situation to blend them with the present moment. There is a like method in instinctive knowledge, bearing witness once more to the unity of life.

A man blind from birth, living among other men born blind, would be unable to admit the possibility of perceiving an object at a distance unless, as with extensible antennae, he had touched all intermediate 
objects. And yet vision works this miracle. Instinct also is knowledge at a distance and is to intellect what vision is to touch. But even though instinct is not embraced in intellect, we need not regard it as wholly mysterious and alien from our ordinary conscious life. In our feelings, in our unreflecting sympathies and antipathies, we are able to watch within ourselves the working-in an elusive form, no doubt, and saturated by intellect,- - of something like the consciousness of an insect acting by its instinct. The insect knows what it practically needs, but knows it in a living intuition not through any process of reasoning; and this intuition is akin to our own sympathetic divination.

Instinct, in short, is sympathy; and if its scope could be sufficiently enlarged and reflexion brought to bear upon its operation it would put into our hands the key of life, just as intellect at its highest may give us the key to the comprehension of matter. But now each is turned in its own special direction. And whereas intellect, through the medium of science, its creation, is now leading us deeper and deeper into the secrets of inert matter, were we to follow intuition,that is to say, an instinct become conscious of itself, set free from slavery to the exigencies of action, and able to reflect upon what it sees-we might be led into the depths of life itself.

That an effort of this nature is not beyond us is already manifest in the artistic power which in man may accompany the power of observation. Intellect 
alone will never comprehend the intention of life or the undivided movement that transcends our fixed lines of demarcation and gives to them their real meaning. It is this intention that the artist strives to lay hold upon, as by an uprush of sympathy he is borne into the heart of his subject and there raises the veil that hangs between man and the beauty of the real.

We can imagine a knowledge in its nature akin to art but having for object life itself. This knowledge-let us call it philosophy-will never grasp its object with the completeness of science. Intellect, whatever we may say, remains the focus of light around which instinct, even when enlarged and purified into intuition, is diffused like some vague nebula. But, by establishing a sympathetic relation between us and other living beings, a philosophy based upon intuition may lead us into the kingdom of life, one and interpenetrating, the kingdom where creation has no end.

Yet although intuition transcends intellect it is by means of intellect that it has grown beyond the limitations of mere instinct. Without the cooperation of intellect it must-as instinct-have remained attached to some special object of a practical utility and have spent itself in outward act.

If we reflect with care upon the contrast between these two elements, intellect and instinct, and upon the important fact of their community of origin, we shall more clearly discern the true meaning of evolution itself. 


\section{Universal evolution.}

If we think of things that are created and a thing creating, as we are accustomed to do, the very idea of creation becomes obscure; yet our understanding finds a difficulty in doing anything else. But things and states are only instantaneous views taken and isolated by our mind within endless Becoming. Both the automatic and strictly determined evolution of our close-knit material world-which is action unmaking its own self-and the forms life cuts out from it-which are unpredictable and themselves capable of action that is unforeseen-have behind them a movement of making or creation, with a double tendency towards concentration or dissolution. It augments as it advances, it creates as it makes its way; and it is something that each one of us can observe as we watch ourselves in action. Before the immense complication of a living organism, and the incalculable number of interacting and interwoven processes that it implies, our intellect stands dismayed. We find it difficult to believe that the mere play of chemical and physical forces can have produced this marvel and given to material atoms so amazing an organization. But if, instead of looking at the material world as composed of atoms, ready-made particles juxtaposed, we see it as a flux, whole like the life which fills it and cuts out in it living beings, then our vision of the whole is changed, and much of our difficulty vanishes. We see two currents, of which the second, materiality, is the inverse movement to the first, which is life and runs 
as it were counter to it; but we see also that life nevertheless gains something from materiality. A modus vivendi between them is established, and this we call organization.

We may express this idea by means of an image. Suppose we have a retort containing steam at high pressure, with here and there a crack through which a jet of steam escapes. The issuing steam is for the most part condensed into falling drops, and this condensation and fall represent a certain loss, an interruption, a deficit. But a little of the steam remains for a few seconds uncondensed, and strives to uphold the falling drops, although at most it can only make them fall more slowly. So from the immense reservoir of life jets are for ever being thrown out, the fall of each making a world. The uprising of living beings within this world shews us that which remains and persists of the primitive impulse of the original jet of life.

Let us then admit that consciousness and matter have found a modus vivendi, that they have come to an understanding and are doing what may be done to travel on together; they are nevertheless opposing forces, the one being the realm of strict determinism (at least in theory, or appearance) whereas the other is the realm of freedom. But life, which uses matter to promote its ends, succeeds in spite of all in bringing these two into an agreement. Life profits, so to speak, by a certain flexibility in matter-small though this be-and inserts itself into 
the rudiment of indetermination that inert matter affords.

As life develops on this earth it is undoubtedly bound up with matter, fixed in an organism subjected to the general laws of matter. But the movement in a river is obviously not the same thing as the windings it is compelled to follow. Consciousness is subject to the chances and changes of the organism that it animates, but its destiny is not determined by the destiny of matter. Consciousness goes to the encounter of matter, supports itself upon it, adapts itself to material conditions ; but at bottom it remains free,-is, in fact, freedom itself. It seems always as though life were doing its best to emancipate itself from the laws which constrain matter. Unable to invert the direction of physical changes (which follow one another according to Carnot's law of the degradation of energy) life nevertheless acts as though it were a force which, left to itself, would work in the opposite direction. It cannot arrest the course of material change but it succeeds at least in retarding it.

We must picture life as a great current emerging from some central point, radiating in all directions but almost everywhere arrested, and diverted into whirlpools and eddies or backwaters. Only in one place does it overcome opposition and flow on in freedom and power. Man is the place where, as nowhere else, the vital current makes a way. $\mathrm{He}$ is in fact that way, 
although he does not bear within him, at least in full and due proportion, all that the life current has included in itself. Something he has lost in the course of his development, something that in reality is part of his own self. And when we look round the organic world we see what he has lost-the fuller development of tendencies and possibilities now inadequately represented in him. Human consciousness is above all intellectual. Should it not have been also intuitional? Would not perfect humanity include, in full development, both these correlative forms of conscious activity? Under different conditions we might have been even more intellectual than we are ; but surely also we might have been more intuitive. We might have had even more mastery over matter ; but we might also have had a better understanding of life. Even as we are, intuition does cast intermittently a faint light upon the deepest facts of life, where intellect is wholly at a loss. Intuition reveals to us, however feebly, something of the deeper truths of our own personality; it shews us something of our freedom, of the profundity of our relations with other living beings, of the marvel of our origin and even, it may be, of the greater marvel of our destiny. And when we have begun to do justice to the reality of life as we possess it in ourselves we may learn to sce it as a community in which the highest are sustained by those of lower rank and enabled to press on, carrying in them the forces of the living movement by which they are upborne. Man is not isolated, although in 
him alone the life current overcomes resistance that elsewhere has arrested its advance. Yet he is different ; for in him we find no limit set to that advance nor do we see any resistance that shall bring it to an end, not even perhaps at the barrier of death. 


\section{CHAPTER VI.}

\section{CONCLUSION.}

\section{The idea of 'Nothing.'}

We have now before us the picture that life may present when examined according to the method of the new philosophy, for which reality is duration and becoming. But this manner of seeing is strange to us and difficult. In general we perceive distinctly only that in life which is made, and do but vaguely feel the making. Just because action is in practice our chief affair we naturally and rightly select and set apart special moments in duration and becoming, that for us have practical interest. Unfortunately, however, for the success of our speculation into the nature of reality we proceed to look at this too in the same way, and so fail to find in it an essential movement of evolution, a true and perpetual becoming. We perceive no more than states and instants in the flow and the duration of life. We fall into the snare of fancying that we can think the changing by means of that which we have fixed, the moving by that which we have rendered incapable of movement. And the same cause makes another snare for us. In practical life action is 
addressed to providing us with something that we want, either ready-made, or to be made, in order that it may fulfil our want. This thing that is required comes, as it were, to fill a place that we recognize as empty, as needing it. It is and was not. It was not real, now it is real. Here we are deceived; for the past unreality of this thing is entirely relative to our interest and attention. In truth we are everywhere surrounded by reality; and it is only because we want one reality rather than another, and fix our attention on the reality we want, that we are able to speak of an absence of reality when the thing we want is not there. We feel that we have 'nothing' only because we have not the particular thing on which our attention is directed. I call the cupboard empty when I find in it only shelves and air and not the boots or the fishingrod I want. And in practical life, of course, this is both practical and right. But again we are misled if we think and speak in this way when examining or discussing the nature of things, irrespective of the practical interest they have for us. And the outcome of these two errors-one through which the unmoving thing comes to seem primary and movement superposed upon it, and the other through which emptiness seems to exist first and something is made or found to fill its void-is that we no sooner begin to speculate about the true nature of reality than we are amazed that there should be anything rather than nothing, and that, if there is anything, it moves and changes rather than stands still. We go back and back in our thinking, 
from ourselves to the universe, from the universe to a supporting or creating principle, and find the same difficulty,--why is there a Principle at all, why is there not Nothing?

But what is Nothing? I try to imagine it, to suppress everything; but I cannot, for I cannot suppress myself. If I blot out the external world. I still keep myself; if I blot out myself, I still keep a world relative to which I am blotted out; I cannot imagine ' nothing.' Can I then conceive it as an idea. There is no single thing in experience of which I cannot suppose the annihilation. Let me carry on the process and in thought annihilate one thing after another until all are gone. Let us suppose that I attempt this task. I begin, let us say, with the table before me, and think that it is not. There is for me no longer anything there. Admitting for the moment that an absolute void is possible in nature (which it is not), what about the place the table occupicd? This place has outlines, a shape ; it is in fact a kind of thing, and the table has left behind it, as it were, the void of itself. This, obviously, is but a partial 'nothing,' but it is the best we can do in the external world. We have only substituted a kind of thing we prefer, for a kind of thing we wish to get rid of. Can we do better within ourselves? I have an emotion, an idea, a desire ; these are facts present to me and I am never without some such facts. I may think of an interruption of the course of my inner life, by sleep or destruction; but, even when I am thinking this, I cannot help 
imagining myself seeing myself asleep or destroyed. When I no longer perceive myself from within I seem to perceive myself from without. Here again one fullness succeeds another fullness; the representation of the void is a representation that is full, and in it there is always " the idea, distinct or confused, of a substitution and the feeling, experienced or imagined, of a desire or a regret." Hence it is absurd to suppose that everything can be annihilated in idea. We can annihilate particular objects, but only if we substitute for them other objects; and to destroy everything would also destroy the very condition which makes the act of destruction possible.

But what are we to say on the other hand in regard, not to destruction, but to non-existence? Surprising as it may seem, when we try to represent the table as non-existent we do but add to the idea of the table the idea of its exclusion by reality in general. The idea of the table not-existing is the idea of the table existing, with, besides, the representation of the table being excluded by the actual mass of real things. But, you may say, I need not attend to those other things; I can simply say that the table did exist and does not now exist. And here we come to the bottom of the difficulty, and find that it lies in regarding negation as exactly corresponding to affirmation and having the power to create ideas, as affirmation does-with this difference alone that they are negative ideas. When I affirm one thing after another ad infinitum, I form the idea of All; when I deny one thing after another 
ad infinitum, I deny all and form the idea of Nothing. But affirmation refers directly to the thing; negation only indirectly, through the medium of an affirmation. When I deny, I deny your assertion about the thing; I affirm something about your affirmation concerning the object; I am telling you that you ought to affirm something else. As to what you ought to substitute for your affirmation, no doubt I tell you nothing, except that you ought to substitute something. I am a social being, related to you, and my negation, unlike my affirmation, is limited by these facts. The likeness between the two is external and superficial. Let us suppose that where you assert that the sun shines, I deny the fact. Logically your affirmation and my denial are symmetrical and alike; but if logic, language, society and every intellectual process in man ceased to be, the sun nevertheless would shine and could be felt. Implicitly your affirmation would remain, but where would my denial be? To reach the point of denying, I must cease to be a mere recipient of the riches of the sun, I must want or pretend to want something else, believe or pretend to believe something else, teach or preach a doctrine that I do not find current elsewhere concerning the shining of the sun. In short, for a mind led wholly in and by the course of experience there could be no negation, no void, no ' nothing' even relative or partial. It would live in the actual and, if capable of judging, it would never affirm anything but the existence of the present. 
Why then do we think of 'nothing' and emptiness as primary, and wonder how it is that 'anything' exists? It is because the habits of action impose themselves on thought, and because every human action, as men really are-that is, reflective and social -arises from some degree of dissatisfaction and the feeling of absence and a want. In action we pass from 'nothing' to 'something' and bring in something where nothing was. But in truth this 'nothing' indicates only the need we have for something that is of use ; it is the absence not of 'anything' but of the useful thing. We spend our lives in filling voids of which under the pressure of vital needs we become aware through desire and regret, and the direction that our action takes is always from void to fullness ; but the void means no more than the absence of utility in things. Speculatively we cannot help following the pattern thus set in practical life, and this is the root of our difficulty in considering true duration,-- that which has no beginning and no end.

\section{Creative time.}

If I give a boy the parts of a model steam-engine and ask him to put them together, he will take a long time about it on his first attempt. But if he pulls it to pieces and tries again he will take a shorter time. The work of construction in this case does not need always the same time, and theoretically may be supposed to be executed instantaneously. But when an artist brings forth a statue from the depths of his soul 
time is not a mere accessory that can be supposed to be done away with, or lengthened or shortened, without effect upon the character of the result. Any change in it would change both the creative psychical evolution and the newly created invention which is its aim and outcome. Here time and the creative process are one with the creation itself. We may watch the sculptor with his model and his mass of clay before him; we may know, in a kind of way, what it is that he has to do and something about the manner in which he will do it; there is a problem for the artist which we see. But the actual solution of that problem will reveal to us something we could never have foreseen, something which is not an affair of matter but of self-creative form. And the upgrowth and manifestation of this form are displayed on an irreducible duration that is one with their being. In nature we see just such a piece of work. But for modern physical science there is no such thing as this creative time. And, since it is limited to taking instantaneous views of a moving reality, it must appeal for a true interpretation of creative evolution to another knowledge. For the ancients, science was a piece-meal metaphysic, and metaphysic was a systematic science; both were of the same order. For us, science and metaphysic are two opposed but complementary ways of knowing, the first concerned only with moments that do not endure, the second occupied with duration itself. And we now find that those scientific men who are carrying science farthest are inclined to think that 
we cannot reason in the same way about the parts and about the whole to which they belong, and that we cannot apply the same principles to the beginning and to the end of an advance. Thus they draw nearer towards concrete duration, in which alone true beginnings, not mere arranging and rearranging of parts, take place. But the philosopher must transcend the limits set to the scientific man by his subject. $\mathrm{He}$ must discard all mere symbols; he must come face to face with reality. Then the material world will for him be a continuity of becoming; and he will find duration, where above all it is most useful for man to find it, in life and consciousness. In regard to inert matter we may ignore this becoming and continuity without doing any serious harm; for the duration of matter lies only in its connexion with that which carries it onward and upward in the scale of being-life and consciousness. And here indeed is creative evolution, wherein philosophy should find itself at home and become the true continuation of science.

There is, however, a certain confusion underlying the relativism of modern philosophers (as it underlay the dogmatism of their predecessors) which constitutes one of their principal difficulties in regard to the problem before them. It is a confusion between two kinds of order, and arises from the fact that the vital and essentially creative order is in the main displayed rather in its accidents (by which the physical and geometrical order is imitated) than in its essence. Life certainly, 
as a whole, is an unending transformation; but it progresses by multitudes of living beings differing little from each other and seeming to repeat each other, in order that the new thing they are carrying on may ripen and advance. As a matter of fact, these beings are never entirely alike ; they inherit not only a pattern of character but a driving power through which character is modified, a driving power which is life itself. Repetition, then, while essential in the order of physical things, is subsidiary or accidental in the vital order. This vital order, if it is not strictly voluntary, is certainly not automatic like the geometrical, and is at least analogous to an order that is willed. As soon as we distinguish between the two kinds of order we are on the way to clear up the difficulty associated with the idea of disorder.

It is natural to us to think of order as greater than disorder, and as superposed upon it. We think of a natural condition of disorder, and we regard the existence of any order (as we regard the existence of 'something ' instead of ' nothing ') as a problem to be solved. It seems wonderful to us that there should be order ; but natural that there should be disorder, or an ' absence' of order. My library is ' in order' when its contents are arranged in such a manner as to correspond with, or to facilitate, a certain course of study I am pursuing, a certain end $I$ have in view. The professional librarian would call it a scene of confusion. He and I have different expectations, different desires, in connexion with a library; and each of 
us regards the absence of the order that he wants as disorder. In short, when we try to discover what we mean by the word disorder, we find that it really affirms implicitly the existence of another kind of order in which for the moment, at least, we have no interest. But our mind may pass from one to the other, and from this passage make a certain artificial confusion, an imagined disorder. Where it discovers the geometrical order, there might have been the vital order; where it discovers the vital, the geometrical was possible. And my idea of incoherence or confusion comes of my passing from one idea to the other and supposing the existence of something between the two. When I have imagined disorder, I have really posited two orders. Order alone is real; the idea of disorder corresponds either to a certain disappointment, or to a hesitation of the mind between two kinds of order. It is a practical affair; but in regard to the problem of knowledge it has been the bane and confusion of philosophy.

\section{Creation and joy.}

When a man follows the road of a philosophy for which the various difficulties we have been considering are removed, and looks at life and the destiny of man in the light of the knowledge he thus gains, he may come to observe that nature or the course of life provides a signal marking steps taken in the accomplishment of human destiny. Life has devised a sign telling us when our activity is fully and success- 
fully shewn; the sign is joy. Observe, it is not pleasure ; for pleasure is no more than nature's bribe, by which is obtained from the individual man the maintaining and the propagation of life. Joy is far more and higher. It points out the direction in which the driving force of life is urging us. It is a sign of triumph, of something new, created, won; and the nobler and richer the creation the more radiant and illuminating is the joy. It is the mark of an uprising from within of new life and power of life made actual in the man himself, come to enrich him and be owned by him. And ever it points forward to new riches, new advance. Every creative act-the birth of a child for its mother, the production of a great work of art for the artist-brings joy. And for every man there lies open one unfailing source of joy, the creation of himself by himself, the enriching of his personality by new elements not procured from without but drawn or driven upward from his own depths. The world into which our senses and our intellect introduce us lacks the fervour of real life, it is a cold world, a world of shadows. But if we learn to look at everything sub specie durationis coldness disappears, and consciousness and life take their own place for us. New life is breathed into the world.

The directive stimulus of joy and the aspiration of our moral nature are not contradictory of any science, even the most abstract or the most exact. Intellect and intuition are not opposed, except when the one refuses to adopt precision through contact with facts 
that have been scientifically questioned and arraigned, or the other, instead of keeping within the limits set to it by science, makes for itself, more or less unawares, a metaphysic falsely pretending to be based on science. Let us look, then, to science for the advantages it gives in the conduct and convenience of our practical life; but let us turn to philosophy for the interpretation and indeed the great encouragement of our joy. For joy, as we have said, is the sign life gives of the real meaning and the true direction of the evolutionary process that we share. It reveals to us our creative power in a life that has become our own-a life we guide and determine towards the fulfilment of our destiny. 


\section{INDEX}

Academy, election to, 53 .

Acquired modifications, transmission of, 199.

Adaptation and the struggle for life, $187 \mathrm{ff} .$, I $94 \mathrm{ff}$.

Aesthetic and moral feelings, the, 9 I ff.

Aine et le corps, $l, 46$.

Angers, 3, 6 .

Animal life and the nervous system, $210 \mathrm{ff}$.

Anti-intellectualism, $37 \mathrm{ff}$.

Aristotle, 4, 33, 69.

- thesis on, 7 .

Art, reality and intuition, 70 .

Artist, the, 71, 72.

Balfour, A. J., 46.

Bibliography of Bergson, vi, 48, 49.

Binet, A., 39.

Birmingham, Huxley lecture at, 46.

Body, the living, $65 \mathrm{ff}$.

- the office of the, 142 .

- and soul, I $39 \mathrm{ff}$.

Bon Sens et l'Éducation, le, I $9 \mathrm{ff}$.

Brain and memory, ${ }_{5} 8 \mathrm{ff}$.

Causality, the law of, I $35 \mathrm{ff}$.

- and duration, 131 .

Change, $54 \mathrm{ff}$.

Clermont-Ferrand, 6.

College de France, 35.

Collège Rollin, 17.

Columbia University, 48.
Common sense and philosophy, I $39 \mathrm{ff}$.

Concentration, mental, 28.

Congress of Philosophy at Bologna, 45 .

- Geneva, 30.

- Paris, 23.

Consciousness and mobility, 206.

Conservation of energy, I 6 , I $8 \mathrm{ff}$.

Courbes respiratoires pendant l'hypnose, article on, $3 \mathrm{I}$.

Creation and joy, 240.

Creative evolution, vi, 3 I, I 89 ff.

Creative Evolution and Philosophic Doubt, 46.

Creative time, $236 \mathrm{ff}$.

Darwinian hypothesis, I94.

Dauriac, Lionel, I 8.

Dawson-Johnston, W., $4^{8}$.

Desaymard, J., 7 .

Descartes, 20.

Determinism, I 5 ff.

- psychological, I2I ff.

Development, direction of, 203.

Dewey, John, 49.

Données immédiates de la conscience, les, vi, 7, 12, 44, 53.

Draghicesco, Professor, 51, 52.

Duration, 105.

— art and life, $85 \mathrm{ff}$.

Ecole Normale, 35.

Effort intellectuel, $l$ ', paper on, 24, I 66.

Eimer's hypothesis, 200. 
Eleatics, the, 75 .

Esprit et Matière, paper on, 24 .

Évolution, créatrice, $l^{\prime}, 3$ I, 36, 38, 44,53 .

Evolution, creative, $189 \mathrm{ff}$.

- and intellect, $184 \mathrm{ff}$.

-, universal, $226 \mathrm{ff}$.

Eye, evolution of the, I77, $194 \mathrm{ff}$.

Faraday, 64 .

Figaro, le, letter to, 52, 53 .

Foi et Vie, 46.

Foretelling of actions, $127 \mathrm{ff}$.

Freedom and automatism, 212 ff.

- necessity, I I 4 ff.

- the will, $88 \mathrm{ff}$.

Galileo, 69.

Gillouin, René, 50, $5 \mathrm{I}$.

Good sense and education, I9 ff.

Hulme, T. E., 29 (note).

Huxley lecture, 46.

Hypnotism, $3 \mathbf{I}$.

Impenetrability of matter, 102.

Impetus of life, the, I 81 ff.

Inconscient dans la vie mentale, paper on, 24.

Index, the Roman, books placed on, 53 .

Instinct and intellect, $216 \mathrm{ff}$.

Intellect and evolution, I $84 \mathrm{ff}$.

- instinct, 2 I $6 \mathrm{ff}$.

- will, address on, $25 \mathrm{ff}$.

Intellection, $166 \mathrm{ff}$.

International Congress of Philosophy at Bologna, 45.

- Geneva, 30.

- Paris, 23.

Introduction to Metaphysics, an, 29.

Intuition, 75 .

- and life, 223.

Intuition philosophique, $l$ ', paper on, 45 .

James, William, preface to Pragmatism, 45 .

Joy, $240 \mathrm{ff}$.
Kant, 74, 75 .

Lamarck, doctrine of, 198.

Le Roy, 35 (note).

Life, the impetus of, $18 \mathrm{I} \mathrm{ff}$.

- and intuition, $223 \mathrm{ff}$.

Living body, the, $65 \mathrm{ff}$.

- time, I05 ff.

London University, the, 46 .

Lucretius, School book on, 6 .

Lycée Henri-Quatre, I 7 .

- Voltaire, address at, 25.

Matérialisme actuel, le, paper on, 46.

Mathematical prediction, I $30 \mathrm{ff}$.

- time, ro5 ff.

Matiève et Mémoire, 44 .

- origin of, 18.

Matter, 6r ff.

- impenetrability of, 102.

Matter and Memory, vi, 8 (note), 48,53 .

Mechanism and finalism, $209 \mathrm{ff}$.

Memory and character, 165.

- the brain, $158 \mathrm{ff}$.

-, its two forms, I $53 \mathrm{ff}$.

Methods, philosophic, $67 \mathrm{ff}$.

Mind and Matter, 152.

Mitchell, Dr., vi.

Mobility and consciousness, 206.

- obstacles to, 214.

Movement and change, $76 \mathrm{ff}$.

- the life of spirit, $83 \mathrm{ff}$.

Myers, F. W. H., 31 .

Nature of the Soul, the, lectures on, 46.

Neo-Darwinian doctrine, 199.

Neo-Lamarckians, 200, 201.

Nervous system, the, 210.

'Nothing,' the idea of, 31, 33, $231 \mathrm{ff}$.

Number, 99 ff.

Order, two kinds of, $239 \mathrm{ff}$.

Organization, $178 \mathrm{ff}$.

Oxford, lectures at, 46 . 
Pain and pleasure, $97 \mathrm{ff}$.

Palmer, W. S., vi.

Parallelism, 24, 30, $169 \mathrm{ff}$.

Paralogisme psycho-physiologique, le, 30.

Paris-Journal, interview with Bergson, 46.

Past, survival of, 173 .

Past and present in consciousness, I6I ff.

Paul, N. M., vi, vii.

Perception, conscious, $147 \mathrm{ff}$.

Perception $d u$ changement, la, lectures on, 46 .

Phases of mental life, the, $88 \mathrm{ff}$.

Place and character of philosophy in secondary education, the, paper on, 24.

Plant and animal, $208 \mathrm{ff}$.

Plants and animals, definitions of, 203 .

Plato, 74 .

Pleasure and pain, $97 \mathrm{ff}$.

Plotinus, 74 .

Pogson, F. L., vi.

Politesse, la, address on, 10.

Prediction, 127 ff.

Present and past, 172 ff.

Psycho-physical parallelism, paper on, 24.

Ravaisson-Mollien, critical study of his work, 30, 32, 34 .

Recognition, I 56 ff.

Religion, 4 I ff.

Rire, le, 9 .
Self, the, and duration, $54 \mathrm{ff}$.

- the two aspects of the, $109 \mathrm{ff}$.

Sensations, $95 \mathrm{ff}$.

Simulation inconsciente dans l'état d'hypnose, paper on, $3 \mathbf{I}$.

Socialism, 50.

Society for Psychical Research, 3I, 40, $47 \mathrm{ff}$.

Sorel, Georges, 50.

Space and the impenetrability of inatter, $\mathrm{I}_{02} \mathrm{ff}$.

Specialization, $3 \mathrm{ff}$.

Struggle for life, the, I $87 \mathrm{ff}$.

Teaching of philosophy, evolution of the, $39 \mathrm{ff}$.

Time and Free IVill, vi, 7 (note), I 2.

Time, creative, $236 \mathrm{ff}$.

- living and mathematical, I $05 \mathrm{ff}$.

Tonquédec, Father Joseph de, answers to, $42 \mathrm{ff}$.

Universal evolution, $226 \mathrm{ff}$.

University College, 46 .

Vérité et Réalité, preface to James's Pragmatism, 45.

Villa Montmorency, $35 \mathrm{ft}$.

Vocabulaire technique et crituque de la philosophie, le, paper on, 24 .

Zeno, 75 .

Z.ones of indetermination, 147 



\section{CREATIVE EVOLUTION. Translated by Arthur Mitchell, Ph.D. 8vo. ios. net.}

WESTMINSTER GAZETTE.-"This book has all the charm and style of manner, all the wide knowledge on the scientific as well as the philosophical side, which makes M. Bergson's books a delight to the reader. It has also a poetical and imaginative background which no formal criticism can do justice to, and which eludes us when we begin to criticise. For all these reasons this book is a remarkable achievement, and Dr. Mitchell, the translator, has done it full justice."

GUARDIAN.-"We are indebted to Dr. A. Mitchell for a translation so good that we often forget we are not reading the original."

ATHENAUM.- "Though faced with the impossible task of reproducing a synthesis of outward form and inward meaning as individual as that which unites body with soul, $\mathrm{Mr}$. Mitchell has nevertheless contrived a version which in its own way is both alive and satisfying."

\section{LAUGHTER. An Essay on the Meaning} of the Comic. Translated by Cloudesley Brereton, M.A., and Fred. Rothwell, B.A. Extra crown 8vo. 3s. 6d. net.

TIMES.- "This translation of Le Rire forms the most suggestive contribution to a study of the comic spirit that has appeared in English since Meredith's famous essay. The two, though not covering exactly the same field, invite comparison; and to read them together is an exercise both profitable and charming. ... The translation appears accurate and happy throughout the essay."

SPECTATOR.—“"M. Bergson's brilliant and delightful essay on the comic has proved the most widely popular of his works. It has all the familiar qualities of his genius, such as superfine analysis and grace of style, a grace, we may add, which has been wonderfully reproduced in Messrs. Brereton and Rothwell's version. M. Bergson here, as in other works, has been fortunate in his translators."

LONDON: MACMILLAN AND CO., LTD. 


\section{BY PROF. HENRI BERGSON}

\section{AN INTRODUCTION TO METAPHYSICS. Translated by T. E. Hulme. Crown 8vo.}

2s. net.

GLOBE._- A word of special praise is due for the excellent translation Mr. Hulme here offers us of M. Bergson's celebrated essay. . . A careful study of the essay is an indispensable preliminary to any attempt at a proper understanding of M. Bergson's position, and this authorised translation should therefore receive a warm welcome as filling a very distinct want."

ATHENAEUM.-" "Its value lies in its lucid exposition of the starting-point of M. Bergson's metaphysics, and, incidentally, of what he means by intuition."

CONTEMPORARY REVIEW._-"A wonderfully lucid English translation."

\section{A CRITICAL EXPOSITION OF BERG- SON'S PHILOSOPHY. By J. M'Kellar Stewart, B.A., D.Phil. 8vo. 5s. net.}

MIND. - "The spirit both of the exposition and criticism merits very high praise. Bergson is not easy to expound except in his own words: Mr. Stewart has essayed to remove 'the brilliant metaphysical dress' in order to trace the main ideas. The result is a very competent exposition. The criticism also has its own strong points. The argument is not clouded by too much zeal in tracing the possible parentage of Bergson's views; nowhere is there a trace of captiousness."

\section{THE PHILOSOPHY OF CHANGE. A} Study of the Fundamental Principle of the Philosophy of Bergson. By H. Wildon Carr, Hon. D.Litt. (Durham), Fellow of University of London, King's College. $8 v o$.

LONDON: MACMILLAN AND CO., LTD. 

s 
Ruhe

B

Henri Bergson ...

2430

. 343 •

R9 
